CARLOS DAHER PADOVEZI

\title{
APLICAÇÃO DE RESULTADOS \\ DE ESCALA REAL NO PROJETO DE HÉlicES \\ DE EMBARCAÇÕES FLUVIAIS
}

Dissertação apresentada

à Escola Politécnica da

Universidade de São Paulo, para obtenção do título de Mestre em Engenharia 
Engenheiro Naval, Escola Politécnica da USP, 1978

\section{APLICAÇÃO DE RESULTADOS DE ESCALA REAL NO PROJETO DE HÉLICES DE EMBARCAÇÕES}

FLUVIAIS

Dissertação apresentada à Escola Politécnica da Universidade de São Paulo, para obtenção do título de Mestre em Engenharia

Orientador: Prof. Dr. MARDEL BONGIOVANNI DE CONTI Escola Politécnica da USP

São Paulo, 1997 
Dedico este trabalho à Ethel, minha esposa, e aos meus filhos Naiara, Daniel e Maíra. Por tudo o que significam para mim somado à força e à motivação que me deram para vencer mais esta etapa. 


\section{AGRADECIMENTOS}

- Ao meu orientador, Dr. Mardel Bongiovanni de Conti, pelo grande estímulo e pela extrema paciência e dedicação demonstrados.

- A todos os meus amigos e colegas do IPT. Particularmente, aos co-participantes das inúmeras viagens de estudo, de ensaios com modelos e de análises dos resultados utilizados neste trabalho: Alexandre Lania Gonçalves, João Dragojevic Bosko, José Carlos Zanutto, Kazuo Hirata, Luis Antonio de Oliveira Lima, Maria Hirose Takano.

- Aos engenheirandos Marcos Pinello e Fábio Rogério Ribeiro.

- À AHITAR, Administração das Hidrovias do Tocantins e Araguaia, pela autorização em utilizar os dados das viagens com o Comboio de Pesquisas do Rio Araguaia, no sentido de efetivar mais e mais sua contribuição ao desenvolvimento do transporte hidroviário brasileiro. 


\section{RESUMO}

O trabalho mostra os resultados de uma série de medições de desempenho propulsivo de um comboio no rio Araguaia, constituído de um empurrador bihélice de potência instalada de $448 \mathrm{~kW}$ e duas chatas de 530 t de deslocamento cada. O empurrador teve, durante o período de medições, dois tipos de propulsores diferentes: da série B-Troost, mais convencional, e da série Kaplan em dutos.

Os resultados de escala real foram analisados fazendo uso, inclusive, de resultados com modelos em tanques de provas, com o objetivo de descobrir os problemas e identificar os melhores procedimentos para o projeto de hélices de embarcações fluviais de cargas. Levando em consideração as características operacionais com alto carregamento das pás dos hélice fluviais, foi proposto um tratamento diferenciado daquele tradicionalmente aplicado em hélices de embarcações marítimas convencionais.

Ao final, foi verificado que existem métodos adequados de estimativas de resistências ao avanço de comboios fluviais, mas que existem problemas nas estimativas dos coeficientes propulsivos, o que influencia decisivamente a qualidade dos projetos dos hélices fluviais.

Com relação à geometria das pás dos hélices, concluiu-se que os hélices fluviais devem apresentar, em termos gerais, pequenos diâmetros, grandes razões de áreas expandidas, pás mais espessas, especialmente nas pontas, simetria do contorno das pás e ausência de caimento. As análises mostraram, também, as vantagens da utilização de hélices em dutos, assim como constataram que as séries sistemáticas de hélices podem ser utilizadas com pleno êxito em projetos de hélices de embarcações fluviais. 


\section{ABSTRACT}

This work shows the results of a series of measurements of propulsive performance of a push-tow in the Araguaia river, with a 448kW twin-screw pusher and two 530t barges. During the measurements the pusher was fitted with two different types of propellers: firstly with a more conventional B-Troost one and later with a Kaplan ducted propeller.

The full scale results were analyzed by using results of towing tank tests in order to find out the problems and identify the best procedures for the design of propellers of inland vessels. Taking into consideration the operational characteristics of heavily loaded blades of inland vessel propellers, it has been proposed a differentiated treatment compared to that usually applied on conventional marine propellers.

At the end, it was verified that there exist good methods of estimating push-tow resistances, but there are problems in estimating the propulsive coefficients, and these influence decisively the quality of inland propeller design.

Regarding the blades geometry of the propeller, it was concluded that inland propellers should have small diameters, great expanded area ratios, thicker blade sections, especially in the tips, no skew and no rake. The analysis showed, also, the advantages of the ducted-propellers in inland vessels, as well as it verified that the propeller systematical series can be used successfully for the selection of such propellers. 


\section{SUMÁRIO}

RESUMO

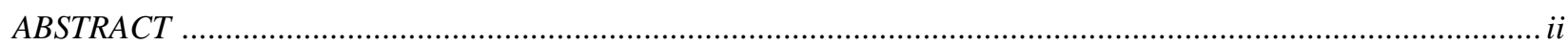

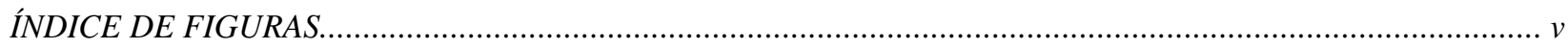

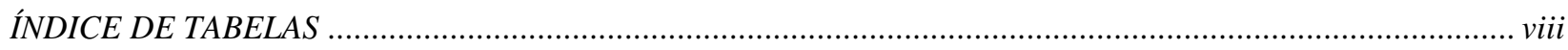

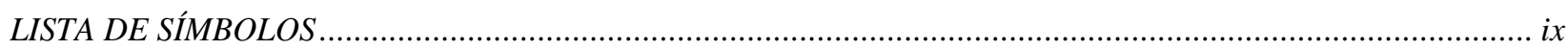

1. INTRODUÇÃO ................................................................................................................

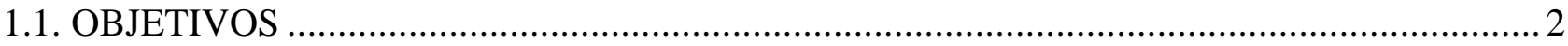

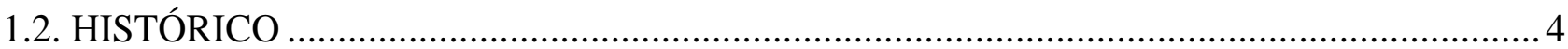

1.3. ORGANIZAÇÃO DO PRESENTE TRABALHO .......................................................

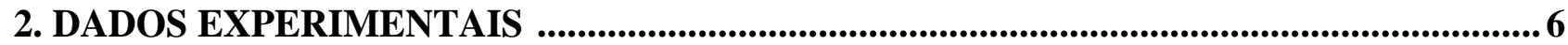

2.1 - OBTENÇÃO DOS DADOS EXPERIMENTAIS EM ESCALA REAL................................. 6

2.1.1 - Instrumentação Utilizada nas Medições em Escala Real ................................................. 7

2.1.2 - Erros das Medições em Escala Real.............................................................................. 8

2.2 - OBTENÇÃO DOS DADOS EXPERIMENTAIS COM MODELOS EM ESCALA

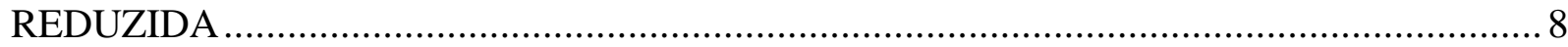

2.2.1. Ensaios de Água Aberta de Modelos de Hélices........................................................... 9

2.2.2. Ensaios de Resistência ao Avanço ............................................................................ 9

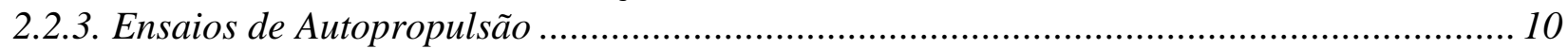

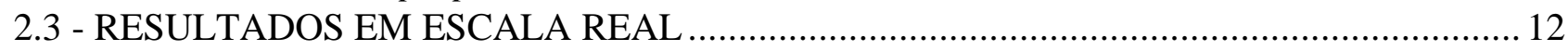

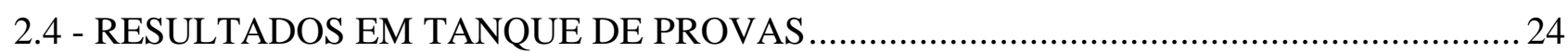

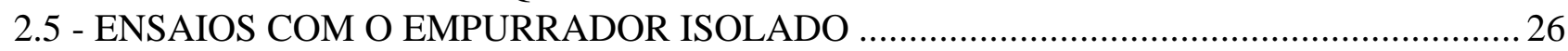

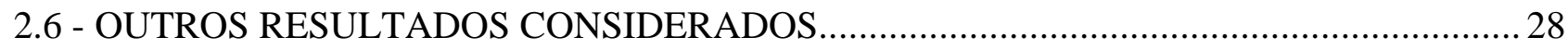

3. RECURSOS PARA ANÁLISE DE DESEMPENHO PROPULSIVO ................................... 29

3.1. ASPECTOS DA TEORIA DE PROJETO E ANÁLISE DE HÉLICES ..................................29

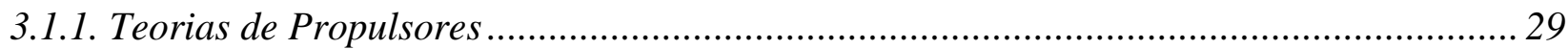

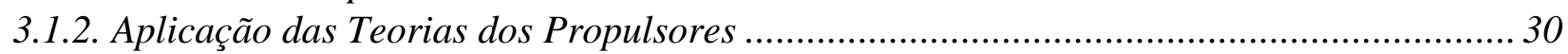

3.1.3. O Caso dos Hélices de Embarcações Fluviais................................................................ 30

3.2. ANÁLISE DOS DADOS DE ENSAIOS DE DESEMPENHO PROPULSIVO .................... 31

3.3. ESTIMATIVAS DE RESISTÊNCIAS E DE COEFICIENTES PROPULSIVOS ................... 33

3.3.1. Estimativas de Resistências ao Avanço de Comboios Fluviais ......................................... 33

3.3.2. Estimativas de Coeficientes Propulsivos de Comboios Fluviais..................................... 35

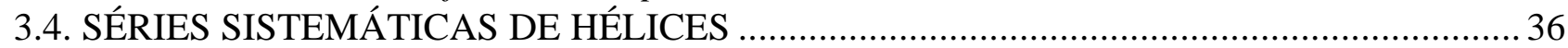

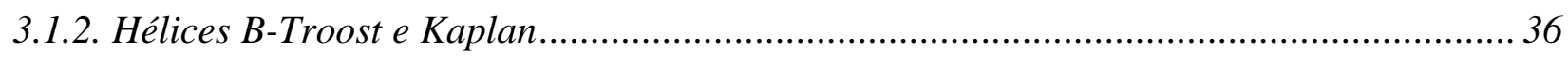

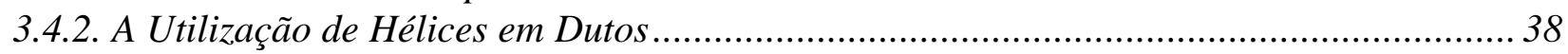

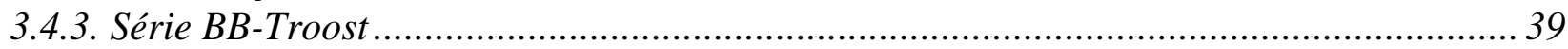

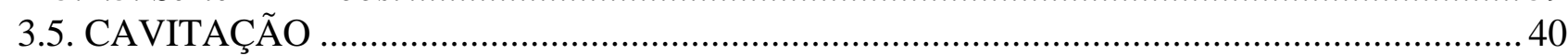

3.6. O PROJETO DE HÉLICES POR SÉRIE SISTEMÁTICA............................................... 43

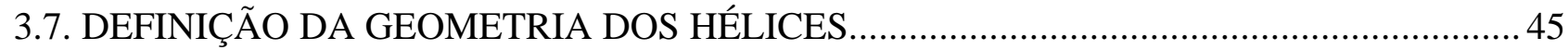

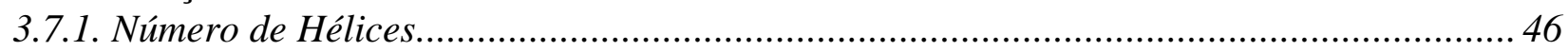

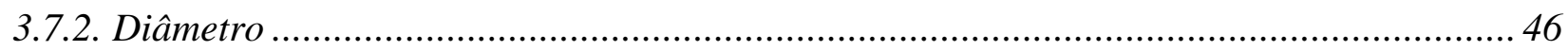

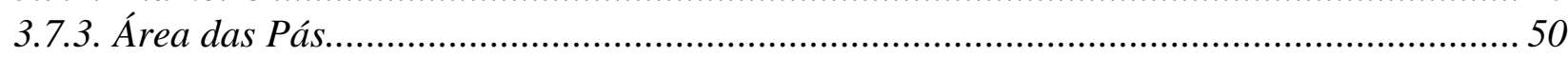

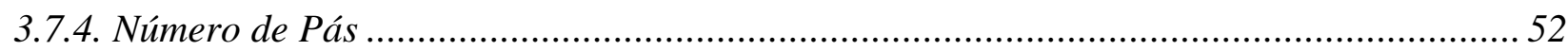




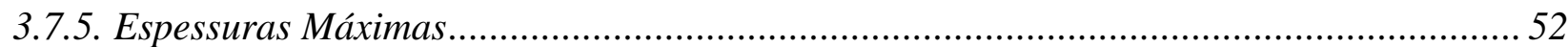

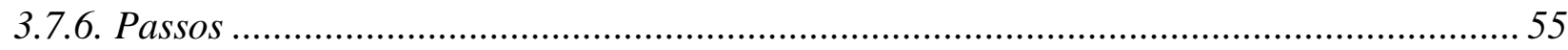

3.7.7. Caimento ("rake”) e Assimetria do Contorno das Pás ("skew”)..................................... 55

4. ANÁLISES DOS ENSAIOS EM ESCALA REAL ..................................................56

4.1. COEFICIENTES PROPULSIVOS OBTIDOS EM ESCALA REAL ....................................56

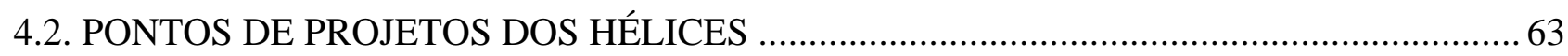

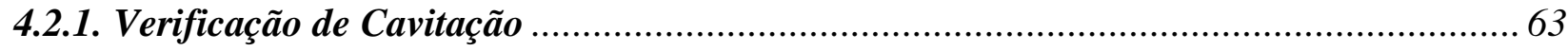

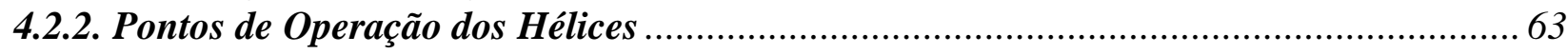

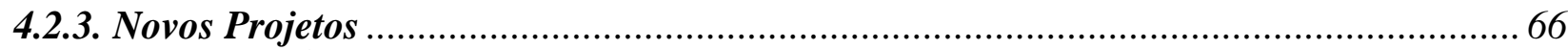

4.3. ENSAIOS EM ÁGUAS PROFUNDAS EM TANQUE DE PROVAS ................................ 70

5. CONTRIBUIÇÕES PARA PROJETO DE HÉLICES DE EMBARCAÇÕES FLUVIAIS..72

5.1. ESCOLHA DO PONTO DE PROJETO DO PROPULSOR ........................................... 72

5.2. ESTIMATIVAS DE RESISTÊNCIA AO AVANÇO E COEFICIENTES PROPULSIVOS .. 73

5.3. DEFINIÇÃO DA GEOMETRIA MAIS APROPRIADA DOS HÉLICES.............................. 74

5.4. RESUMO DOS PROBLEMAS DE PROPULSORES DE EMBARCAÇÕES FLUVIAIS ...... 76

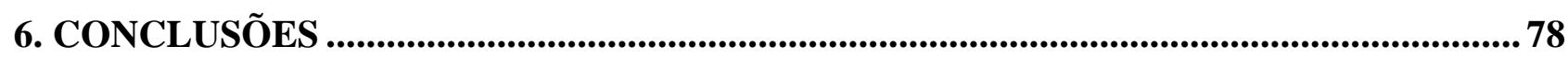

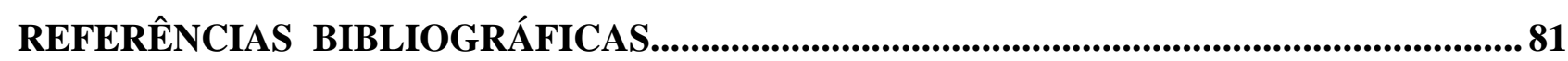

APÊNDICE A - DADOS MEDIDOS NOS ENSAIOS COM O COMBOIO DE PESQUISAS

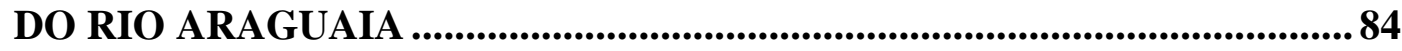




\section{ÍNDICE DAS FIGURAS}

Figura 1 Sistema de Proteção de Hélices e Lemes Contra Choques Instalado no Empurrador

Figura 2 Potências por Eixo - Hélices B-Troost, Uma Chata, Calado de 1,60 m. Profundidade de 5 $\mathrm{m}$.

Figura 3 Potências por Eixo - Hélices B-Troost, Duas Chatas em Paralelo, Calado de 1,60 m. Profundidade de $5 \mathrm{~m}$.

Figura 4 Potências por Eixo - Hélices B-Troost, Duas Chatas em Chatas em Linha, Calado de 1,60 $\mathrm{m}$. Profundidade de $5 \mathrm{~m}$.

Figura 5 Potências por Eixo - Hélices B-Troost, Uma Chata, Calado Médio de 0,70 m. Profundidade 17 de $5 \mathrm{~m}$.

Figura 6 Potências por Eixo - Hélices com Dutos, Duas Chatas em Paralelo, Calado de 1,60 m. Profundidade de $9 \mathrm{~m}$.

Figura 7 Potências por Eixo - Hélices com Dutos, Duas Chatas em Linha, Calado de 1,60 m. Profundidade de $9 \mathrm{~m}$.

Figura 8 Potências por Eixo - Hélices com Dutos, Uma Chata, Calado de 1,98 m. Profundidade: 9m.

Figura 9 Potências por Eixo - Hélices com Dutos, Duas Chatas em Paralelo, Calado de 1,98 m. Profundidade de $9 \mathrm{~m}$.

Figura 10 Comparação entre Condições Semelhantes Com e Sem Lemes de Flancos no Empurrador. Quarta Viagem - Uma Chata Carregada.

Figura 11 Ensaios com Comboio com Uma Chata Carregada, em Várias Profundidades

Figura 12 Ensaios com Comboio com 2 Chatas em Linha, em Várias Profundidades

....... 22

Figura 13 Ensaios com Comboio com 2 Chatas em Paralelo, em Várias Profundidades

Figura 14 Velocidades Médias em Função do Número de Rotações Médios dos Motores - Sexta Viagem. Profundidade $\mathrm{h}=5 \mathrm{~m}$.

Figura 15 Velocidades Médias em Função do Número de Rotações Médios dos Motores - Oitava Viagem. Profundidade $\mathrm{h}=9 \mathrm{~m}$.

Figura 16 Resultados dos Ensaios de Resistência em Tanque de Provas Extrapolados para Escala Real. Condição Carregado, Profundidade Infinita.

Figura 17 Resultados dos Ensaios de Autopropulsão em Tanque de Provas. Coeficientes de Esteira Efetiva Extrapolados para Escala Real. Hélices Convencionais, Calado Carregado. Profundidade Infinita.

Figura 18 Resultados dos Ensaios de Autopropulsão em Tanque de Provas. Coeficientes de Redução da Força Propulsora. Condição Carregado, Profundidade Infinita

Figura 19 Resultados dos Ensaios de Autopropulsão em Tanque de Provas. Eficiência Relativa Rotativa. Condição Carregado, Profundidade Infinita

Figura 20 Trim Dinâmico Verificado em Corrida Livre com o Empurrador Escoteiro.

Figura 21 Exemplo de Identificação de Problemas de Cavitação a Partir de Dados de Provas

Figura 22 Comparação entre Potências Efetivas Medidas em Tanque de Provas para um Casco de $\mathrm{C}_{\mathrm{B}}$ = 0,87 em Águas Rasas ( $\mathrm{h} / \mathrm{H}=1,82)$ com as Calculadas pela Formulação de Howe $(\mathrm{F}=0,04)$.

Figura 23 Comparação entre Potências Efetivas Medidas em Tanque de Provas para o Comboio Araguaia e Calculadas pela Formulação de Howe. $\mathrm{H}=2 \mathrm{~m}$. Profundidade $\mathrm{h}=58 \mathrm{~m}$, 
Largura $\mathrm{W}=86 \mathrm{~m}$.

Figura 24 Eficiência Ideal e das Séries Sistemáticas B-Troost e Kaplan em Função de Coeficiente de

Carregamento $\mathrm{C}_{\mathrm{T}}$.

Figura 25 Razões Entre as Eficiências de Hélices com e sem Dutos ( $\eta_{I}-$ Razão entre Eficiências Ideais e $\eta_{\mathrm{O}}$ - Razão entre Eficiências em Água Aberta - Ae/Ao=0,50, 4 pás, P/D=0,80).

Figura 26 Distribuições de Cordas das Séries Sistemáticas B-Troost, BB-Troost e Kaplan. Hélices de 4 Pás e $\mathrm{Ae} / \mathrm{Ao}=0,50$.

Figura 27 Diagrama de Burril para Previsão de Quantidades de Cavitação em Pás de Hélices.

Figura 28 Representação do Projeto a Partir das Curvas de Água Aberta. Caso a partir da Relação $\mathrm{K}_{\mathrm{T}}$ navio $=$ cte. $\mathrm{J}^{2}$

Figura 29 Representação das Formas Básicas de Projeto de Hélices

Figura 30 Representação da Eficiência em Água Aberta de Hélice da Série B-Troost (B 4-70) em Função de $1 / \mathrm{J}$, Parametrizados em P/D e $C T J=\sqrt[4]{\frac{K_{T}}{J^{4}}}$. Faixa de Operação Típica de Embarcações Fluviais.

Figura 31 Representação da Eficiência em Água Aberta de Hélice da Série B-Troost (B 4-70) em 48 Função de 1/J, Parametrizados em P/D e RTJ $2=\sqrt{\frac{K_{T}}{J^{2}}}$.

Figura 32 Representação da Eficiência em Água Aberta de Hélice da Série B-Troost (B 4-70) em Função de $1 / \mathrm{J}$, Parametrizados em P/D e $C T J=\sqrt[4]{\frac{K_{T}}{J^{4}}}$.

Figura 33 Representação da Eficiência em Água Aberta de Hélice da Série Kaplan em Dutos em 49 Função de 1/J, Parametrizados em P/D e RTJ $2=\sqrt{\frac{K_{T}}{J^{2}}}$.

Figura 34 Perdas de Eficiência de Um Hélice em Função do Carregamento das Pás

Figura 35 Análise Espectral de Uma Série Temporal de Medidas de Torques no Eixo do Empurrador, $\mathrm{n}=1690 \mathrm{rpm}=8,99 \mathrm{rps}$.

Figura 36 Estimativa de Coeficientes de Esteira Efetiva a Partir dos Ensaios em Escala Real - Sexta

Viagem - Hélices Convencionais. $\mathrm{H}=1,6 \mathrm{~m}$.

Figura 37 Estimativa de Coeficientes de Redução da Força Propulsora a Partir dos Ensaios em Escala 56 Real - Sexta Viagem Hélices Convencionais. $\mathrm{H}=1,6 \mathrm{~m}$.

Figura 38 Estimativa de Coeficientes Propulsivos a Partir dos Ensaios em Escala Real - Sexta Viagem - Hélices Convencionais. Comparações com Curvas Obtidas em Ensaios na Escala 1:13. Uma chata $\mathrm{H}=1,6 \mathrm{~m}$.

Figura 39 Estimativa de Coeficientes Propulsivos a Partir dos Ensaios em Escala Real - Sexta Viagem - Hélices Convencionais. Comparações com Curvas Obtidas em Ensaios na Escala 1:13. Duas Chatas em Paralelo, $\mathrm{H}=1,6 \mathrm{~m}$.

Figura 40 Estimativa de Coeficientes Propulsivos a Partir dos Ensaios em Escala Real - Sexta Viagem - Hélices Convencionais. Comparações com Curvas Obtidas em Ensaios na Escala 1:13. Duas Chatas em Linha, $\mathrm{H}=1,6 \mathrm{~m}$.

Figura 41 Estimativa do Coeficiente de Esteira a Partir dos Ensaios em Escala Real - Oitava Viagem. Hélices em Dutos.

Figura 42 Estimativa do Coeficiente de Redução da Força Propulsora a Partir dos Ensaios em Escala Real - Oitava Viagem. Hélices em Dutos. 
Figura 43 Valores de Eficiências Propulsivas. Sexta Viagem. H=1,60 m. h=5,0 m.

Figura 44 Valores de Eficiências Propulsivas. Oitava Viagem. H=1,60 m. h=5,0 m.

Figura 45 Valores de $K_{Q}$ em Função de J, Utilizados na Estimativa de $\omega$ em Escala Real - Sexta $\quad$....... 63 Viagem. Indicação das Eficiências em Água Aberta. Eixo de BB.

Figura 46 Valores de Velocidades em Função do Número de Rotações dos Motores n. Comparações 68 dos Resultados Medidos para a Condição de Duas Chatas em Paralelo $\mathrm{H}=1,6 \mathrm{~m}$, com Aqueles Esperados nos Três Projetos.

Figura 47 Comparações de Potências Medidas em Escala Real e em Tanque de Provas. Uma Chata.

Figura 48 Comparações de Potências Medidas em Escala Real e em Tanque de Provas. Duas Chatas 70 em Linha. Hélices B-Troost.

Figura 49 Comparações de Potências Medidas em Escala Real e em Tanque de Provas. Duas Chatas 71 em Paralelo. Hélices B-Troost. 


\section{ÍNDICE DAS TABELAS}

Tabela 1 Instrumentação Utilizada nos Ensaios do Comboio de Pesquisas do Araguaia

Tabela 2 Características Principais do Comboio de Pesquisas do Araguaia

Tabela 3 Características dos Hélices do Empurrador e Locais da Sexta e da Oitava Viagens do Comboio Araguaia

Tabela 4 Condições de Ensaios para Comparações de Resultados. (Condições: uma chata, duas chatas em linha e duas chatas paralelos).

Tabela 5 Resultados de Medidas de Forças Máximas de Tração Estática no Empurrador.

Tabela 6 Valores do Fator $\mathbf{F}$ da Formulação de Howe, Obtidos a Partir de Comparação com Resultados de Ensaios em Tanque de Provas do IPT

Tabela 7 Equações Aproximadas para Estimativas de Áreas Cobertas de Cavitação no Dorso das Pás Obtidas do Diagrama de Burril.

Tabela 8 Comparações de Eficiências em Água Aberta de Hélices B-Troost com Três Razões de Áreas Expandidas, em Função do Coeficiente de Carregamento $C_{\mathrm{T}} .4$ Pás, P/D = 1,00.

Tabela 9 Valores de Espessuras Máximas das Seções das Pás ao Longo do Raio para Séries B-Troost, Kaplan e Navio Quebra-Gelo. Hélices de 4 pás.

Tabela 10 Valores de Coeficientes de Esteiras $\omega$ para as Condições da Sexta e Oitava Viagens $(\mathrm{H}=1,6 \mathrm{~m})$ e Estimados de Acordo com Item 3.3.2.

Tabela 11 Valores de Coeficientes de Redução da Força Propulsora t para as Condições da Sexta e Oitava Viagens $(\mathrm{H}=1,6 \mathrm{~m})$ e Estimados de Acordo com Item 3.3.2.

Tabela 12 Valores de Eficiência Propulsiva $\eta_{D}$ em Função da Velocidade. Sexta Viagem $(\mathrm{H}=1,6 \mathrm{~m})$.

Tabela 13 Valores dos Coeficientes CT, $\sqrt{\frac{K_{T}}{J^{2}}}$ e $\sqrt[4]{\frac{K_{T}}{J^{4}}}$ dos Pontos Experimentais. Sexta Viagem.

Tabela 14

Valores dos Coeficientes CT, $\sqrt{\frac{K_{T}}{J^{2}}}$ e $\sqrt[4]{\frac{K_{T}}{J^{4}}}$ dos Pontos Experimentais. Oitava Viagem.

Tabela 15 Comparações Entre Valores Medidos e os Esperados por Três Novos Projetos. Duas Chatas em Paralelo. H=1,6 m. h= 5 m. PB=221 kW, n=1800 rpm, Relação de Redução 3,13:1.

Tabela 16 Comparações Entre Valores Medidos e Esperados na Condição de Tração Estática ("Bollard-Pull").

Tabela 17 Resumo dos Problemas Típicos de Hélices de Embarcações Fluviais e Soluções 


\section{LISTA DE SÍMBOLOS}

$\mathrm{A}_{\mathrm{E}}$ - área expandida do hélice,

$\mathrm{A}_{\mathrm{o}}$ - área do disco do hélice $: \mathrm{Ao}=\pi . \mathrm{D}^{2} / 4$,

BHP - potência do motor em hp,

$\mathrm{C}_{\mathrm{A}}$ - coeficiente de resistência devido à rugosidade do casco da embarcação,

$\mathrm{C}_{\mathrm{D}}$ - coeficiente de arrasto,

$\mathrm{C}_{\mathrm{F}}$ - coeficiente de resistência de atrito,

$\mathrm{C}_{\mathrm{L}}$ - coeficiente de sustentação,

$\mathrm{C}_{\mathrm{r}}$ - corda da seção da pá de raio $\mathrm{r}$,

$\mathrm{C}_{\mathrm{T}}$ - coeficiente de resistência total,

$\mathrm{C}_{\mathrm{TH}}$ - coeficiente de carregamento do propulsor: $\mathrm{CT}_{\mathrm{H}}=\mathrm{T} /\left(1 / 2 . \rho\right.$. Ao. $\left.\mathrm{V}^{2}\right)$,

$\mathrm{C}_{\mathrm{V}}$ - coeficiente de resistência viscosa,

$\mathrm{C}_{\mathrm{W}}$ - coeficiente de resistência de ondas,

D - diâmetro do propulsor,

DHP - potência absorvida pelo hélice em hp,

EHP - potência efetiva do casco em hp,

$\mathrm{F}_{\mathrm{n}}$ - número de Froude $F_{n}=\frac{V}{\sqrt{g \cdot L}}$,

$\mathrm{F}_{\text {nh }}$ - número de Froude de profundidade $\quad F_{n h}=\frac{V}{\sqrt{g \cdot h}}$,

g - aceleração da gravidade,

$\mathrm{h}$ - profundidade do canal de navegação,

H - calado médio da embarcação,

$\mathrm{J}$ - coeficiente de avanço do hélice,

$\mathrm{K}_{\mathrm{Q}}$ - coeficiente de torque do hélice, em água aberta,

$\mathrm{K}_{\text {Qnavio }}$ - coeficiente de torque obtido em provas da embarcação, com o hélice junto ao casco,

$\mathrm{K}_{\mathrm{T}}$ - coeficiente de empuxo do hélice, ou da soma hélice+duto no caso de hélices em dutos,

$\mathrm{K}_{\mathrm{Tn}}$ - coeficiente de empuxo do duto,

$\mathrm{K}_{\text {Tnavio }}$ - coeficiente de empuxo obtido em provas da embarcação, com o hélice junto ao casco,

n - número de rotações,

$\mathrm{P}$ - passo geométrico das pás do hélice,

$\mathrm{P}_{\mathrm{B}}$ - potência do motor em unidades do S.I.,

$P_{D}$ - potência absorvida pelo hélice em unidades do S.I.,

$\mathrm{P}_{\mathrm{E}}$ - potência efetiva do casco em unidades do S.I.,

$P_{O}$ - pressão estática referida ao centro do eixo do hélice,

$\mathrm{P}_{\mathrm{V}}$ - pressão de vaporização da água,

$\mathrm{Q}$ - torque absorvido pelo hélice,

$R$ - raio total do hélice: $R=D / 2$,

$\mathrm{r}$ - raio de uma determinada seção da pá,

$\mathrm{R}_{\mathrm{T}}$ - resistência ao avanço da embarcação,

$\mathrm{R}_{\mathrm{n}}$ - número de Reynolds,

$\mathrm{t}$ - coeficiente de redução da força propulsora,

$\mathrm{T}$ - empuxo fornecido pelo hélice, ou pelo soma hélice+duto no caso de hélices em dutos,

$\mathrm{T}_{\mathrm{D}}$ - empuxo fornecido pelo duto,

$\mathrm{T}_{\mathrm{H}}$ - empuxo fornecido apenas pelo hélice no caso de hélices em dutos,

$\mathrm{V}$ - velocidade da embarcação,

$\mathrm{V}_{\mathrm{A}}$ - velocidade de avanço: $\mathrm{V}_{\mathrm{A}}=\mathrm{V} .(1-\omega)$,

$\mathrm{Z}$ - número de pás de um hélice,

$\omega$ - coeficiente de esteira efetiva,

$\gamma$ - densidade da água ( $=$ massa / volume),

$\rho$ - densidade específica da água: $\rho=\gamma / \mathrm{g}$,

$\eta_{D}$ - eficiência propulsiva $-\eta_{D}=P_{E} / P_{D}$, 
$\eta_{\mathrm{O}}$ - eficiência do propulsor em água aberta: $\eta_{\mathrm{O}}=\mathrm{J} \cdot \mathrm{K}_{\mathrm{T}} /\left(2 \cdot \pi \cdot \mathrm{K}_{\mathrm{Q}}\right)$,

$\eta_{\mathrm{r}}$ - eficiência relativa rotativa,

$\lambda$ - razão de escala do modelo da embarcação.

obs.: índice "m" indica modelo e "s" indica a embarcação em escala real. 


\section{INTRODUÇÃO}

As embarcações fluviais de carga apresentam, geralmente, duas características básicas e importantes: calados relativamente pequenos, devido às restrições de profundidades da maior parte das vias navegáveis, e deslocamentos grandes, resultantes da necessidade de otimização econômica do transporte de cargas, as quais são, na sua maioria, de baixos valores agregados.

A conjunção destes dois fatores - baixos calados e grandes deslocamentos - faz com que os hélices das embarcações tenham diâmetros restritos e enormes empuxos, resultando em altos carregamentos das pás, o que, via de regra, resulta em eficiência baixa e em possibilidade de ocorrência de sérios problemas relacionados com cavitação e vibrações.

Outros fatores interferem no desempenho hidrodinâmico dos hélices de embarcações fluviais de carga:

- frequientes alterações das condições de operação das embarcações - calados e formação de comboios (número e posições relativas das chatas), resultando em variações significativas dos valores de resistência ao avanço e de coeficientes propulsivos;

- operação em águas rasas e restritas, implicando em interferências no desempenho hidrodinâmico dos hélices;

- necessidade de realização freqüente de manobras, exigindo boa eficiência a ré dos propulsores e características que não prejudiquem a manobrabilidade da embarcação e garantam um bom desempenho em parada brusca;

- presença, em alguns casos, de lemes instalados em posições imediatamente a vante dos hélices, denominados lemes de flanco, com interferência direta no escoamento e na distribuição de esteiras;

- as formas cheias e de fundos planos dos seus cascos, às vezes até com a adoção de túneis de popa, piorando a distribuição de esteiras nas regiões de instalação dos hélices;

- possível presença de troncos ou outros corpos na água, podendo tornar necessária a instalação de estruturas para proteção dos hélices e dos lemes contra choques; 
- presença constante de alterações geométricas nos hélices, principalmente localizadas nas pontas das pás, resultantes de choques com pedras e troncos e de defeitos de fabricação, com conseqüente operação dos propulsores fora de suas características de projeto.

Todo este quadro apresentado ilustra a especificidade e a complexidade do projeto e da avaliação de desempenho hidrodinâmico dos hélices de embarcações fluviais de carga. Tais hélices devem conseguir adaptar-se eficientemente aos fatores físicos condicionantes (como restrições de calados, formas de popa, etc.) e às frequientes alterações radicais de suas condições de operação.

Ao mesmo tempo que deve ser buscada a maior eficiência possível nas mais variadas condições operacionais, deve ser evitado que os custos necessários à implementação da melhor solução sejam impeditivos. Desta forma, algumas soluções tecnicamente atraentes, como hélices de passos controláveis, tendem a não ser adotadas por apresentarem custos inicial e de manutenção extremamente altos.

O projetista de hélices de embarcações fluviais de carga tem convivido com a falta de uma base sólida teórica e/ou empírica que lhe possibilite, com segurança e precisão, resolver os problemas encontrados na busca de maiores eficiências dos propulsores e conseqüente redução de custos operacionais e economia de transportes de cargas

O desenvolvimento da teoria de propulsores, em estágio avançado, não tem se refletido, por conta da alta complexidade do fenômeno físico, em facilidades para o projeto dos hélices de embarcações fluviais de carga. Atualmente, o projeto destes hélices é feito utilizando-se séries sistemáticas em conjunto com adoções de processos empíricos, geralmente baseados em resultados de experimentação com modelos em escala reduzida, que permitem prever valores de resistências de cascos e de coeficientes propulsivos.

\subsection{OBJETIVOS}

O presente documento tem o objetivo de indicar procedimentos e apresentar elementos que possam contribuir para o aprimoramento do processo de projeto de propulsores de embarcações fluviais de carga, a partir da análise de resultados de ensaios com um comboio em escala real. São também utilizados resultados de ensaios em tanque de provas com modelo do mesmo comboio em escala reduzida e alguns outros resultados experimentais presentes em referências bibliográficas. 
São destacados os pontos mais importantes para o projeto hidrodinâmico do propulsor: a geometria dos hélices e a obtenção dos coeficientes propulsivos e da resistência ao avanço das embarcações.

A partir da análise de resultados de ensaios em escala real (realizados sob coordenação técnica do autor), de ensaios com modelos em escala reduzida e outros obtidos em referências bibliográficas, o estudo deve ter, como frutos, algumas indicações de elementos, de procedimentos e de formas adequadas de condução do processo de projeto de hélices de embarcações fluviais de cargas.

Os dados disponíveis serão exaustivamente verificados, com comparações entre si (efeitos das alterações de formações do comboio, de profundidades e de calados, por exemplo) e com aqueles que seriam esperados por meio de formulações e métodos empíricos e semi-empíricos.

Especialmente, são utilizados:

- a formulação de Howe [10] para estimativas de resistências ao avanço de comboios em canais com restrições lateral e de fundo;

- formulações para estimativas de coeficientes propulsivos de embarcações fluviais da Rússia, dadas na referência [2].

A interpretação dos resultados dos ensaios também será utilizada para a obtenção de elementos técnicos que possam contribuir para a tomada de decisões de projeto de hélices de embarcações fluviais, como:

$\Rightarrow$ as vantagens e desvantagens de adoção de hélices em dutos (com tubos Kort);

$\Rightarrow$ a escolha adequada do ponto de projeto dos hélices de uma embarcação;

$\Rightarrow$ a importância de cada um dos parâmetros geométricos (diâmetro, número de pás, razão de área, distribuições de passos, de cordas e de espessuras) para o projeto de um hélice com alto carregamento;

$\Rightarrow$ a influência da presença na popa da embarcação de lemes de flancos e de estruturas de proteção contra choques em lemes e hélices. 


\subsection{HISTÓRICO}

Há mais de um século os hélices vêm sendo utilizados como propulsores de embarcações com as mais variadas formas, finalidades e dimensões.

Ao longo de todo o período de tempo a partir de sua concepção, o projeto e a análise do desempenho dos propulsores tipo hélice evoluíram baseados em três atividades complementares entre si: as teorias de propulsores, as experiências com modelos em escala reduzida e as experiências em escala real ou em protótipos.

Para uma grande parte das embarcações existentes no mundo, a questão do projeto de hélices está satisfatoriamente solucionada. As ferramentas teóricas satisfazem plenamente às expectativas dos projetistas, apresentando resultados muito próximos daqueles verificados em ensaios em escala reduzida e em escala real. Os ensaios com modelos de embarcações são utilizados, geralmente, para levantamento dos dados necessários para o projeto do sistema de propulsão, como a resistência ao avanço, os coeficientes propulsivos, a distribuição de esteira nominal, etc. Os ensaios em escala real são utilizados principalmente para comprovação dos resultados esperados pelo projeto e para calibrar os métodos de extrapolação de resultados e de previsão de desempenho da embarcação. Às vezes, os dois tipos de ensaios podem servir para indicar e orientar a introdução de alterações para melhoria do desempenho do conjunto casco-hélice(s)-motor(es).

Uma constatação salta aos olhos de quem analisa todo o período de existência dos propulsores tipo hélice: regra quase geral, as eficiências máximas dos hélices projetados nos tempos atuais são muito próximas daquelas dos hélices existentes em tempos mais remotos. Por outro lado, também é evidente que ao longo dos anos houve uma evolução sensível em aspectos cruciais ao rendimento do sistema propulsivo: foram desenvolvidas formas de minimizar e controlar o fenômeno da cavitação e as vibrações induzidas pelos propulsores, assim como ferramentas teóricas e experimentais que tornaram possível o entendimento e a otimização da integração dos hélices aos $\operatorname{cascos}[12]$.

No que se refere a hélices de alto carregamento e, mais especificamente, a hélices de embarcações fluviais de cargas, muito pouco existe em bibliografias, apesar de haver concordância de vários autores de que devem ser utilizados métodos de análise e de projeto diferentes daqueles utilizados para hélices de carregamentos leves (VOLKER [45], NARITA et alli. [36] e CHRISTOPOULOS \& LATORRE [10]). CHRISTOPOULOS \& LATORRE desenvolveram um 
procedimento de projeto deste tipo de hélice, aplicando-o, anos após, no desenvolvimento de um hélice denominado semi-Kaplan [11], com alterações das distribuições de cordas e de passos da série sistemática de hélices em dutos "Kaplan". Os resultados do desempenho em viagens com estes hélices mostraram que o novo procedimento de projeto introduziu uma melhoria em cerca de $10 \%$ da eficiência propulsiva do empurrador, comparando-se consumos de combustível e velocidades médias.

A bibliografia existente sobre embarcações fluviais é principalmente referente a ensaios com modelos em tanques de provas [3], [33], [44]. Não são encontradas referências bibliográficas que apresentem resultados completos de provas de propulsão em escala real de comboios. Neste sentido, o presente trabalho, com a apresentação e análise de uma série de dados obtidos em medições em escala real pode significar uma contribuição efetiva ao estudo do desempenho propulsivo de comboios fluviais.

\subsection{ORGANIZAÇÃO DO PRESENTE TRABALHO}

O presente trabalho foi desenvolvido em quatro partes:

- no capítulo 2, é feita uma descrição dos ensaios e a sistematização dos resultados obtidos;

- no capítulo 3, apresentação dos recursos que serão utilizados para a análise dos dados e para a consolidação dos entendimentos sobre a questão do desempenho propulsivo de embarcações fluviais;

- no capítulo 4, são apresentados os resultados da análise dos dados experimentais;

- no capítulo 5, a partir das indicações técnicas obtidas no item anterior, são elencadas as recomendações para melhoria do projeto de hélices de embarcações fluviais. 


\section{DADOS EXPERIMENTAIS}

\section{1 - OBTENÇÃO DOS DADOS EXPERIMENTAIS EM ESCALA REAL}

A obtenção de dados experimentais do desempenho de embarcações fluviais em escala real tem como principal problema a ser equacionado, a presença, na região de realização das medições, de correntezas, de variações de profundidades dos canais e de ventos. Diferentemente de um laboratório como um tanque de provas de embarcações, onde se pode controlar tais condições externas, em escala real há a necessidade de conviver com variáveis indesejáveis, que podem tornar a análise dos resultados complexa e mais imprecisa.

A fim de evitar maiores imprecisões de análise dos resultados de desempenho, o local das provas deve ser escolhido de tal forma que haja a menor velocidade de corrente possível e uma razoável uniformidade dos valores de profundidades da região, assim como largura adequada, de modo a não ocorrer interferências das margens sobre o desempenho da embarcação.

Os ensaios não devem ser realizados em dias e períodos que apresentem ventos de média ou alta intensidade. Os efeitos da correnteza podem ser minimizados efetuando-se corridas em uma mesma direção e em sentidos diferentes (a favor e contra a correnteza) e obtendo-se os valores médios de desempenho para uma mesma condição de operação dos motores. Os efeitos da variabilidade das profundidades podem ser evitados através de uma paciente busca de um local que apresente maior uniformidade de fundo possível.

Para a análise experimental do desempenho propulsivo de uma embarcação em escala real, de uma forma completa, devem ser medidos os seguintes parâmetros: velocidade, rotações, torques e empuxos nos eixos dos propulsores e parâmetros físicos ambientais como velocidade de corrente, intensidade e direção de ventos e profundidade média. Há, contudo, uma enorme dificuldade técnica em medir-se, com precisão satisfatória, empuxos em escala real, devido ao fato que os sensores convencionais, baseados em deformações dos eixos, apresentam baixíssima sensibilidade no sentido longitudinal dos eixos relativamente longos das embarcações.

Dadas as razões já citadas, não foram medidos os valores de empuxo nos eixos dos propulsores nos ensaios em escala real apresentados neste trabalho. Passa a ter importância redobrada, como ver-se-á durante o desenvolvimento da análise, a determinação da geometria real 
dos hélices da embarcação e a estimativa da potência efetiva do casco (ou da resistência ao avanço da embarcação) na condição de ensaio.

\subsection{1 - Instrumentação Utilizada nas Medições em Escala Real}

A Tabela 1 apresenta as grandezas medidas nos ensaios em escala real do Comboio Araguaia, assim como a instrumentação utilizada. A aquisição dos dados foi feita por meio de um sistema composto por condicionadores e amplificadores de sinais, placas conversoras analógica/digital e microcomputador com "software" especial para obtenção e análise dos dados.

Tabela 1 - Instrumentação Utilizada nos Ensaios do Comboio de Pesquisas do Araguaia

\begin{tabular}{|l|l|}
\hline MEDIDAS & INTRUMENTOS \\
\hline TORQUES NOS EIXOS DE & $\begin{array}{l}\text { Torquímetros IPT (com extensômetros elétricos colados } \\
\text { ao eixo e sistema de radio freqüência para envio de sinais } \\
\text { para fora do sistema preso ao eixo) }\end{array}$ \\
\hline ROTAÇÕES DOS EIXOS BB e BE & Tacômetros óticos \\
\hline ANGULOS DOS LEMES & Potenciômetros \\
\hline PROFUNDIDADE & Ecobatímetro \\
\hline VELOCIDADE ANGULAR & “Rate Gyro” \\
\hline RUMO & Giroscópio \\
\hline VELOCIDADE E DIREÇÃO DO & Anemômetro \\
\hline VENTO & nas margens, com leituras simultâneas a cada 15s. \\
\hline COMBOIO / VELOCIDADES & \\
\hline
\end{tabular}




\subsection{2 - Erros das Medições em Escala Real}

Os erros das medições realizadas em escala real podem ser estimadas da forma proposta na referência [26]. Os erros são divididos em dois tipos: aqueles advindos da imprecisão dos instrumentos de medições e aqueles resultantes de todas as interferências externas sobre a embarcação. Assim,

$$
\sigma_{\text {total }}^{2}=\sigma_{\text {medidas }}^{2}+\sigma_{\text {outros }}^{2}
$$

onde: $\quad \sigma_{\text {medidas }}-$ erros e imprecisões de instrumentação (torquímetros, medidores de velocidades, etc.);

$\sigma_{\text {outros }}$ - erros devidos a diferenças geométricas dos hélices (entre série e real), a trim, banda, ventos, correntezas, alterações de temperaturas e densidades da água, cavitação de hélices, etc.

Estima-se que os erros envolvidos nos resultados de potências em escala real são de aproximadamente $6 \%$, enquanto que os erros de estimativas dos coeficientes propulsivos $(\omega, \mathrm{t})$ são da ordem de 0,03 .

\section{2 - OBTENÇÃO DOS DADOS EXPERIMENTAIS COM MODELOS EM ESCALA REDUZIDA}

Os ensaios típicos com modelos em escala reduzida de embarcações em tanques de provas são os ensaios de água aberta de hélices, de resistência ao avanço do casco e de autopropulsão. No túnel de cavitação é possível a realização de ensaios que simulam a operação em escala real de hélices e verificam a possibilidade de ocorrência de todos os tipos de cavitação. 


\subsubsection{Ensaios de Água Aberta de Modelos de Hélices}

Este ensaio serve para determinar as características hidrodinâmicas dos propulsores - o que significa quantificar qual a relação entre as potências absorvidas e as forças de empuxo gerados por cada hélice.

O modelo do hélice é instalado na ponta de um eixo longo de um casco preso ao carro dinamométrico do tanque de provas, a fim de evitar quaisquer interferências na região em que está instalado. Dentro do casco são instalados um motor e um dinamômetro para medidas de torque e empuxo no eixo. Imprimindo uma velocidade ao carro, com o eixo do hélice sempre a vante, e um determinado número de rotações ao eixo, são medidos os valores de torque e de empuxo, conseguindo-se, deste modo, as chamadas curvas características do hélice, em água aberta, ou seja, sem interferência de qualquer tipo de esteira.

As curvas características são, basicamente as do coeficiente de empuxo $\mathrm{K}_{\mathrm{T}}$, do coeficiente de torque $K_{Q}$ e da eficiência do hélice $\eta_{\mathrm{O}}$ em função do coeficiente de avanço J. As definições destes coeficientes são:

$$
\begin{aligned}
& K_{T}=\frac{T}{\rho \cdot n^{2} \cdot D^{4}} ; \\
& K_{Q}=\frac{Q}{\rho \cdot n^{2} \cdot D^{5}} ; \\
& J=\frac{V_{A}}{n \cdot D} ; \\
& \eta_{O}=\frac{K_{T} \cdot J}{2 \pi \cdot K_{Q}} .
\end{aligned}
$$

No caso dos ensaios de água aberta, $\mathrm{V}_{\mathrm{A}}=\mathrm{V} .(1-\omega)=\mathrm{V}$, já que o coeficiente de esteira efetiva $\omega$ é igual a zero devido ao fato de não haver interferências na região onde está instalado o propulsor.

\subsubsection{Ensaios de Resistência ao Avanço}

Os ensaios de resistência ao avanço de modelos de embarcações em tanque de provas são de realização aparentemente simples, mas que requerem cuidados especiais com a precisão da realização das medidas e com a extrapolação de seus resultados para escala real. 
Os ensaios consistem do arrasto do modelo pelo carro dinamométrico em determinada velocidade, com o objetivo de se medir a força de resistência ao avanço. Variando-se a velocidade, consegue-se obter uma curva de resistência ao avanço $\mathrm{R}_{\mathrm{T}}$ (ou de potência efetiva do casco $\mathrm{P}_{\mathrm{E}}$ ) em função da velocidade.

A velocidade é extrapolada para escala real pela igualdade do número de Froude $\mathrm{F}_{\mathrm{n}}$ entre modelo e embarcação real e a extrapolação da resistência é feita a partir da sua separação em componentes. A componente de atrito é extrapolada em função do número de Reynolds $R_{n}$, utilizando-se formulações de coeficientes de atrito para placas planas como a de Schoenherr ou a da ITTC (International Towing Tank Conference). São geralmente introduzidos um fator de forma, ou coeficiente de resistência de forma $(1+\mathrm{k})$ praticamente independente do número de Reynolds, e um coeficiente de acréscimo de resistência devido à rugosidade $\mathrm{C}_{\mathrm{A}}$.

Uma seqüência de extrapolação pode ser resumida pelas expressões a seguir:

$$
\begin{aligned}
& C_{T_{s}}=C_{V_{s}}+C_{W_{s}}+C_{A} \\
& C_{V_{s}}=(1+k) \cdot C_{F s} \\
& C_{W_{s}}=C_{W_{m}}=C_{T_{m}}-C_{V_{m}} \\
& C_{V m}=(1+k) \cdot C_{F m} \\
& V_{s}=V_{m} \cdot \sqrt{\lambda}
\end{aligned}
$$

Para compensar as diferenças de regimes de escoamento entre escala real e modelo, com este tendendo ao regime laminar, são introduzidos excitadores de turbulência na proa das embarcações. No IPT (Instituto de Pesquisas Tecnológicas do Estado de São Paulo), são utilizados pequenos pinos de alumínio igualmente espaçados, dispostos em uma seção do casco a uma distância predeterminada do espelho de proa, segundo critério adotado em vários laboratórios do mundo.

\subsubsection{Ensaios de Autopropulsão}

O método de ensaio utilizado é o denominado continental. O modelo de um casco bihélice, como é a maior parte das embarcações fluviais, é dotado de um motor elétrico com controle de número de rotações, de um divisor para saída de dois eixos, de dois dinamômetros para medidas de torques e empuxos nos eixos e de dois modelos de hélices. Os ensaios são realizados em toda a faixa 
de velocidades de interesse, convertidas para a escala do modelo através da igualdade do número de Froude $F_{n}$ entre embarcação e modelo.

O modelo é fixado ao carro dinamométrico através de um sistema de braços que não permite o desalinhamento, embora não impeça o seu deslocamento longitudinal. O avanço do modelo, que deve ser igual ao do carro dinamométrico, é dado pela ação de duas forças: a principal, que é o empuxo dos hélices, e uma força $\mathrm{R}_{\mathrm{A}}$ aplicada para compensar a diferença entre as componentes de resistência que atuam sobre o modelo e a embarcação em escala real, calculada a partir da seguinte expressão:

$$
R_{A}=\frac{1}{2} \cdot \rho_{m} \cdot S_{m} \cdot V_{m}^{2} \cdot\left[C_{F m}-\left(C_{F s}+C_{A}\right)\right]
$$

Os valores de $\mathrm{C}_{\mathrm{Fm}}$ e $\mathrm{C}_{\mathrm{Fs}}$ podem ser obtidos através de expressão da linha de coeficiente de atrito de placas planas de Schoenherr:

$$
\frac{0,242}{\sqrt{C_{F}}}=\log _{10}\left(R_{n} \cdot C_{F}\right)
$$

Os valores de $C_{A}$ foram admitidos como sendo iguais a $0,4 \times 10^{-3}$.

A análise dos ensaios de propulsão segue, há mais de 100 anos, o princípio de Froude, de dividir a eficiência propulsiva em componentes. Desta forma, define-se:

$$
\eta_{D}=\frac{P_{E}}{P_{D}}=\eta_{O} \cdot \eta_{H} \cdot \eta_{R}
$$

onde $\eta_{\mathrm{O}}$ é a eficiência do hélice em água aberta e $\eta_{\mathrm{H}}$ é a eficiência do casco, definida como:

$$
\eta_{H}=\frac{(1-t)}{(1-\omega)}
$$

Os coeficientes propulsivos (de esteira $\omega$, de redução da força propulsora t e eficiência relativa rotativa $\eta_{R}$ ) foram obtidos adotando-se a identidade de empuxo, ou seja, igualando-se os coeficientes de empuxo $\mathrm{K}_{\mathrm{T}}$ do modelo e em escala real. A descrição da obtenção dos coeficientes propulsivos é apresentada no item 3.2.

Seguindo recomendações da ITTC [ 26 ], é razoável assumir que os valores do coeficiente de redução de força propulsora e da eficiência relativa rotativa são os mesmos em escala real e em 
escala reduzida, ou seja, não há necessidade de correção de efeito escala para eles. Já para o coeficiente de esteira, o efeito escala é importante e deve ser levado em consideração. No presente trabalho adotou-se um dos métodos recomendados, o de Brard-Aucher [25 ].

\section{3 - RESULTADOS EM ESCALA REAL}

Os ensaios de desempenho propulsivo em escala real foram realizados no rio Araguaia com o Comboio de Pesquisas, de propriedade da AHITAR / CDP (Administração das Hidrovias do Tocantins e Araguaia / Companhia Docas do Pará) e com recursos do Fundo da Marinha Mercante. O comboio foi projetado por uma equipe técnica da Divisão de Tecnologia de Transportes do IPT com o objetivo de servir à avaliação das condições de navegabilidade do rio Araguaia e à indicação das melhores soluções técnicas para as embarcações que lá poderão operar no futuro.

O comboio é formado por um empurrador e por duas chatas. O empurrador possui túneis de popa para possibilitar a instalação de hélices com diâmetros da ordem do seu calado; os túneis têm formas que evitam a aeração na região dos propulsores em operação. As chatas foram projetadas com linhas baseadas na chata padronizada para o rio Reno, denominada Europa IIa. As principais características do empurrador e das duas chatas do Comboio de Pesquisas do Araguaia são apresentadas na Tabela 2 .

Nas primeiras viagens realizadas com o comboio, as ocorrências de choques com o fundo do rio ou com troncos foram freqüentes e resultaram em danos significativos a propulsores e lemes. A solução adotada para diminuir os danos à embarcação foi a introdução, na região dos propulsores, de uma estrutura de proteção confeccionada com barras de aço soldadas ao casco, conforme mostrada na Figura 1. Nesta figura, também estão indicadas a geometria e a posição longitudinal dos lemes de flancos, em número de dois a vante de cada hélice, que foram utilizados no empurrador até a quarta viagem de pesquisas.

Com a instalação da estrutura de proteção, os problemas mais graves causados por choques no fundo do rio e em grandes troncos em lemes e hélices foram resolvidos. Contudo, alguns danos de menor envergadura continuaram ocorrendo nas pás dos hélices, provocados por choques com pequenas pedras ou com pedaços de troncos. 
Tabela 2 - Características Principais do Comboio de Pesquisas do Araguaia

\begin{tabular}{|l|c|c|}
\cline { 2 - 3 } \multicolumn{1}{l|}{} & Empurrador & Chata \\
\hline Comprimento Total (m) & 18,5 & 40,0 \\
\hline Comprimento entre Perpendiculares (m) & 16,3 & 39,2 \\
\hline Boca Moldada (m) & 6,0 & 8,0 \\
\hline Calado Máximo (m) & 1,4 & 2,0 \\
\hline Calado Médio Mínimo (m) & 1,1 & 0,7 \\
\hline Calado de Projeto (m) & 1,2 & 2,0 \\
\hline Deslocamento de Projeto (t) & 91,5 & 530 \\
\hline Deslocamento da Chata com H =1,60 m (t) & - & 408 \\
\hline Deslocamento Leve (t) & 73,2 & 130 \\
\hline Potência Instalada (kW) & $2 \times 224$ & - \\
\hline Rotação Máxima dos Motores (rpm) & 1.800 & - \\
\hline Relação de Redução de Rotações & $1: 3,13$ & - \\
\hline
\end{tabular}
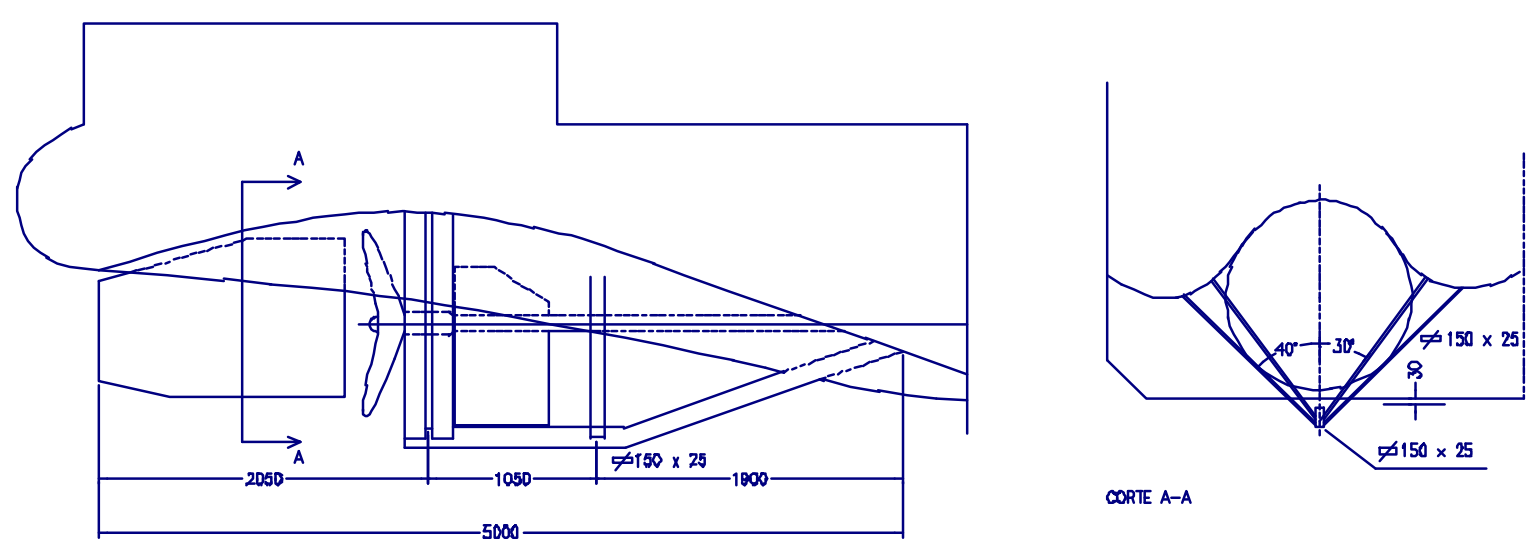

Figura 1 - Sistema de Proteção de Hélices e Lemes Contra Choques Instalado no Empurrador (no caso, incluindo leme de flancos, utilizados até a quarta viagem do comboio). 
Neste trabalho são apresentados os resultados de medições de desempenho propulsivo de algumas das viagens do Comboio de Pesquisas, principalmente da sexta e da oitava. Até a sexta viagem, o empurrador possuía dois hélices convencionais da série sistemática B-Troost (ou de Wageningen). Antes da sétima viagem, o empurrador foi retirado da água para que fossem instalados dois tubos Kort, com hélices da série sistemática Kaplan.

Os ensaios da sexta e da oitava viagens foram realizados nas proximidades da cidade de São Félix do Araguaia (MT), onde foi possível encontrar um trecho com largura e uniformidade de profundidades adequadas às medições.

A Tabela 3 apresenta as características de projeto dos propulsores utilizados nas viagens em análise, assim como dados sobre o local e datas das realizações das medições de desempenho propulsivo.

As Figuras 2 a 5 mostram os resultados de medidas de potências em função do número de rotações do eixo na sexta viagem, com o empurrador dotado de hélices convencionais.

A Figura 2 mostra os resultados das medições com o comboio formado pelo empurrador com apenas uma chata com calado de $1,6 \mathrm{~m}$.

A Figura 3 mostra os resultados com comboio formado por duas chatas em paralelo, ou lado a lado, com calado de $1,6 \mathrm{~m}$.

A Figura 4 apresenta os resultados dos ensaios da sexta viagem com a formação das duas chatas em linha. A fim de diminuir os problemas de vorticidades geradas por diferenças de geometrias na junção de uma chata com outra, as duas chatas são ligadas entre si pelas suas popas, ficando o empurrador ligado à proa da chata de ré.

A Figura 5 mostra os resultados com uma chata em condição leve, com calado médio de $0,7 \mathrm{~m}$ (trim pela popa de $0,2 \mathrm{~m}$ ). 
Tabela 3 - Características dos Hélices do Empurrador e Locais da Sexta e da Oitava Viagens do Comboio Araguaia

\begin{tabular}{|l|c|c|}
\hline VIAGEM & SEXTA & OITAVA \\
\hline SÉRIE DOS HÉLICES & B-TROOST & KAPLAN \\
\hline DIÂMETRO DOS HÉLICES & $1,15 \mathrm{~m}$ & $1,14 \mathrm{~m}$ \\
\hline NÚMERO DE PÁS & 4 & 4 \\
\hline RAZÃO DE ÁREA EXPANDIDA & 0,50 & 0,70 \\
\hline RAZÃO PASSO / DIÂMETRO & 0,55 & 0,74 \\
\hline DUTOS (TUBOS KORT) & - & NSMB $37[17]$ \\
\hline Porcentagem do perímetro dos dutos junto ao casco & - & $30 \%$ \\
\hline
\end{tabular}

\begin{tabular}{|l|l|c|c|}
\hline \multirow{4}{*}{ MEDIÇÕES } & LOCAL & São Félix & São Félix \\
\cline { 2 - 4 } & DATA & 9 a $14 / 12 / 91$ & 7 a $12 / 03 / 93$ \\
\cline { 2 - 4 } & PROFUNDIDADE MÉDIA & $5,0 \mathrm{~m}$ & $9,5 \mathrm{~m}$ \\
\cline { 2 - 4 } & LARGURA (aproximada) & $300 \mathrm{~m}$ & $300 \mathrm{~m}$ \\
\hline
\end{tabular}

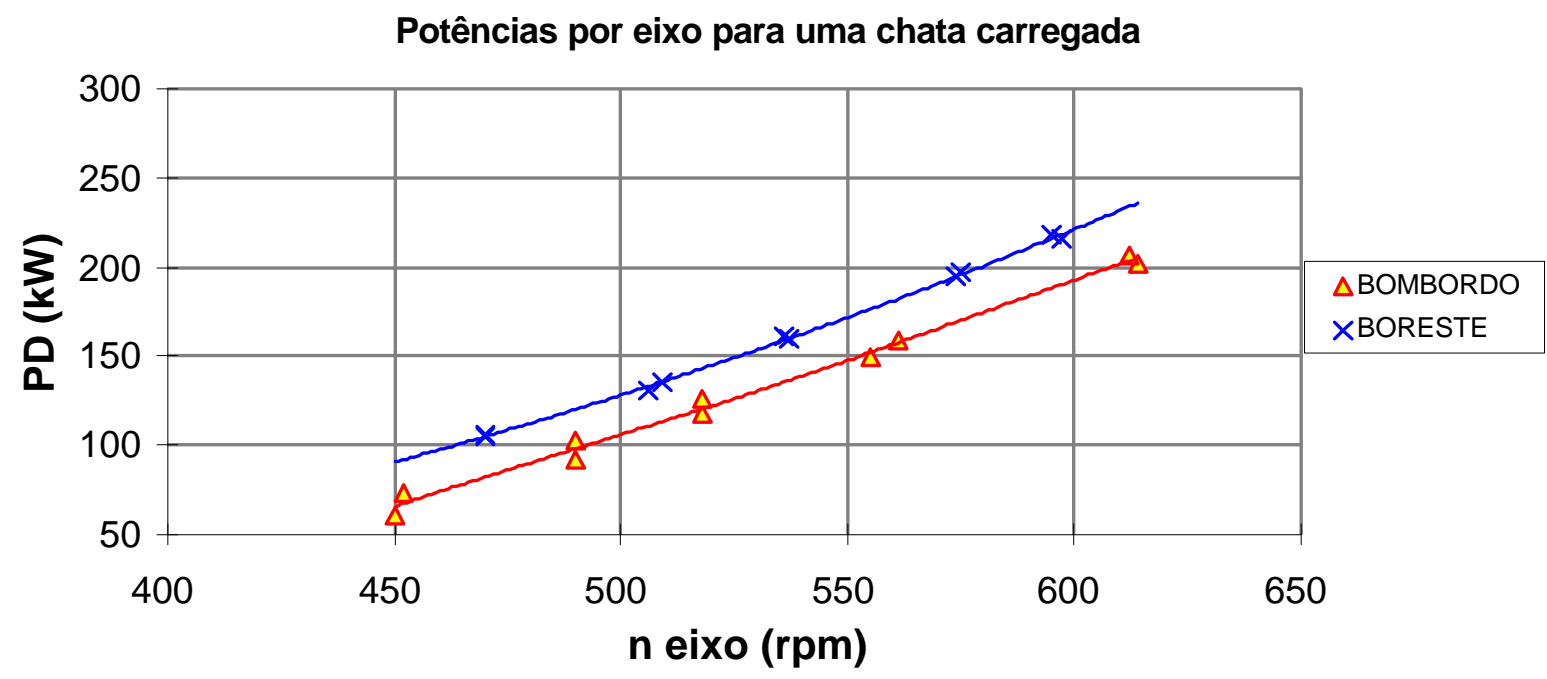

Figura 2 - Potências por Eixo - Hélices B-Troost, Uma Chata, Calado de 1,60 m. Profundidade de $5 \mathrm{~m}$. 


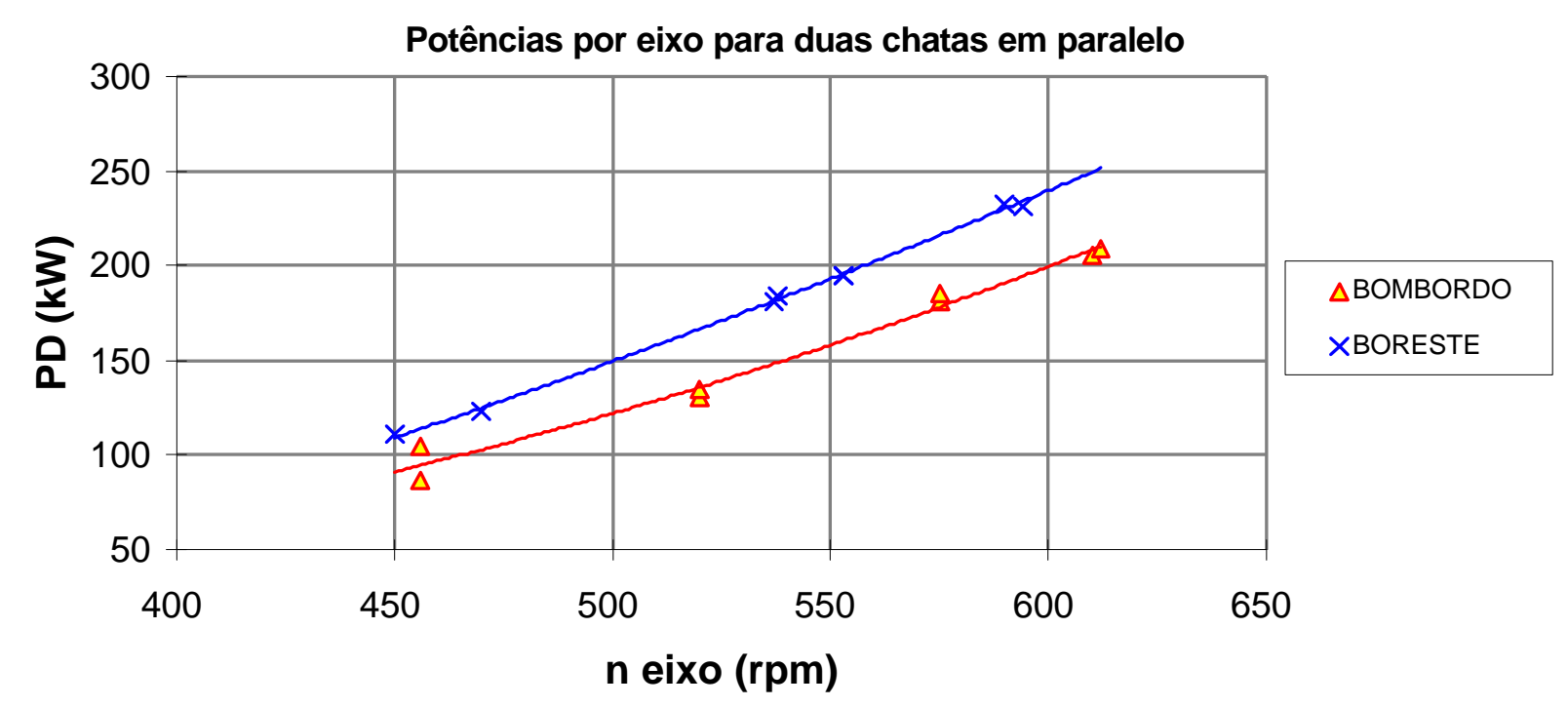

Figura 3 - Potências por Eixo - Hélices B-Troost, Duas Chatas em Paralelo, Calado de 1,60 m. Profundidade de $5 \mathrm{~m}$.

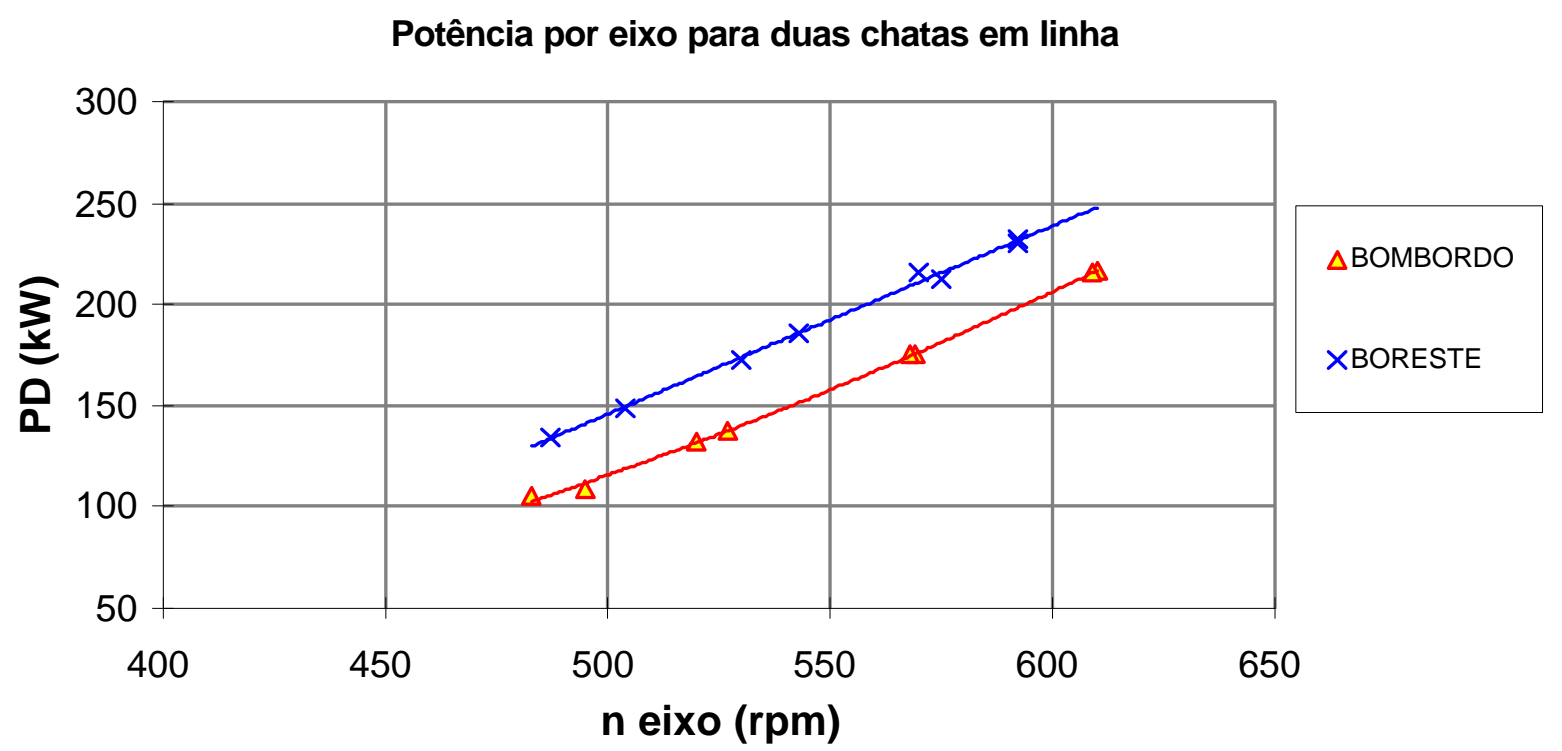

Figura 4 - Potências por Eixo - Hélices B-Troost, Duas Chatas em Chatas em Linha, Calado de 1,60 $\mathrm{m}$. Profundidade de $5 \mathrm{~m}$. 


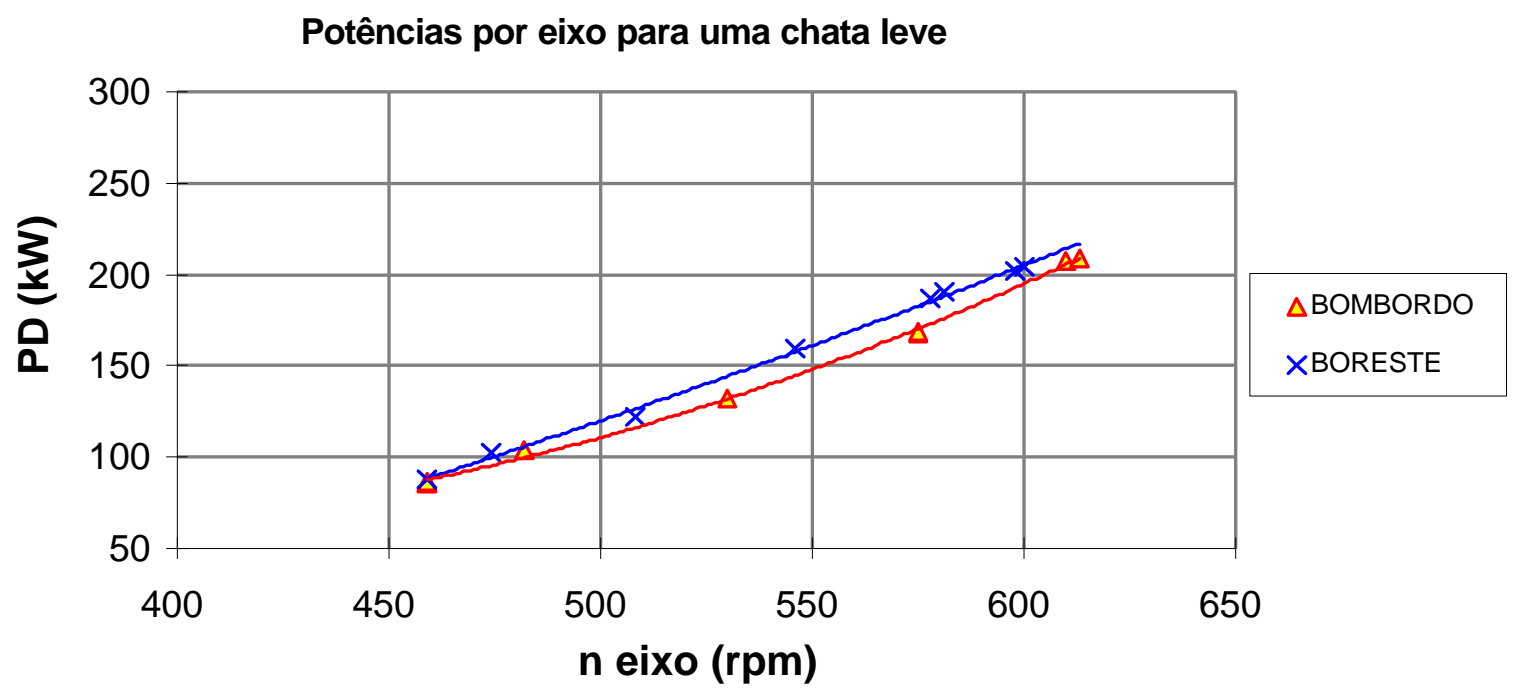

Figura 5 - Potências por Eixo - Hélices B-Troost, Uma Chata, Calado Médio de 0,70 m. Profundidade de $5 \mathrm{~m}$.

Como pode ser verificado nas Figuras 2 a 5, que mostram as curvas de potência em função da rotações dos eixos, há diferenças significativas de respostas (potências para uma mesma rotação e uma mesma velocidade do comboio) entre os hélices de bombordo e de boreste, no caso da sexta viagem com hélices convencionais. A explicação é que dificilmente eram realizadas viagens no rio Araguaia sem acidentes que danificassem parte dos hélices. A sexta viagem não foi uma exceção: o hélice de boreste sofreu danos em sua geometria, infelizmente não quantificados, que provavelmente levaram a um aumento da potência absorvida maior que aquela que deveria ter pelo seu projeto.

As Figuras 6 a 9 apresentam os resultados de potências medidas em função do número de rotações dos eixos na oitava viagem do comboio, com hélices em dutos instalados no empurrador. As Figuras 6 e 9 mostram resultados com a formação em paralelo, com calados de, respectivamente, de 1,6 m e 1,98 m. A Figura 7 apresenta os resultados com a formação em linha, calado de 1,6 m e a Figura 8 mostra as medições com apenas uma chata carregada $(\mathrm{H}=1,98 \mathrm{~m})$. 


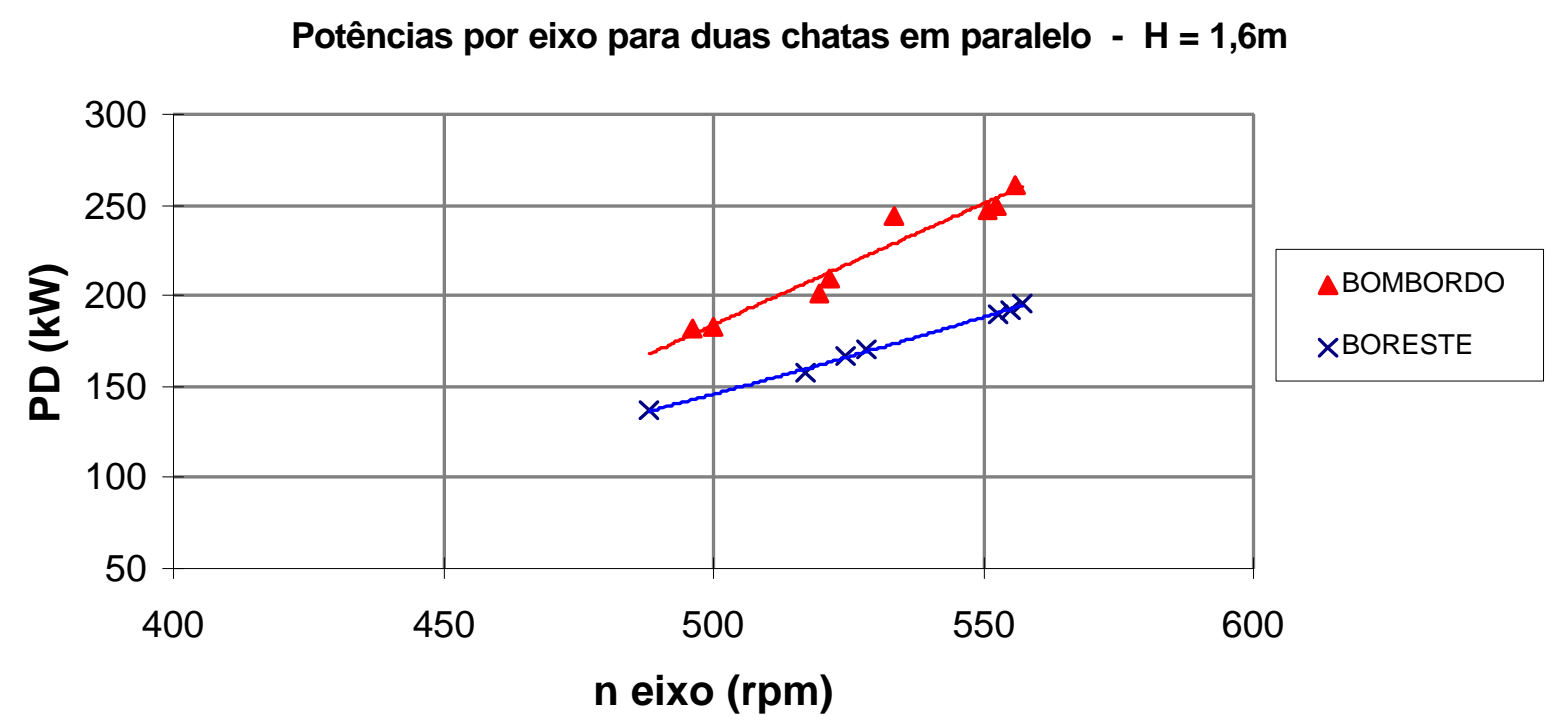

Figura 6 - Potências por Eixo - Hélices com Dutos, Duas Chatas em Paralelo, Calado de 1,60 m. Profundidade de $9 \mathrm{~m}$.

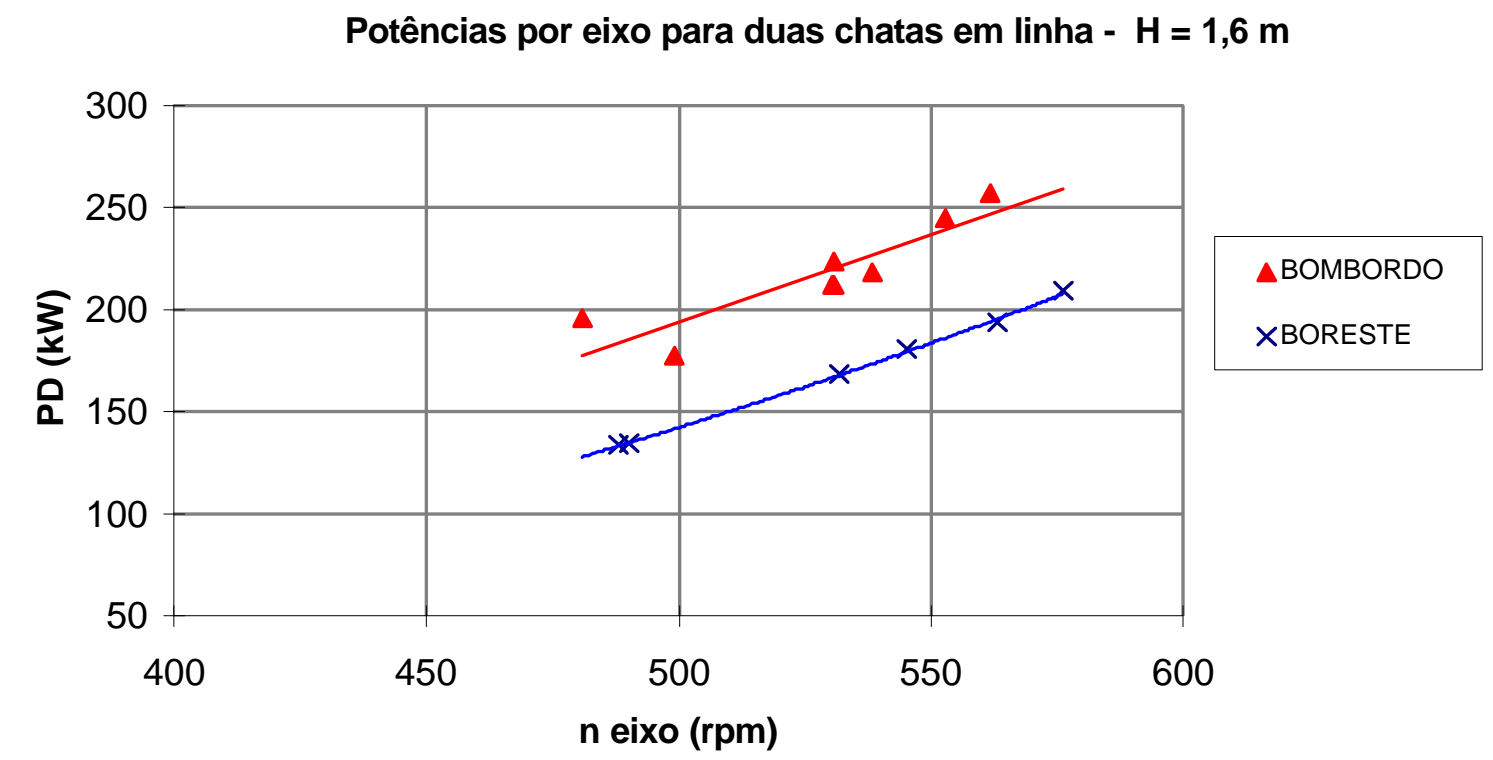

Figura 7 - Potências por Eixo - Hélices com Dutos, Duas Chatas em Linha, Calado de 1,60 m. Profundidade de $9 \mathrm{~m}$. 
Potências por eixo para uma chata carregada $-\mathrm{H}=1,98 \mathrm{~m}$

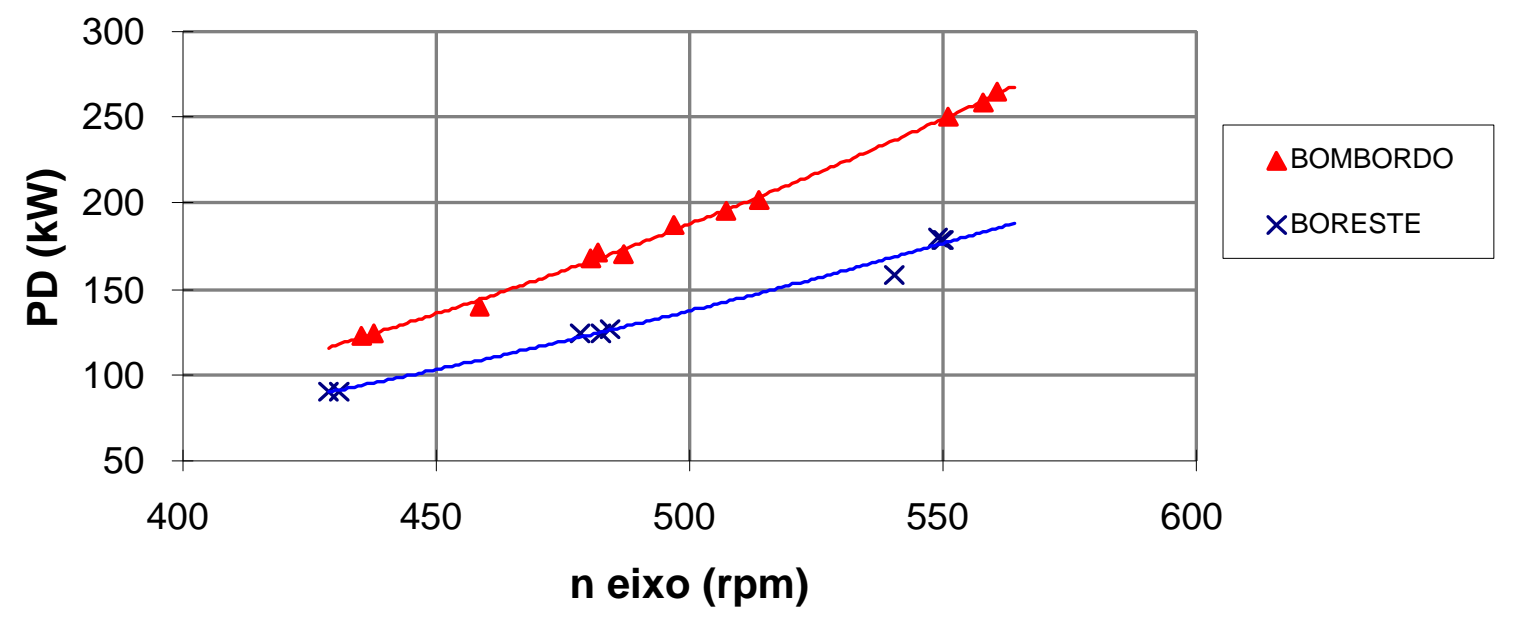

Figura 8 - Potências por Eixo - Hélices com Dutos, Uma Chata, Calado de 1,98 m. Profundidade: $9 \mathrm{~m}$.

Potências por eixo para duas chatas em paralelo $-\mathrm{H}=1,98 \mathrm{~m}$

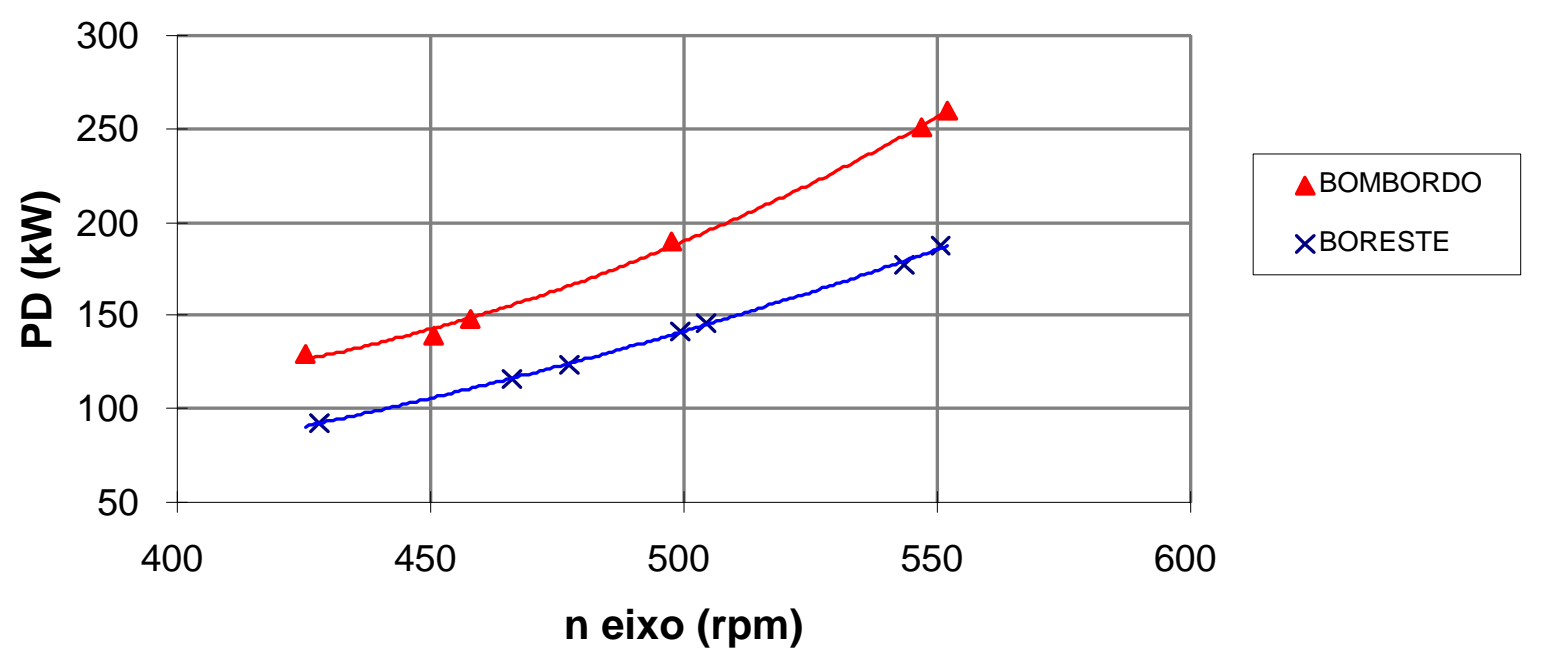

Figura 9 - Potências por Eixo - Hélices com Dutos, Duas Chatas em Paralelo, Calado de 1,98 m. Profundidade de $9 \mathrm{~m}$.

Também nos resultados obtidos na oitava viagem, com hélices em dutos, podem ser verificadas grandes diferenças de potências absorvidas pelo hélices de bombordo e o de boreste. $\mathrm{Na}$ oitava viagem, o hélice de boreste sofreu uma avaria, quando entrou um pedaço de pau entre as pontas das pás e o tubo Kort; após a sua desmontagem, verificou-se que o grau de torção das extremidades era grande, não sendo possível recuperá-lo sem cortar cerca de 15 milímetros da ponta de cada uma das pás (diminuição do diâmetro em aproximadamente $30 \mathrm{~mm}$ ). 
As ocorrências de choques com danos às pás dos hélices, freqüentes nas viagens do rio Araguaia e em outras hidrovias brasileiras, levam à conclusão que devem ser introduzidas alterações geométricas nos hélices que possam contribuir para diminuir os choques e as suas consequiências. Algumas destas alterações, que serão discutidas neste trabalho, podem ser, por exemplo, diminuição de diâmetros e aumentos de espessuras das pás.

A presença de avarias em um dos hélices de cada viagem não impossibilita a análise dos dados medidos. As estimativas de coeficientes propulsivos serão realizadas em relação aos eixos onde não ocorreram problemas.

A fim de levantar a influência das profundidades e da presença de lemes de flancos sobre o desempenho propulsivo do comboio, serão apresentados os resultados medidos em quatro viagens do empurrador com hélices convencionais, conforme mostra a Tabela 4.

Tabela 4 - Condições de Ensaios para Comparações de Resultados. (Condições: uma chata, duas chatas em linha e duas chatas paralelos).

\begin{tabular}{|c|c|c|c|l|}
\hline VIAGEM & $\begin{array}{c}\text { Profundidade } \\
\mathrm{h}(\mathrm{m})\end{array}$ & $\begin{array}{c}\text { Calado } \\
\mathrm{H}(\mathrm{m})\end{array}$ & $\mathrm{h} / \mathrm{H}$ & Observação \\
\hline $3^{\mathrm{a}}$ & 5,0 & 1,93 & 2,59 & com lemes de flancos \\
\hline $4^{\mathrm{a}}$ & 4,0 & 1,91 & 2,09 & com e sem lemes de flancos \\
\hline $5^{\mathrm{a}}$ & 3,4 & 1,60 & 2,13 & \\
\hline $6^{\mathrm{a}}$ & 5,0 & 1,60 & 3,13 & \\
\hline
\end{tabular}

A Figura 10 mostra as diferenças entre potências médias medidas nos eixos do empurrador com e sem lemes de flancos instalados à vante dos hélices, em uma mesma condição operacional (formação de comboio, calado, local, profundidade). A potência representada é a potência do motor $\mathrm{P}_{\mathrm{B}}$, obtida a partir da potência medida no eixo $\mathrm{P}_{\mathrm{D}}$, admitindo uma eficiência de transmissão de $95 \%$ $\left(\mathrm{P}_{\mathrm{B}}=\mathrm{P}_{\mathrm{D}} / 0,95\right)$. Como pode ser observado, há um acréscimo de potência da ordem de $4 \%$ para uma mesma velocidade com lemes de flancos instalados à frente dos propulsores, o que deve estar provocando alterações no escoamento e, conseqüentemente, nos coeficientes propulsivos. 
UMA CHATA CARREGADA - $\mathrm{H} / \mathrm{T}=2,09$

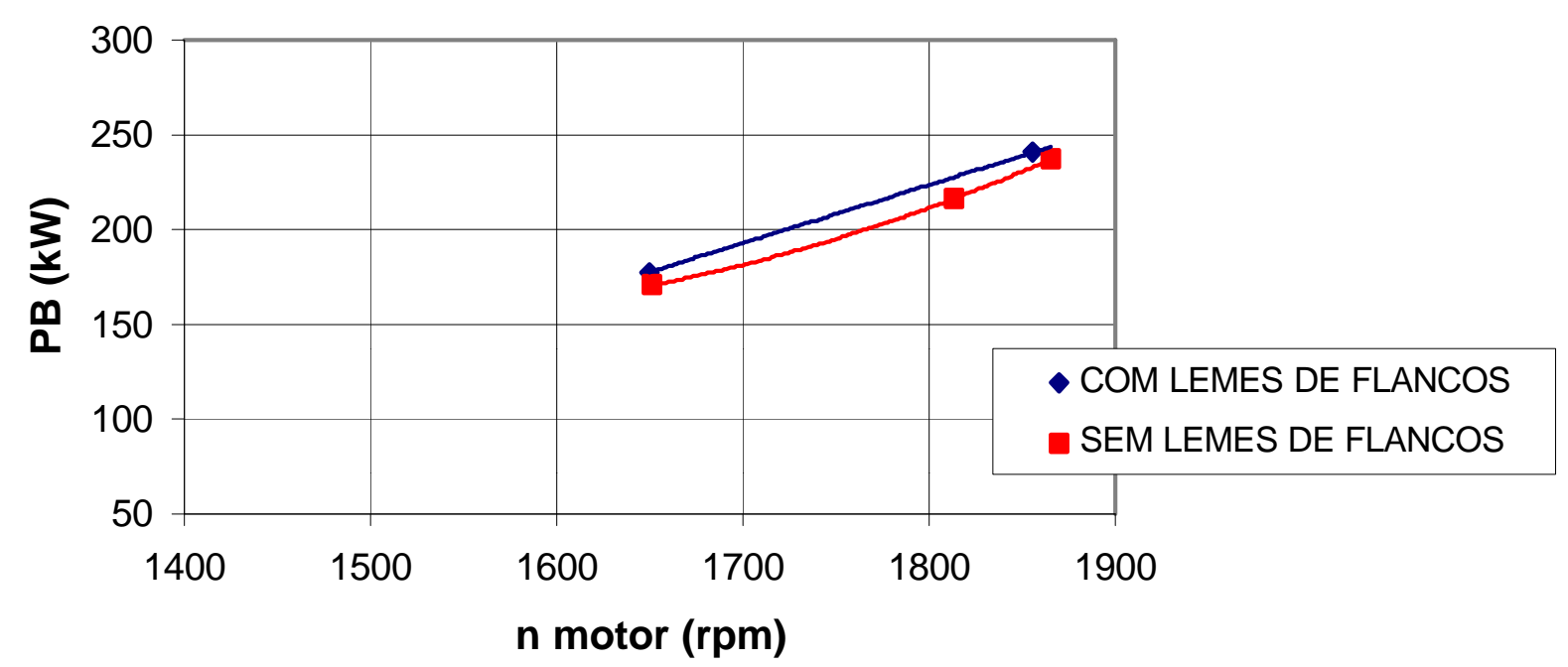

Figura 10 - Comparação entre Condições Semelhantes Com e Sem Lemes de Flancos no Empurrador. Quarta Viagem - Uma Chata Carregada.

As Figuras 11, 12 e 13 apresentam, respectivamente, os resultados de ensaios com uma chata, com duas chatas em linha e com duas chatas em paralelo, em várias relações de profundidades por calados $(\mathrm{h} / \mathrm{H})$.

\section{UMA CHATA CARREGADA}

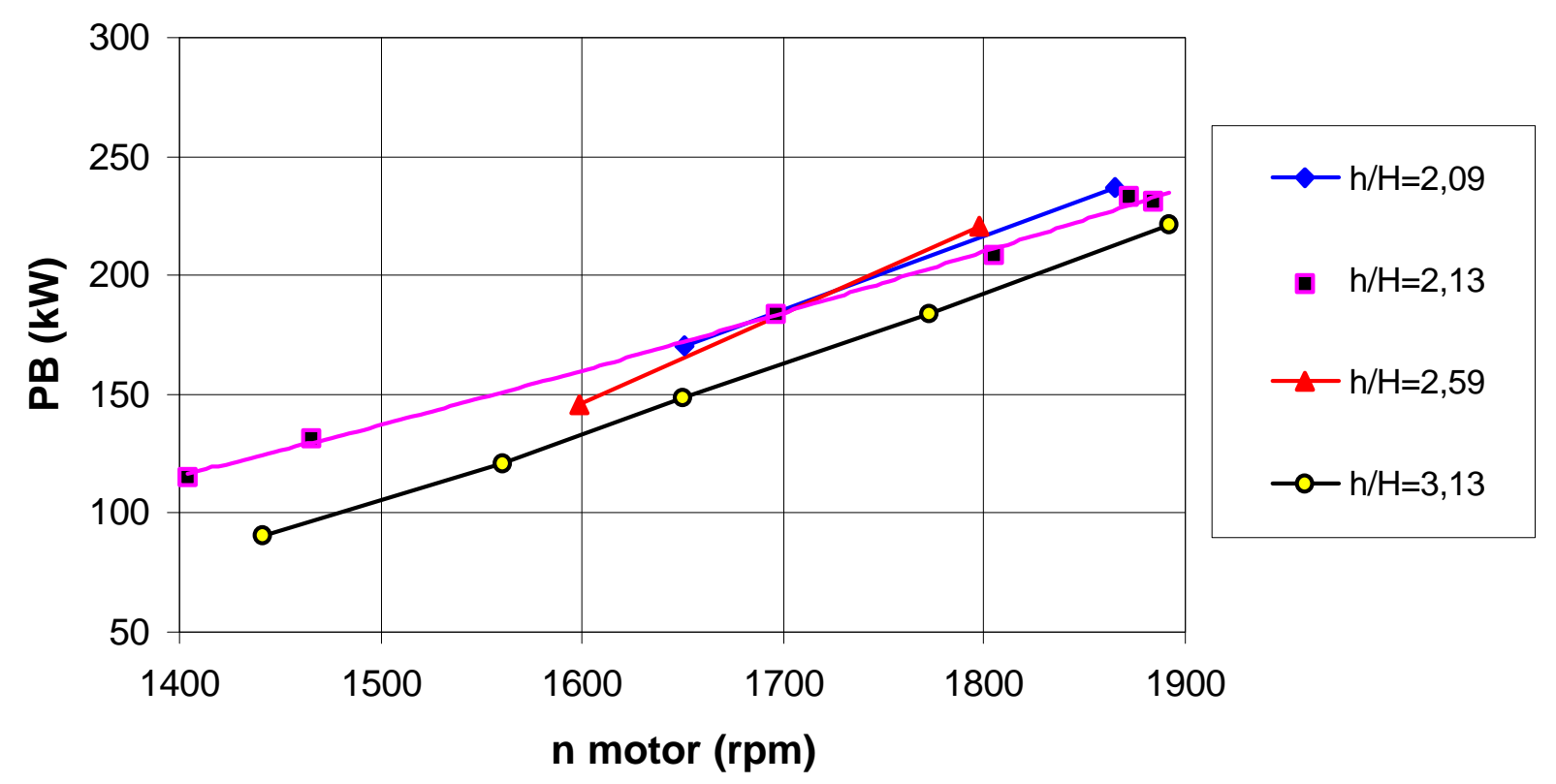

Figura 11 - Ensaios com Comboio com Uma Chata Carregada, em Várias Profundidades 


\section{DUAS CHATAS EM LINHA}

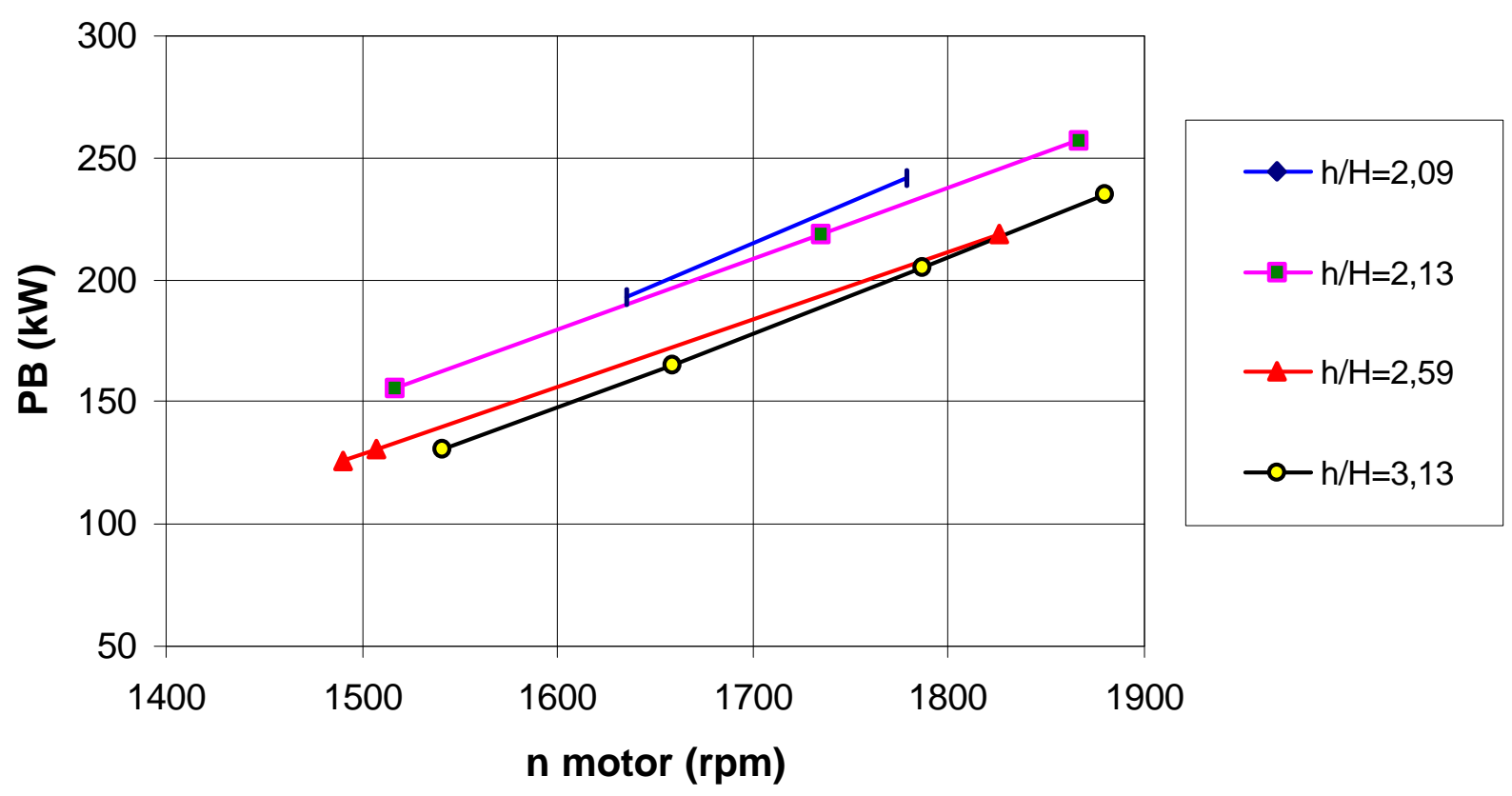

Figura 12 - Ensaios com Comboio com Duas Chatas em Linha, em Várias Profundidades

\section{DUAS CHATAS EM PARALELO}

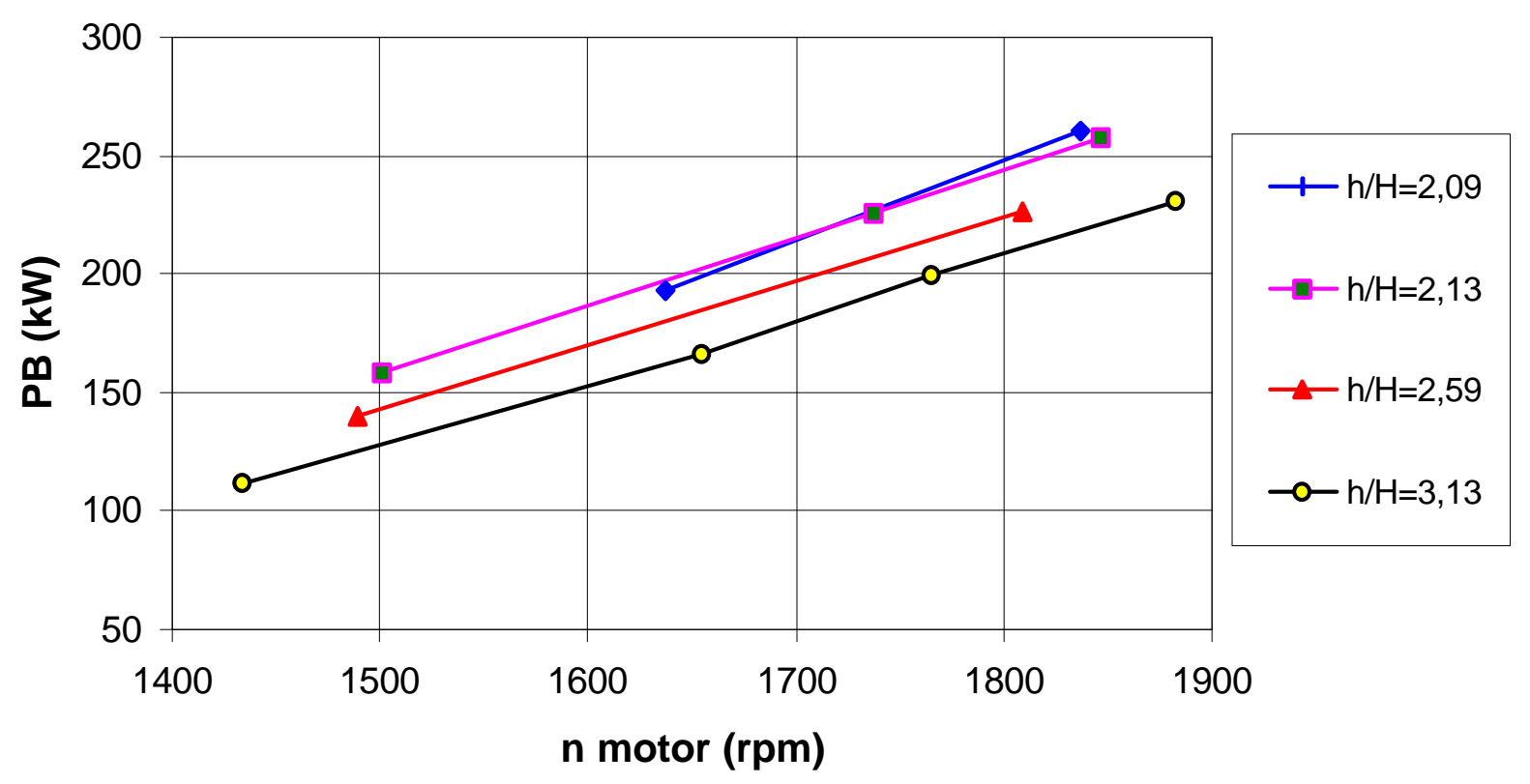

Figura 13 - Ensaios com Comboio com Duas Chatas em Paralelo, em Várias Profundidades

Como pode ser verificado nas figuras anteriores, há aumentos expressivos de potências em função da diminuição das profundidades do canal de navegação, nas três formações do comboio. 
As Figuras 14 e 15 apresentam, respectivamente, os resultados das medições da sexta e da oitava viagens, com valores de velocidades médias em função dos números de rotações dos motores.

Como pode ser visto, as velocidades médias resultantes, para formações de comboio e calados iguais, são maiores com os hélices Kaplan em dutos do que com os hélices B-Troost. Há, também, diferenças importantes nos números máximos de rotações dos motores de cada uma das viagens. Estes resultados serão objeto de análise posterior (capítulo 4).

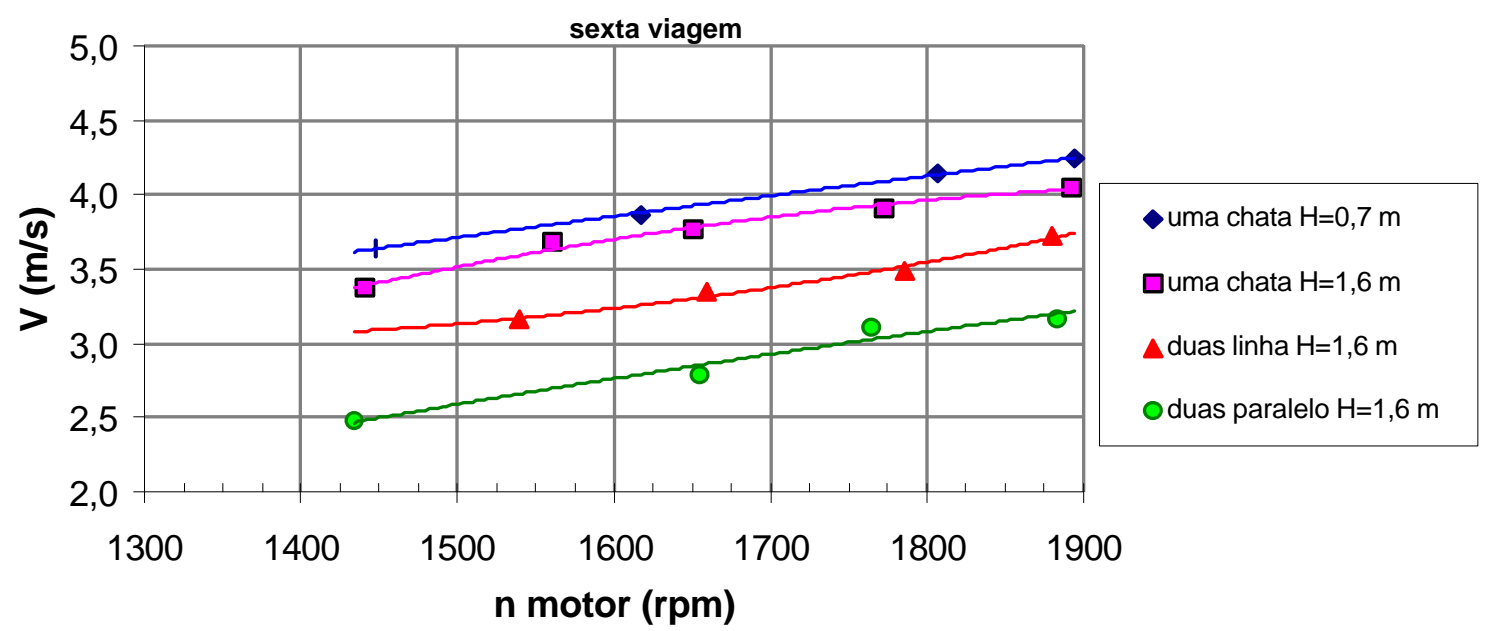

Figura 14 - Velocidades Médias em Função do Número de Rotações Médios dos Motores - Sexta Viagem. Profundidade h $=5 \mathrm{~m}$.

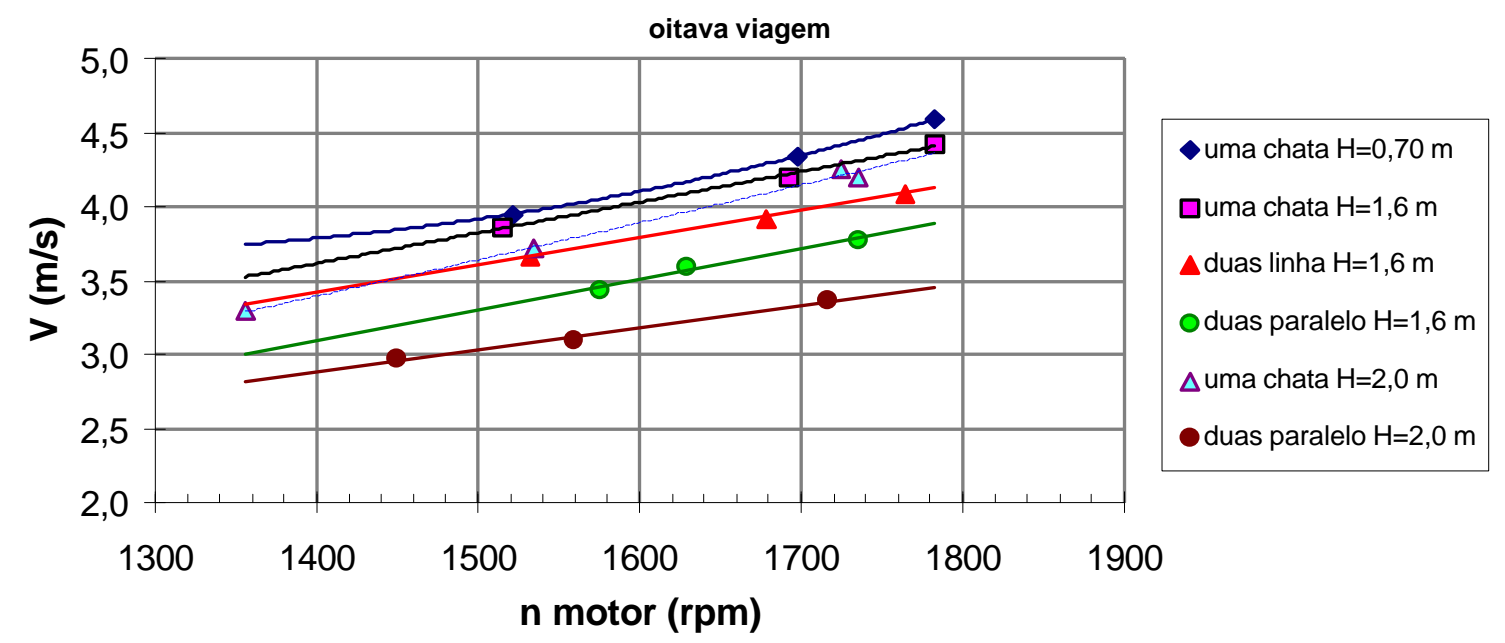

Figura 15 - Velocidades Médias em Função do Número de Rotações Médios dos Motores - Oitava Viagem. Profundidade $\mathrm{h}=9 \mathrm{~m}$. 


\section{4 - RESULTADOS EM TANQUE DE PROVAS}

A Figura 16 mostra os resultados dos ensaios de resistência ao avanço do modelo do comboio Araguaia na escala 1:13, realizados no tanque de provas do IPT, já extrapolados para escala real, para três formações (uma chata, duas chatas em linha e duas em paralelo) com calado correspondente a 2,0 m. Um dos resultados dignos de nota é que a formação em linha, por apresentar uma relação mais adequada entre comprimento e boca total, tem resistência menor que a formação em paralelo para uma mesma velocidade. As formações de chatas em paralelo, ou lado a lado, apesar de resultarem em maiores resistências ao avanço, são utilizadas em comboios devido a ocorrência de restrições de raios de curvaturas dos traçados das hidrovias e por apresentarem melhores desempenhos em manobras que as formações com chatas em linha.

As Figuras 17, 18 e 19 apresentam os resultados dos ensaios de autopropulsão. Tanto os ensaios de resistência como o de autopropulsão foram realizados em profundidades consideradas infinitas, sem simulação de águas rasas.

Os resultados de coeficientes de esteira efetiva devem sempre ser corrigidos do efeito escala, através da utilização de métodos recomendados [25], [26]. Os resultados dos coeficientes de redução da força propulsora e da eficiência relativa rotativa geralmente não necessitam de quaisquer correções de efeito de escala.

Como na maior parte dos ensaios em escala real há restrições de profundidades, deverá ser levado em conta o fato que há alterações dos coeficientes propulsivos em águas rasas [3], [20], [21]. 
RESULTADOS DE TANQUE DE PROVAS

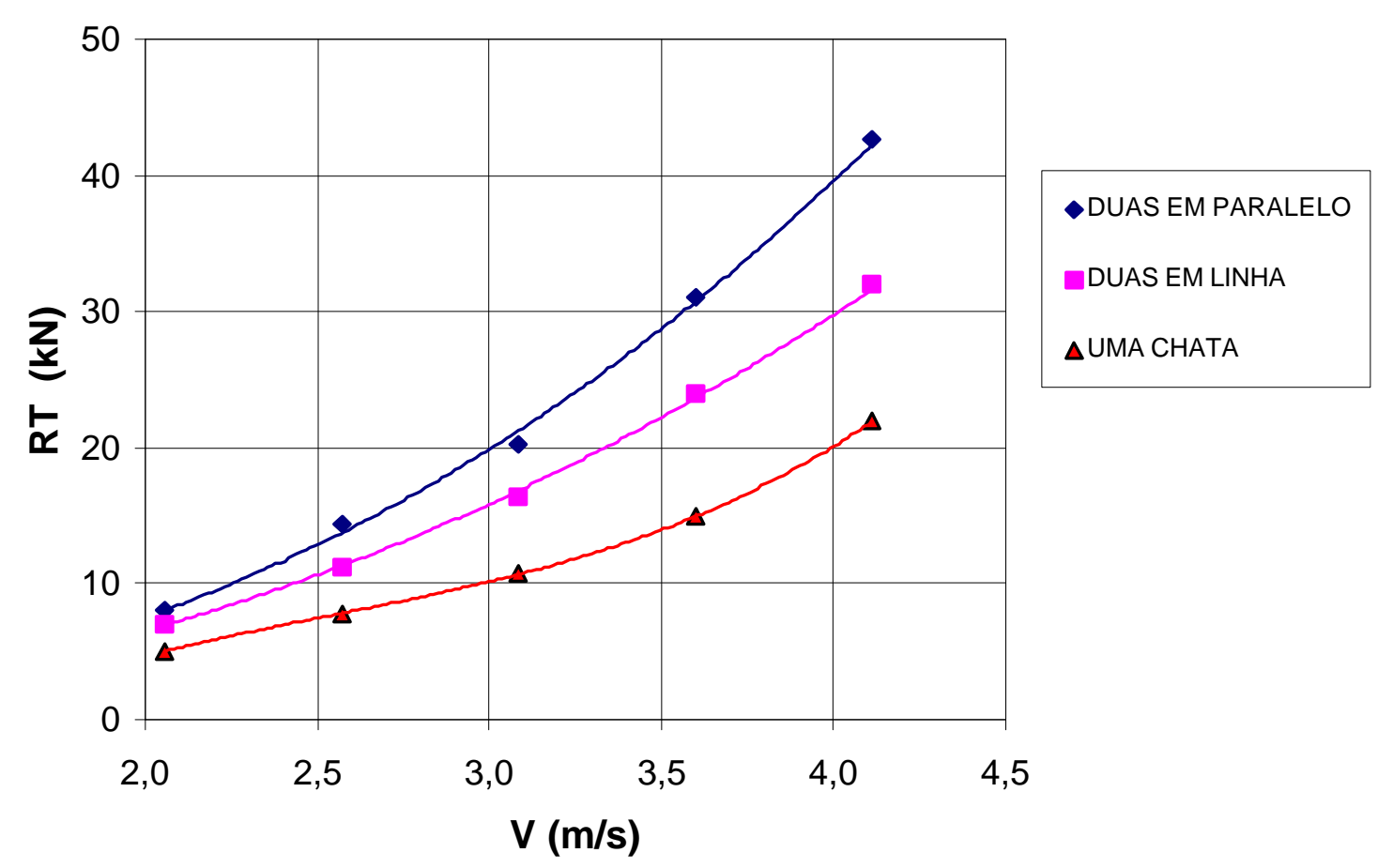

Figura 16 - Resultados dos Ensaios de Resistência em Tanque de Provas Extrapolados para Escala Real. Condição Carregado, Profundidade Infinita.

\section{coeficiente de esteira corrigido para escala real}

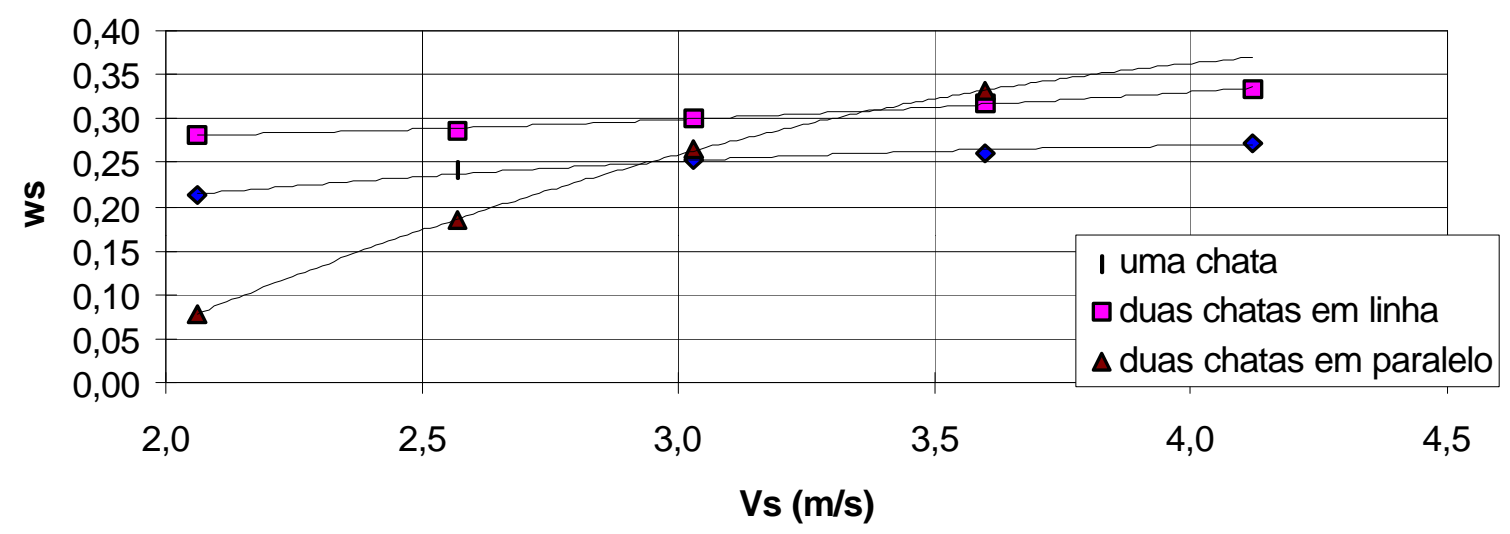

Figura 17 - Resultados dos Ensaios de Autopropulsão em Tanque de Provas. Coeficientes de Esteira Efetiva Extrapolados para Escala Real. Hélices Convencionais, Calado Carregado.

Profundidade Infinita. 
modelo escala 1:13

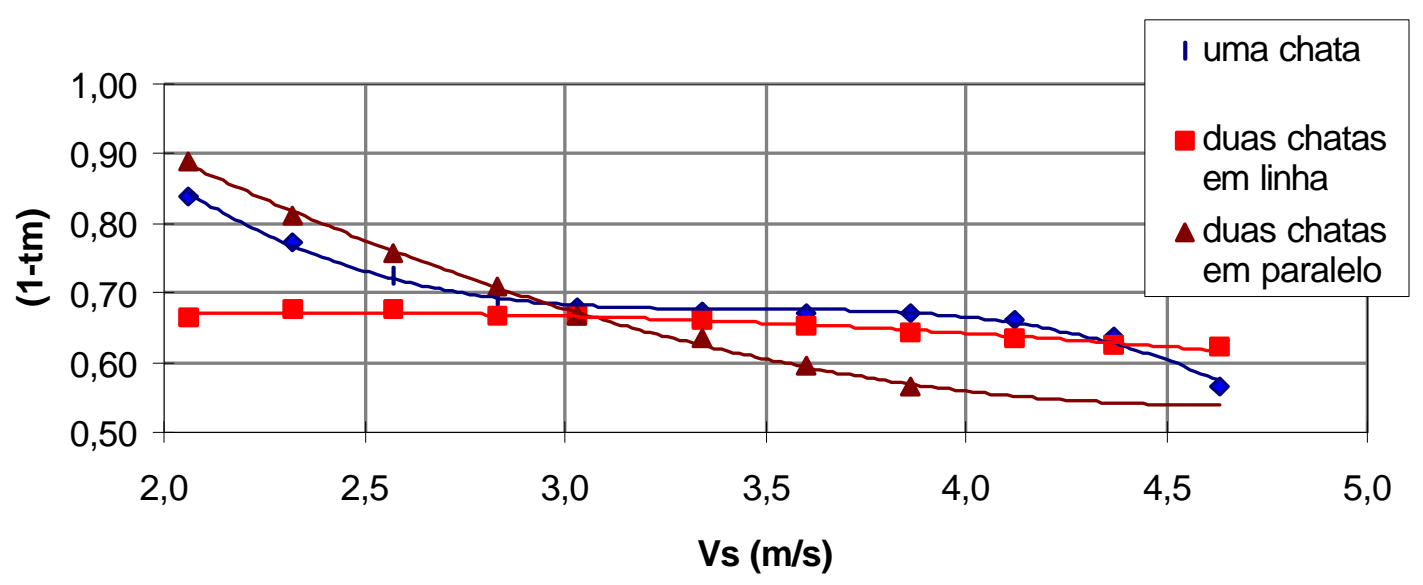

Figura 18 - Resultados dos Ensaios de Autopropulsão em Tanque de Provas. Coeficientes de Redução da Força Propulsora. Condição Carregado, Profundidade Infinita

modelo escala 1:13

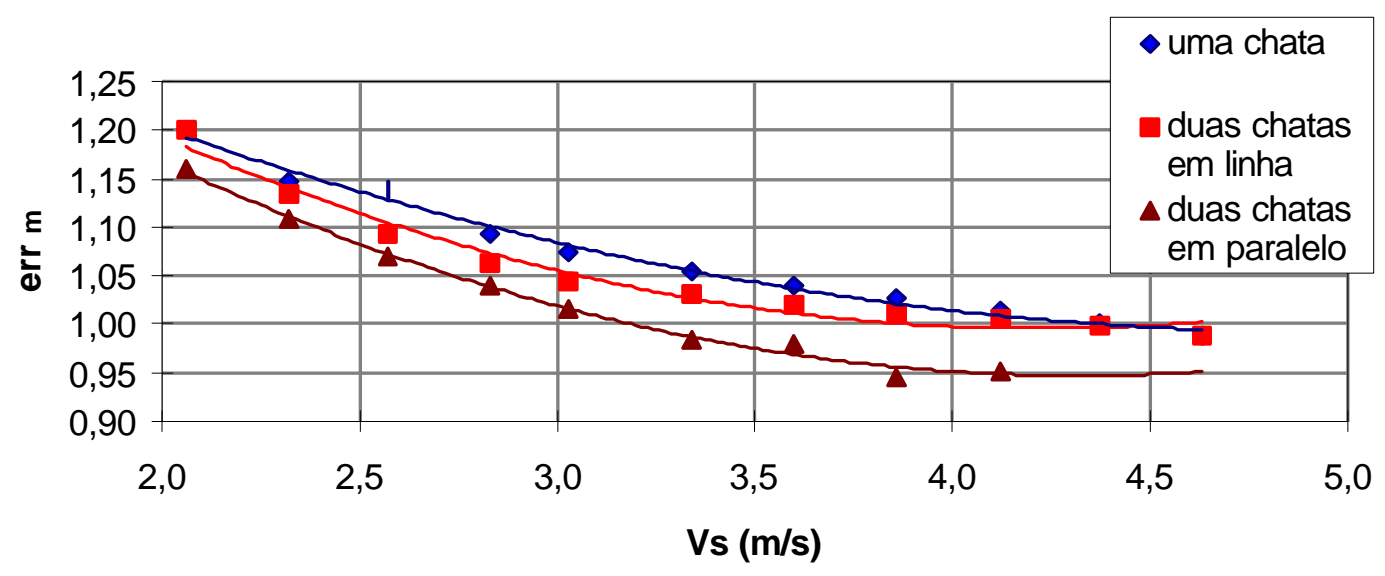

Figura 19 - Resultados dos Ensaios de Autopropulsão em Tanque de Provas. Eficiência Relativa Rotativa. Condição Carregado, Profundidade Infinita

\section{5 - ENSAIOS COM O EMPURRADOR ISOLADO}

Foram também realizados dois tipos ensaios com o empurrador sozinho, escoteiro: de tração estática ("bollard-pull”) e de corrida livre.

O ensaio de tração estática foi realizado com o empurrador dotado com hélices B-Troost e com hélices Kaplan em dutos. Basicamente, consiste em medir a força de tração do empurrador, por 
meio de uma célula de carga, em velocidade zero, amarrando um cabo a um ponto fixo em terra. Os resultados obtidos são mostrados na Tabela 5.

Tabela 5 - Resultados de Medidas de Forças Máximas de Tração Estática no Empurrador. Comparações com as Forças de Projeto

\begin{tabular}{|l|c|c|}
\cline { 2 - 3 } \multicolumn{1}{c|}{} & \multicolumn{2}{|c|}{ FORÇA DE TRAÇÃO ESTÁTICA (MN) } \\
\hline PROPULSORES & MEDIDA & PROJETO \\
\hline KAPLAN EM DUTOS & 59,7 & 65,7 \\
\hline B-TROOST & 52,1 & 53,9 \\
\hline
\end{tabular}

As diferenças entre valores de tração estática de projeto e medidas se devem às variações geométricas dos hélices devido a choques com pedaços de troncos.

Os ensaios de corrida livre com o empurrador escoteiro não puderam ser realizados como previstos inicialmente, devido a um problema verificado durante a operação nesta condição: o empurrador, à medida que o número de rotações dos motores eram aumentados, adotava um trim pela proa, a ponto de imergi-la quando os motores estavam a cerca de $1.200 \mathrm{rpm}$ (66\% da rotação correspondente à potência máxima contínua). Por razões de segurança optou-se por não ultrapassar tal número de rotações dos motores.

A Figura 20 mostra o trim resultante na condição com cerca de $1.200 \mathrm{rpm}$ nos motores do empurrador.

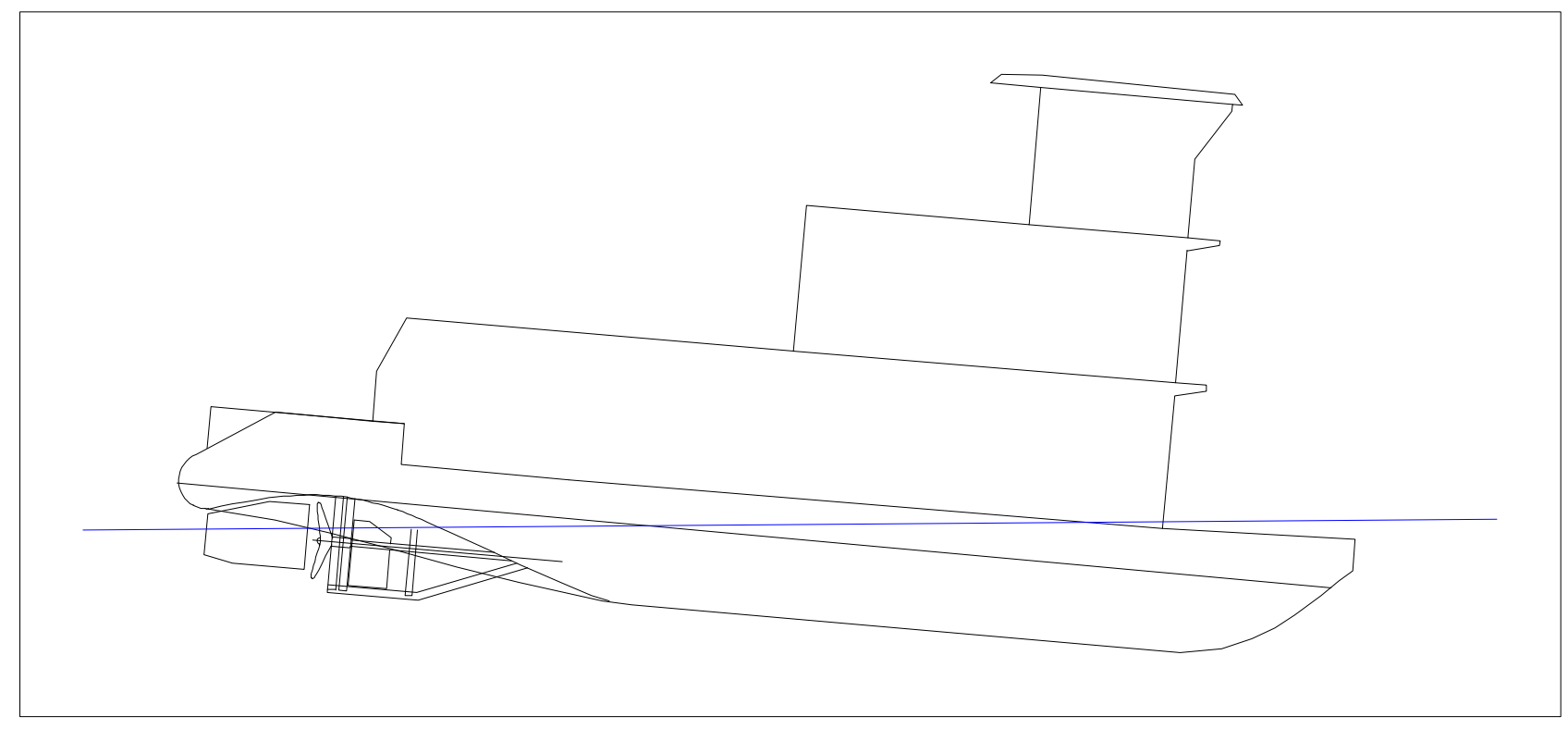

Figura 20 - Trim Dinâmico Verificado em Corrida Livre com o Empurrador Escoteiro 
A razão deste problema de afundamento da proa do empurrador está, sem dúvida, na geometria da saída do túnel de popa, onde a distribuição de pressões devida ao escoamento junto ao casco deve estar resultando em força que atua verticalmente na popa, elevando-a. O trim dinâmico verificado é relativamente sério, a ponto de prejudicar, como veremos adiante, o desempenho propulsivo do comboio composto pelo empurrador e chatas.

\section{6 - OUTROS RESULTADOS CONSIDERADOS}

Os resultados de dois trabalhos experimentais com modelos em escala reduzida de comboios fluviais, LUTHRA [33] e BINEK \& MÜLLER [3], serão utilizados no presente estudo, com enfoque sobre os valores de coeficientes propulsivos medidos em comboios com restrição de profundidade de canal.

O estudo de LUTHRA [33] apresenta os resultados de ensaios de resistência ao avanço, de autopropulsão e de medidas de distribuição de esteira nominal em um empurrador bihélice e em um empurrador catamarã empurrando chatas, realizado no tanque de provas em águas rasas do BVD (Versuchsanstalt fur Binnenschiffbau, Duisburg, Alemanha). O empurrador catamarã mostrou um melhor desempenho, cerca de $10 \%$ de potência a menos para manter uma mesma velocidade do empurrador convencional. Contudo, dado o presente interesse em embarcações atualmente existentes no Brasil, serão citados e analisados apenas os resultados relacionados com os comboio formado com o empurrador bi-hélice convencional, nas duas profundidades diferentes ensaiadas.

O artigo de BINEK \& MÜLLER [3] mostra os resultados de ensaios de propulsão com comboios fluviais. Variou-se a profundidade, os calados das chatas e as formações dos comboios. Foram medidos o trim, o afundamento paralelo, a rotação dos eixos dos hélices e a resistência ao avanço. Também foram apresentados os valores de coeficientes de esteira em função da velocidade para os vários comboios. 


\section{RECURSOS PARA ANÁLISE DE DESEMPENHO PROPULSIVO}

\subsection{ASPECTOS DA TEORIA DE PROJETO E ANÁLISE DE HÉLICES}

\subsubsection{Teorias de Propulsores}

As teorias mais antigas sobre a ação dos hélices seguiram duas linhas independentes de concepção [32]. Na primeira delas, a teoria do Disco Atuador, a obtenção de empuxo é explicada pelas alterações de quantidades de movimentos junto ao fluido. Na segunda, a teoria de elementos de pás, o empuxo é obtido através da análise das forças que atuam em cada uma das seções das pás e, depois, integrando-as ao longo do raio do hélice.

As teorias do Disco Atuador são baseadas em princípios fundamentais corretos, mas não fornecem informações sobre a forma do hélice que poderia produzir aquele empuxo calculado. Nestas teorias, um “disco atuador”, ou algo similar, representa um hélice por um número infinito de pás finas, ou seja, praticamente por um disco que absorve potência e transforma-a em empuxo, através de um acréscimo instantâneo de pressão no fluido que passa por ele. A mais importante conclusão destas teorias é que a eficiência de um hélice ideal tem um limite máximo que é função do carregamento das pás. Esta eficiência ideal é obtida pelas expressões [32], [15]:

$$
\begin{gathered}
\eta_{I}=\frac{2}{1+\sqrt{1+C_{T H}}} \text { para hélices convencionais e } \\
\eta_{I}=\frac{2}{1+\sqrt{1+\tau \cdot C_{T H}}} \text { para hélices em dutos, sendo: } \\
C_{T H}=\frac{T}{\frac{1}{2} \cdot \rho \cdot A_{0} \cdot V_{A}^{2}} \text { e } \tau=\frac{T_{H}}{T} \text {, onde } \mathrm{T} \text { é o empuxo total e } \mathrm{T}_{\mathrm{H}} \text { é o empuxo fornecido pelo duto. }
\end{gathered}
$$

Por outro lado, as teorias de elementos de pás, por si só, são capazes de prever os efeitos de alterações geométricas nos hélices, mas apresentam incorretamente a eficiência de um hélice ideal como sendo igual à unidade.

As diferenças entre os dois grupos de teorias só foram resolvidas com o desenvolvimento da Teoria da Circulação, inicialmente criada por Lanchester para a aeronáutica, em 1907, e depois aplicada a hélices marítimos por Prandtl e por Betz. Esta teoria mostrou a relação entre as mudanças 
de quantidade de movimentos no escoamento com as forças atuando em cada elemento de pá. Como grande vantagem, apresentou formas adequadas para aplicações em projetos práticos, com grande concordância com resultados experimentais. Ao longo do tempo, e acompanhando a evolução das ferramentas e capacidades computacionais, foram sendo desenvolvidas aplicações como a teoria da linha de sustentação e a teoria da superfície de sustentação [8], [18], [19].

A teoria da linha de sustentação, basicamente, modela a pá como uma linha rígida de vórtices, que possui circulação ao longo do raio do propulsor. A teoria da superfície de sustentação faz a representação da pá por meio de uma superfície de vórtices, obtendo-se, desta forma, um modelo tridimensional.

\subsubsection{Aplicação das Teorias dos Propulsores}

Durante muitos anos, os hélices foram projetados, quase que exclusivamente, utilizando as curvas de séries sistemáticas. A grande vantagem das séries era proporcionar previsões de desempenho próximas da realidade, dada a quantidade e qualidade dos dados experimentais disponíveis. A maior desvantagem da utilização das séries é que grande parte da geometria do hélice já encontra-se definida, não possibilitando uma otimização completa do projeto para cada caso.

Surgiu, então, a necessidade de se desenvolver métodos baseados na teoria da circulação com aplicações práticas ao projeto que permitissem a obtenção da geometria ótima de cada hélice. Como as diferenças entre as eficiências obtidas por séries e por teoria são geralmente mínimas, a principal razão para utilização do projeto teórico é conseguir melhorar o comportamento com relação à cavitação e a vibrações induzidas, principalmente no caso de hélices que operam em esteiras não uniformes [12]. A prática tem demonstrado que os ganhos do projeto teórico em diminuir riscos de danos devidos a cavitação e a vibrações são significativos.

\subsubsection{O Caso dos Hélices de Embarcações Fluviais}

A seguir, serão descritas algumas justificativas para a não utilização da teoria da circulação para o projeto e a análise do desempenho dos hélices de embarcações fluviais:

A) Os hélices de embarcações fluviais de carga são de alto carregamento, ou seja, apresentam altos valores de empuxo em área relativamente pequena das pás. Os hélices de 
embarcações marítimas convencionais são, geralmente, de médio carregamento, enquanto que os hélices de embarcações rápidas, como iates, corvetas e fragatas, apresentam baixo carregamento. Os hélices altamente carregados apresentam contração significativa da esteira após o hélice, enquanto que os hélices levemente carregados não apresentam tal contração. Os métodos teóricos têm apresentado dificuldades em levar a contração de esteiras em consideração, não obtendo, ainda, resultados adequados para o projeto de hélices altamente carregados [6].

B) O projeto teórico otimiza a geometria de um hélice para uma determinada condição de operação. No caso de hélices de embarcações fluviais, onde ocorrem variações freqüentes e até abruptas das condições de operação (mudanças de profundidades, de formação dos comboios, de calados, etc.), mesmo se houvesse possibilidade de aplicação de um método teórico de projeto com resultado satisfatório, haveria garantias de boa adequação do hélice "ótimo" apenas para a condição em que foi projetado.

C) O projeto por teoria da circulação poderia possibilitar a melhoria do desempenho em relação à cavitação e à vibração. No caso de hélices de embarcações fluviais, pode-se afirmar que estes fenômenos dependem mais fortemente das restrições físicas (diâmetros e distâncias dos hélices aos cascos, por exemplo) do que das formas das seções das pás.

\subsection{ANÁLISE DOS DADOS DE ENSAIOS DE DESEMPENHO PROPULSIVO}

Existem três métodos que podem ser utilizados (BROCKETT et alli. [8]) para analisar os dados de ensaios de autopropulsão com modelo ou de ensaios de desempenho propulsivo em escala real: coeficiente de esteira $\omega$ efetiva baseado na identidade de empuxo, $\omega$ baseado na identidade de torque e $\omega$ baseado na média de empuxo e torque. Será utilizado o método baseado na identidade de empuxo, cuja seqüência de aplicação é mostrada a seguir:

Dados:

- velocidade $\mathrm{V}$,

- rotação do hélice $n$,

- torque $\mathrm{Q}$ e empuxo T.

- curva $P_{E} x V$

\section{Obter:}

- coeficiente de esteira $\omega$,

- coeficiente de redução da força propulsora t,

- eficiência relativa rotativa $\eta_{R}$ 
$\Rightarrow$ Com os dados, calcular $\mathrm{K}_{\mathrm{T}}$;

$\Rightarrow$ Nas curvas do hélice em água aberta, obter $\mathrm{J}$ com o $\mathrm{K}_{\mathrm{T}}$;

$\Rightarrow$ Usando J, determina-se $\omega$;

$\Rightarrow$ Com $\mathrm{J}$, obter $\mathrm{K}_{\mathrm{Q}}$ das curvas do hélice;

$\Rightarrow$ Com os dados, calcular $\mathrm{K}_{\text {Qnavio }}$;

$\Rightarrow$ Obter $\eta_{\mathrm{R}}=\frac{K_{Q}}{K_{Q_{\text {navio }}}}$;

$\Rightarrow \mathrm{Na}$ curva $\mathrm{P}_{\mathrm{E}} \mathrm{X} \mathrm{V}$, obter $\mathrm{R}_{\mathrm{T}}$;

$\Rightarrow$ Obter $\mathrm{t}=1-\frac{R_{T}}{T}$.

Para a análise dos ensaios em escala real, onde não foi possível medir os valores de empuxos, adotou-se o seguinte procedimento:

$\Rightarrow$ Com os dados, calcular $\mathrm{K}_{\mathrm{Qnavio}}$;

$\Rightarrow$ Adotar valores de $\eta_{\mathrm{R}}=\frac{K_{Q}}{K_{Q_{\text {navio }}}}$;

$\Rightarrow$ Nas curvas do hélice em água aberta, obter $\mathrm{J}$ com o $\mathrm{K}_{\mathrm{Q}}$;

$\Rightarrow$ Usando J, determina-se $\omega$;

$\Rightarrow$ Com $\mathrm{J}$, obter $\mathrm{K}_{\mathrm{T}}$ das curvas do hélice;

$\Rightarrow$ Com $\mathrm{K}_{\mathrm{T}}$, estimar $\mathrm{t}=1-\frac{R}{T}$.

Uma forma simples de verificar se há problemas de queda de torque e de empuxo devido ao fenômeno da cavitação em hélices, a partir de dados obtidos em provas com as embarcações (BROCKETT et alli. [8]) é desenhar as curvas de $\mathrm{K}_{\text {Qnavio }} \mathrm{x} \mathbf{J}$ e verificar se há alterações abruptas nas tendências das curvas, como indicado na Figura 21.

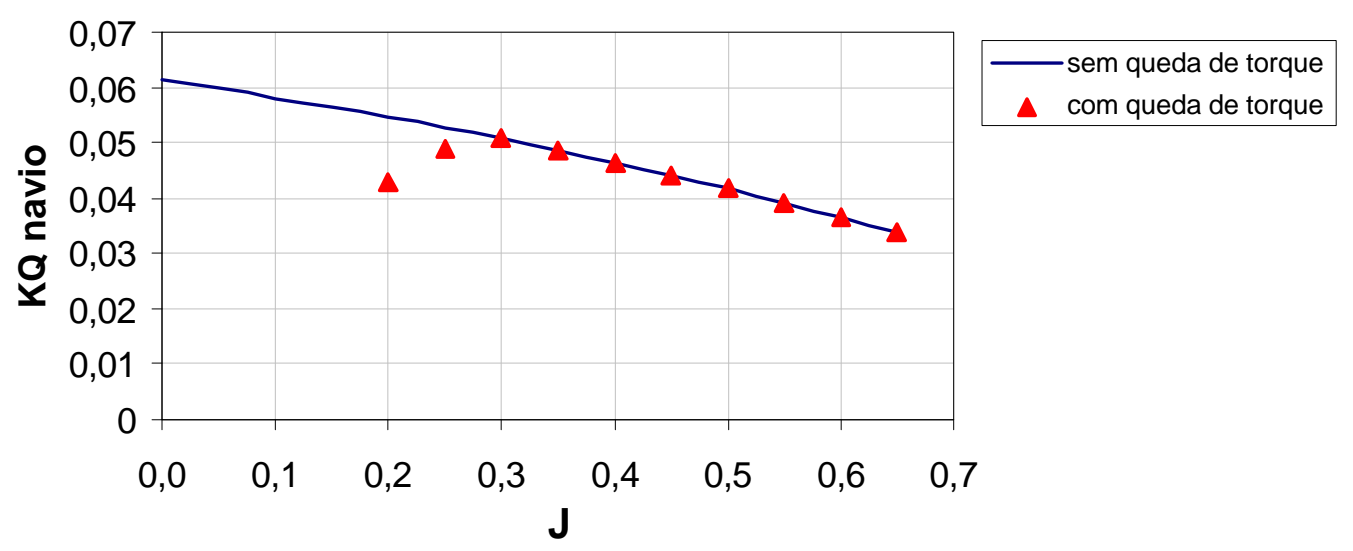

Figura 21 - Exemplo de Identificação de Problemas de Cavitação a Partir de Dados de Provas 


\subsection{ESTIMATIVAS DE RESISTÊNCIAS E DE COEFICIENTES PROPULSIVOS}

\subsubsection{Estimativas de Resistências ao Avanço de Comboios Fluviais}

A fim de obter estimativas de resistência ao avanço (ou potência efetiva do casco $\mathrm{P}_{\mathrm{E}}$ ) em função da velocidade $\mathrm{V}$, foi utilizada a formulação de Howe [10] para comboios fluviais, adaptada para utilização de valores em unidades métricas:

$$
\begin{gathered}
P_{E}=0,14426 \cdot F \cdot e^{\frac{0,445}{\left(h-H_{C}\right)}} \cdot\left(\frac{H_{C}}{0,3048}\right)^{0,6+\frac{15,24}{\left(W-B_{C}\right)}} \cdot L_{C}^{0,38} \cdot B_{C}^{1,19} \cdot V^{3}+\Delta P_{E} \\
\Delta \mathrm{P}_{\mathrm{E}}=0 \quad \text { para } \mathrm{F}_{\mathrm{nh}} \leq 0,50 \\
\Delta P_{E}=75 \cdot(V-3,3)^{3} \text { para } \mathrm{F}_{\mathrm{nh}}>0,50
\end{gathered}
$$

Sendo que os símbolos $\mathrm{H}_{\mathrm{C}}, \mathrm{L}_{\mathrm{C}}$ e $\mathrm{B}_{\mathrm{C}}$ representam, respectivamente, o calado médio, o comprimento total e a boca total do comboio de chatas. $F_{n h}=\frac{V}{\sqrt{g . h}}$ é o número de Froude relacionado com a profundidade.

A constante (75) e o índice (3) da formulação de correção $\Delta \mathrm{P}_{\mathrm{E}}$ foram obtidos a partir de comparações com dados experimentais de embarcações fluviais em águas rasas, existentes no IPT e na referência [3]. A Figura 22 mostra a estimativa pela formulação de Howe, com a inclusão da correção para uma embarcação fluvial, comparada com resultados de ensaios de resistência ao avanço no Tanque de Provas do IPT de um casco típico de chata, com coeficiente de bloco de 0,87.

Os valores do fator $\mathrm{F}$ da formulação de Howe foram obtidos comparando-se, para cada formação do comboio, as curvas de estimativas de $\mathrm{P}_{\mathrm{E}}$ com os resultados dos ensaios de resistência à propulsão com os modelos em escala 1:13 [23] do Comboio Araguaia, como mostrado na Figura 23. Os valores adotados de F são apresentados na Tabela 6. 


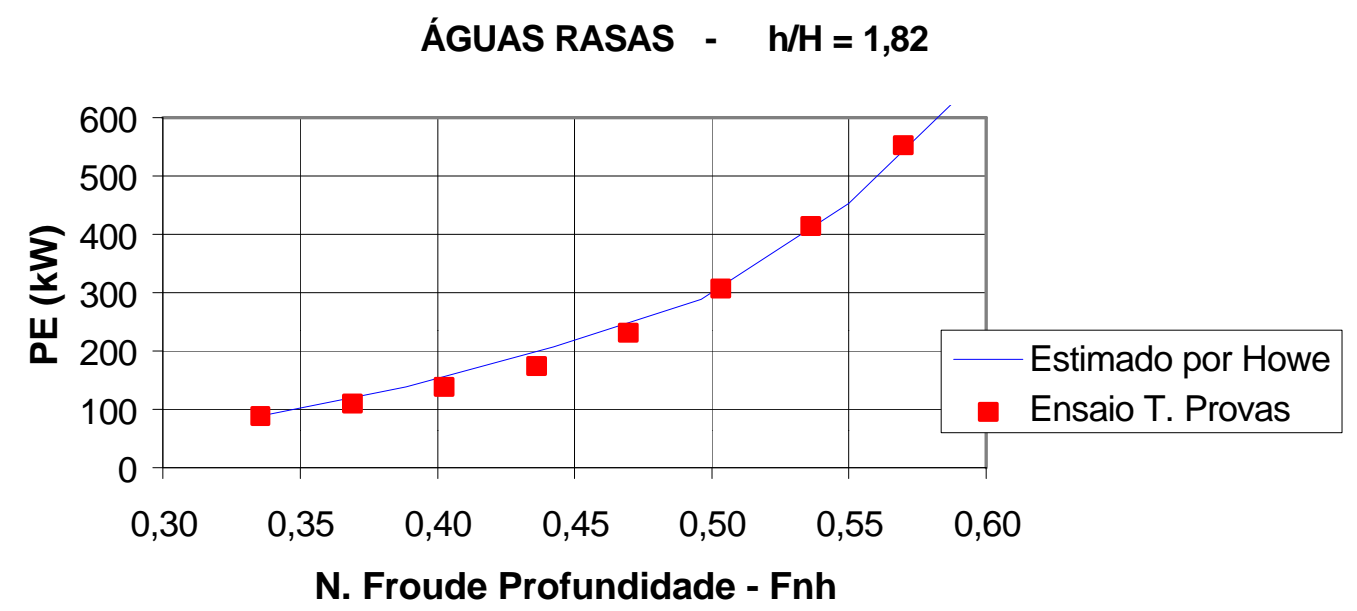

Figura 22 - Comparação entre Potências Efetivas Medidas em Tanque de Provas para um Casco de $\mathrm{C}_{\mathrm{B}}=0,87$ em Águas Rasas $(\mathrm{h} / \mathrm{H}=1,82) \mathrm{com}$ as Calculadas pela Formulação de Howe $(\mathrm{F}=0,04)$.

Tabela 6 - Valores do Fator F da Formulação de Howe, Obtidos a Partir de Comparação com Resultados de Ensaios em Tanque de Provas do IPT

\begin{tabular}{|l|c|}
\hline condição & F \\
\hline Uma chata carregada & 0,040 \\
\hline Duas chatas carregadas em linha & 0,045 \\
\hline Duas chatas carregadas em paralelo & 0,033 \\
\hline
\end{tabular}

Resultados obtidos em Tanque de Provas e por Howe

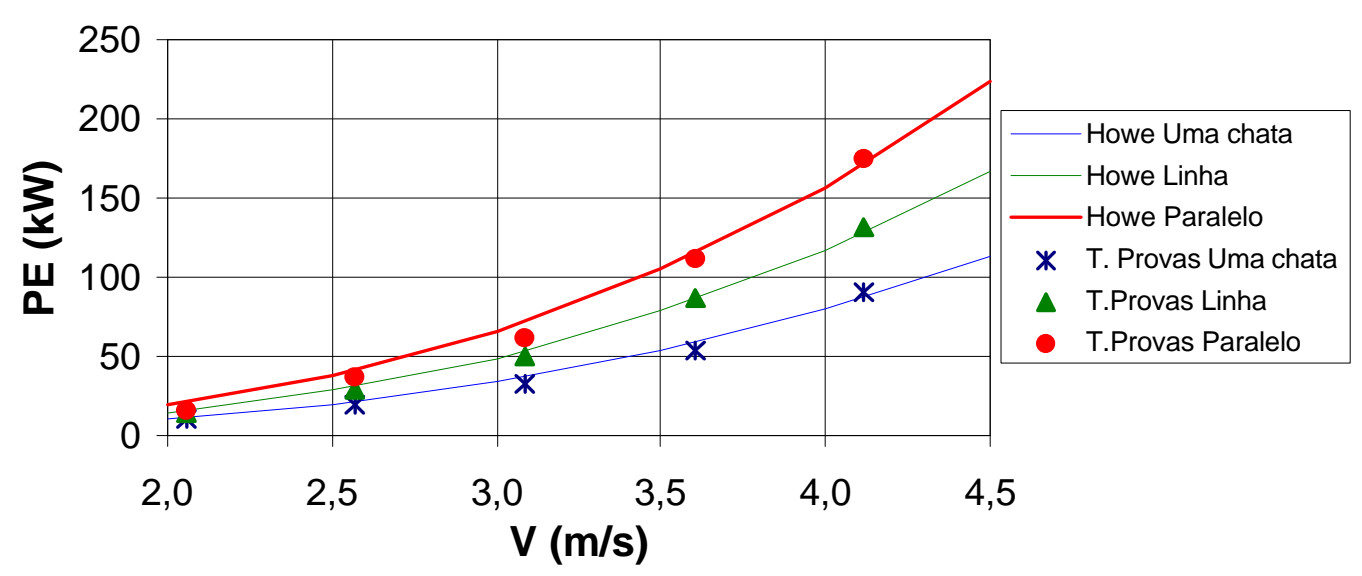

Figura 23 - Comparação entre Potências Efetivas Medidas em Tanque de Provas para o Comboio Araguaia e Calculadas pela Formulação de Howe. $\mathrm{H}=2 \mathrm{~m}$. Profundidade $\mathrm{h}=58 \mathrm{~m}$, Largura $\mathrm{W}=86 \mathrm{~m}$. 


\subsubsection{Estimativas de Coeficientes Propulsivos de Comboios Fluviais}

A referência [2] apresenta uma formulação empírica especial para embarcações fluviais, denominada fórmula modificada de Papmel para estimativas de coeficientes de esteira efetiva:

$$
\omega=0,11+\frac{0,16}{x} \cdot C_{B}^{x} \cdot \sqrt{\frac{\sqrt[3]{\nabla}}{D}}-\Delta \omega
$$

onde: $\quad \mathrm{x}=1$ para hélices na linha de centro do casco;

$\mathrm{x}=2$ para hélices laterais (caso de bihélices);

D - diâmetro do hélice (quando há túnel de popa, D é o calado), em m;

$\mathrm{C}_{\mathrm{B}}$ - coeficiente de bloco;

$\nabla$ - volume do deslocamento, $\mathrm{em}^{3}$

$$
\Delta \omega=0,1 .\left(\mathrm{F}_{\mathrm{N}^{-}} 0,2\right)-\text { correção para } F_{N}=\frac{V}{\sqrt{g \cdot L}}>0,2 .
$$

Para este tipo de embarcação, com túneis de popa, é recomendado que o coeficiente de redução da força propulsora seja adotado como igual ao coeficiente de esteira: $t=\omega$. 


\subsection{SÉRIES SISTEMÁTICAS DE HÉLICES}

Uma série sistemática de hélices consiste, basicamente, na fixação de alguns parâmetros geométricos e na variação de outros, obtendo-se, através de ensaios de água aberta com modelos em Tanque de Provas ou Túnel de Cavitação, as curvas características de cada hélice, ou seja, de cada uma das combinações geométricas resultantes.

Geralmente, as séries fixam as distribuições de cordas, de espessuras máximas e de passos, assim como as formas dos perfis das seções das pás e o diâmetro do bosso. Os parâmetros que variam são número de pás, razão de área expandida, razão passo/diâmetro.

Ao longo dos anos de utilização dos hélices, foram criadas inúmeras séries sistemáticas para os vários tipos de embarcações, a fim de facilitar o seu projeto e a análise da operação. Há séries de hélices apropriadas para embarcações mercantes convencionais, para navios de guerra, para lanchas rápidas, etc., como mostrado na referência [40].

\subsubsection{Hélices B-Troost e Kaplan}

Para o estudo e o projeto de hélices de embarcações fluviais de cargas, bastam duas séries sistemáticas: a B-Troost (do MARIN - Netherlands Maritime Research Institute, de Wageningen) [39], [32] e a Kaplan, esta especial para operação em dutos ou tubos Kort [17], [32]. As duas séries apresentam as seguintes vantagens:

- grande número de dados disponíveis, inclusive com previsões de cavitação,

- altas eficiências,

- geometrias relativamente simples, apresentando facilidades de construção,

- cobertura de toda a faixa de utilização das embarcações fluviais de cargas,

- no caso da série Kaplan, simetria entre bordo ataque e de fuga das pás, possibilitando boa eficiência a ré; no caso da B-Troost, possibilidade de adaptação de sua geometria, incluindo a eliminação do "skew" (assimetria do contorno da pá).

A Figura 24 apresenta uma comparação entre as eficiências em água aberta de hélices das duas séries e a eficiência ideal $\eta_{I}$, obtida através da Teoria do Disco Atuador, em função do 
coeficiente de carregamento em empuxo dos hélices. Como pode ser verificado, em altos carregamentos, os hélices em dutos apresentam maiores eficiências em água aberta, o que é explicado pela contribuição do empuxo resultante nos dutos. Quanto menor a velocidade da embarcação, maior o carregamento $\mathrm{C}_{\mathrm{TH}}$ das pás e maior o diferencial entre velocidades externa e interna nos dutos, resultando em maior empuxo. À medida que a velocidade da embarcação (a velocidade externa do duto) aumenta, diminui a contribuição em empuxo do duto (a sustentação) e aumenta a sua resistência (arrasto).

$$
\begin{aligned}
& C_{T H}=\frac{T}{\frac{1}{2} \cdot \rho \cdot A_{0} \cdot V_{A}^{2}}=\frac{T}{\frac{1}{8} \cdot \rho \cdot \pi \cdot D^{2} \cdot V_{A}^{2}} \\
& \eta_{I}=\frac{2}{1+\sqrt{1+C_{T H}}}
\end{aligned}
$$

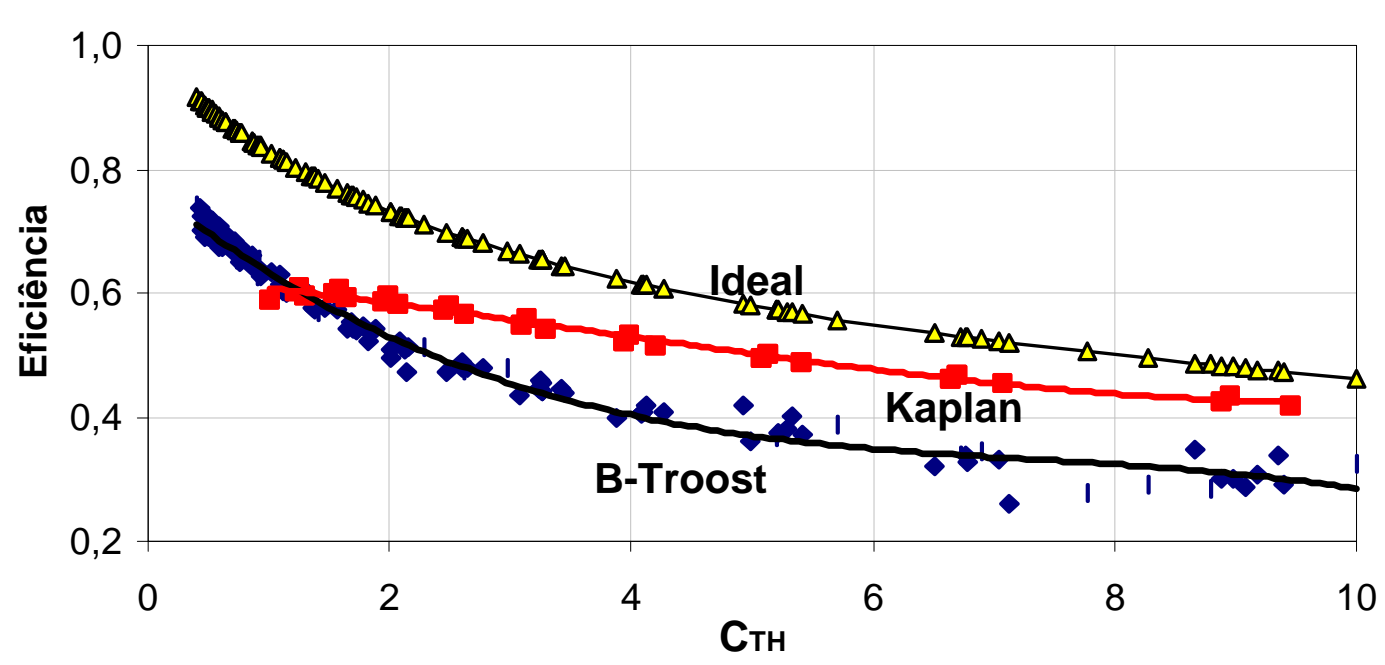

Figura 24 - Eficiência Ideal e das Séries Sistemáticas B-Troost e Kaplan em Função de Coeficiente de Carregamento $\mathrm{C}_{\mathrm{TH}}$

A Figura 25 apresenta uma comparação das eficiências ideais e reais, medidas em ensaios de água aberta, entre hélices com e sem dutos. Nesta figura estão indicadas os acréscimos (ou decréscimos) de eficiências da seguinte forma:

$$
\begin{aligned}
& \Delta \eta_{I}=\frac{1+\sqrt{1+C_{T H}}}{1+\sqrt{1+\tau \cdot C_{T H}}}-1 \\
& \Delta \eta_{O}=\frac{\eta_{O(B-T R O O S T)}}{\eta_{O(\text { KAPLAN })}}-1
\end{aligned}
$$




$$
\text { sendo } \tau=\frac{T_{H}}{T}
$$

Contudo, segundo NARITA [36], as diferenças entre as eficiências em água aberta dos hélices com e sem dutos tendem a diminuir quando se encontram instalados nas popas das embarcações. Esta redução é causada pela influência do duto sobre o coeficiente de esteira efetiva $\omega$, aumentando-o, e, consequentemente, tornando o coeficiente de avanço $\mathrm{J}$ do hélice em duto menor.

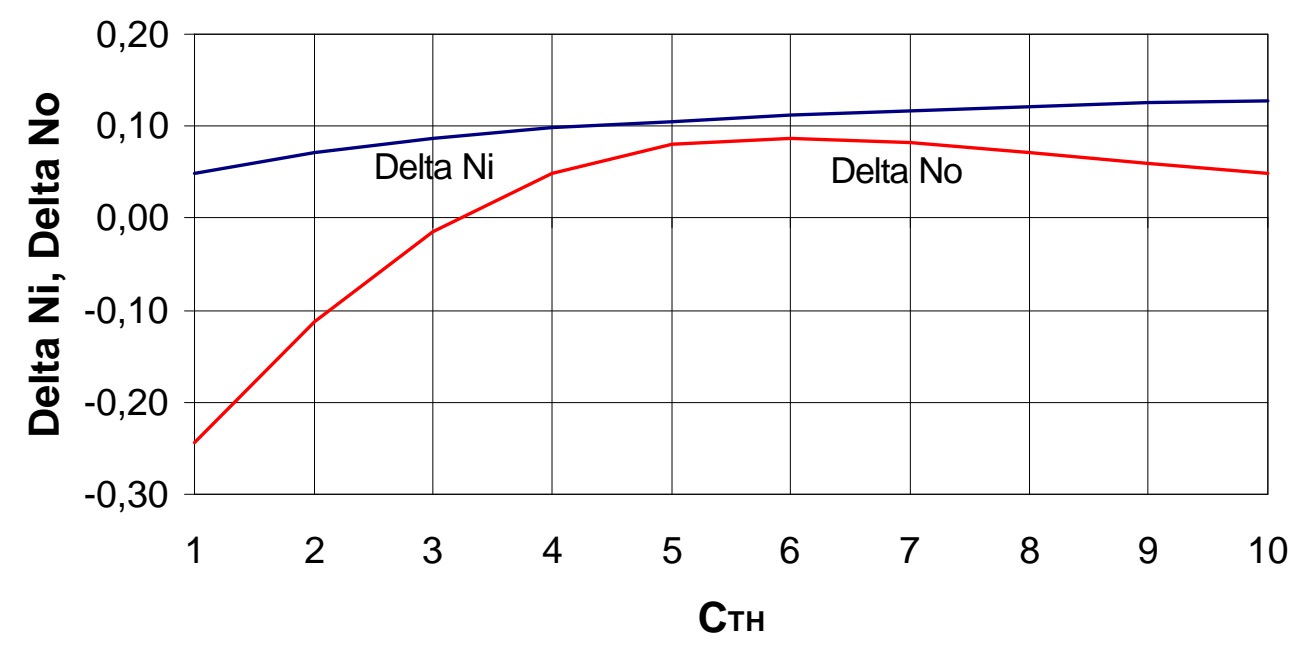

Figura 25 - Razões Entre as Eficiências de Hélices com e sem Dutos $\left(\eta_{I}\right.$ - Razão entre Eficiências Ideais e $\eta_{\mathrm{O}}$ - Razão entre Eficiências em Água Aberta - Ae/Ao=0,50, 4 pás, P/D=0,80).

\subsubsection{A Utilização de Hélices em Dutos}

Como visto, do ponto de vista puramente hidrodinâmico, os hélices em dutos representam os melhores tipos de propulsores de embarcações fluviais de carga, pois apresentam maiores rendimentos nas faixas de operação típicas - baixas velocidades, altos carregamentos. Outra vantagem do hélice em duto sobre o convencional é que os dutos apresentam tendência de regularizar o escoamento, resultando em menores variações de empuxos e de torques durante a operação.

A experiência tem mostrado que em rios com características como as do Araguaia, com troncos e detritos em suspensão na água, os dutos podem aumentar os problemas de avarias por choques das pás dos hélices, já que há uma concentração da sucção da água e dos corpos nela 
presentes. Um pequeno detrito que atingisse uma ponta de pá de um hélice sem duto seria empurrado para longe, resultando em avaria única devida ao impacto. Contudo, aquele mesmo detrito poderia causar um estrago maior chocando-se com as pás de um hélice confinado dentro de um duto.

Os dutos devem ser projetados e construídos adequadamente para não ficarem ovalados durante a instalação ou operação (no caso de toques no fundo do rio). A distância entre as pontas dos hélices e as paredes internas dos dutos deve ser a menor possível, para não haver perdas significativas de eficiência - como limite superior, tal folga deve ser de $0,7 \%$ do diâmetro do hélice.

No caso do duto ser instalado junto ao casco do empurrador, como acontece com o empurrador Araguaia, haverá regiões do perímetro do duto em que não ocorrerá escoamento externo. Assim, tais regiões não poderão contribuir com a sua parcela de empuxo devido ao duto. Cabe, então, ao projetista, descontar do empuxo do duto uma parcela proporcional ao arco do perímetro correspondente à região afetada pela proximidade do casco. No empurrador Araguaia, a porcentagem do duto que não produz empuxo é de $30 \%$ - desta forma: $\mathrm{T}=\mathrm{T}_{\mathrm{H}}+0,70 . \mathrm{T}_{\mathrm{D}}$ onde $\mathrm{T}$, $\mathrm{T}_{\mathrm{H}}$ e $\mathrm{T}_{\mathrm{D}}$ são os empuxos total, do hélice e do duto, respectivamente.

\subsubsection{Série BB-Troost}

Um dos problemas da série B-Troost, detectado durante seu longo período de utilização, era a sua maior suscetibilidade ao fenômeno da cavitação em faixas de operação com maiores carregamentos das pás. A explicação era que o contorno de suas pás apresentava cordas relativamente pequenas nos raios mais externos (nas pontas), criando no local distribuições de pressões mais concentradas, com picos de pressões abaixo da pressão de vaporização da água. Como forma de minimizar este problema, foi alterada a distribuição de cordas ao longo do raio, resultando em uma série praticamente idêntica à original, mas com cordas maiores nas proximidades das pontas das pás - tal série foi denominada de BB-Troost [32].

A Figura 26 apresenta a distribuição de cordas das pás dos hélices de 4 pás e razão de área expandida Ae/Ao = 0,50 das séries B-Troost (e de sua variante BB) e Kaplan. Como pode ser notado, a série Kaplan apresenta as maiores cordas nas pontas das pás, pois aproveita a vantagem de operar junto à camada limite da parte interna do duto, diminuindo as perdas nas pontas. 


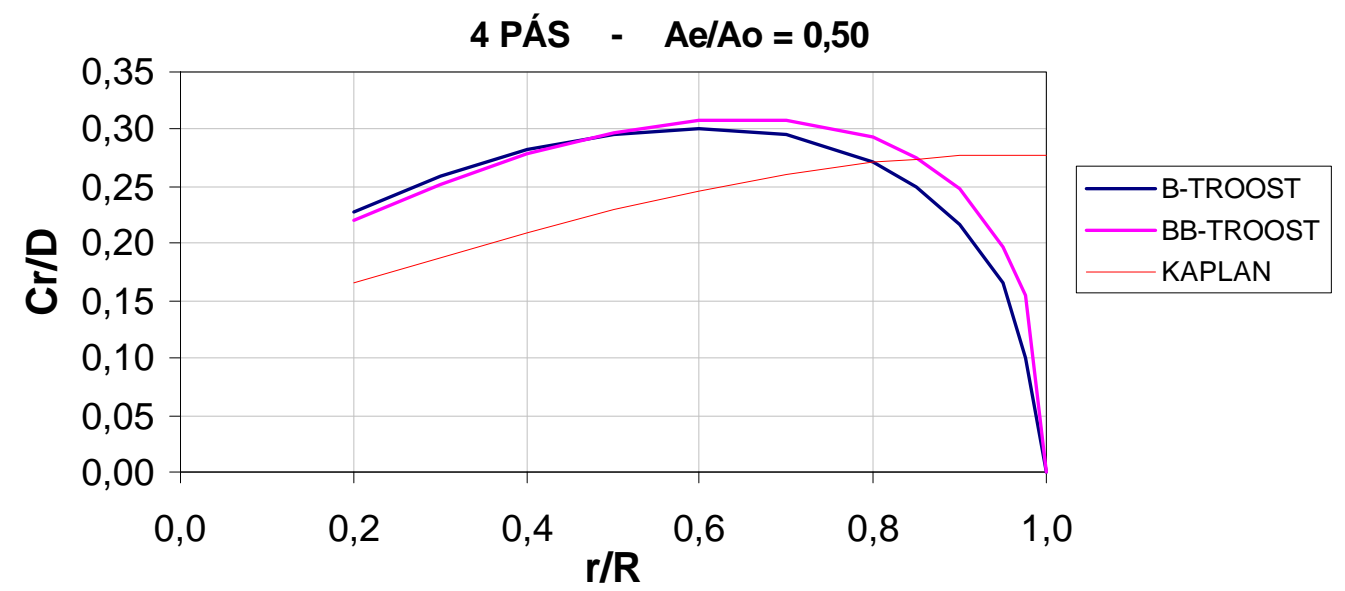

Figura 26 - Distribuições de Cordas das Séries Sistemáticas B-Troost, BB-Troost e Kaplan. Hélices de 4 Pás e Ae/Ao=0,50.

\subsection{CAVITAÇÃO}

Um dos aspectos mais estudados em propulsores, a cavitação é um fator de limitação ao projeto de um hélice. Explicado como um fenômeno que ocorre a partir do aparecimento de regiões das pás com pressões abaixo da pressão de vapor da água, formando-se cavidades a partir da vaporização da água, a cavitação quase sempre traz grandes preocupações aos projetistas, já que pode apresentar efeitos indesejáveis como queda de empuxo, erosão das pás e aumento de vibrações induzidas pelo propulsor.

Uma das formas mais práticas de prever-se problemas relacionados com cavitação é a utilização do diagrama de Burril (Figura 27) [6], baseado em dezenas de ensaios em túneis de cavitação de hélices de geometrias variadas. O diagrama relaciona o coeficiente de carregamento relacionado com pressões presentes nas pás $\tau_{\mathrm{C}} \mathrm{e}$ o índice de cavitação relativo à velocidade resultante na seção a $\mathrm{r} / \mathrm{R}=0,70$ das pás $\sigma_{0,7 \mathrm{R}}$. Tanto $\tau_{\mathrm{C}}$ como $\sigma_{0,7 \mathrm{R}}$ levam em conta as componentes rotacional e axial das velocidades nas pás.

No diagrama de Burril, são apresentadas as definições de seus parâmetros e as equações aproximadas de suas curvas, que indicam a porcentagem da área das pás cobertas por cavitação no dorso dos hélices. Apesar de ser um método empírico, que apresenta informações quanto ao comportamento aproximado e médio dos hélices, a prática tem demonstrado que seus resultados são confiáveis. 


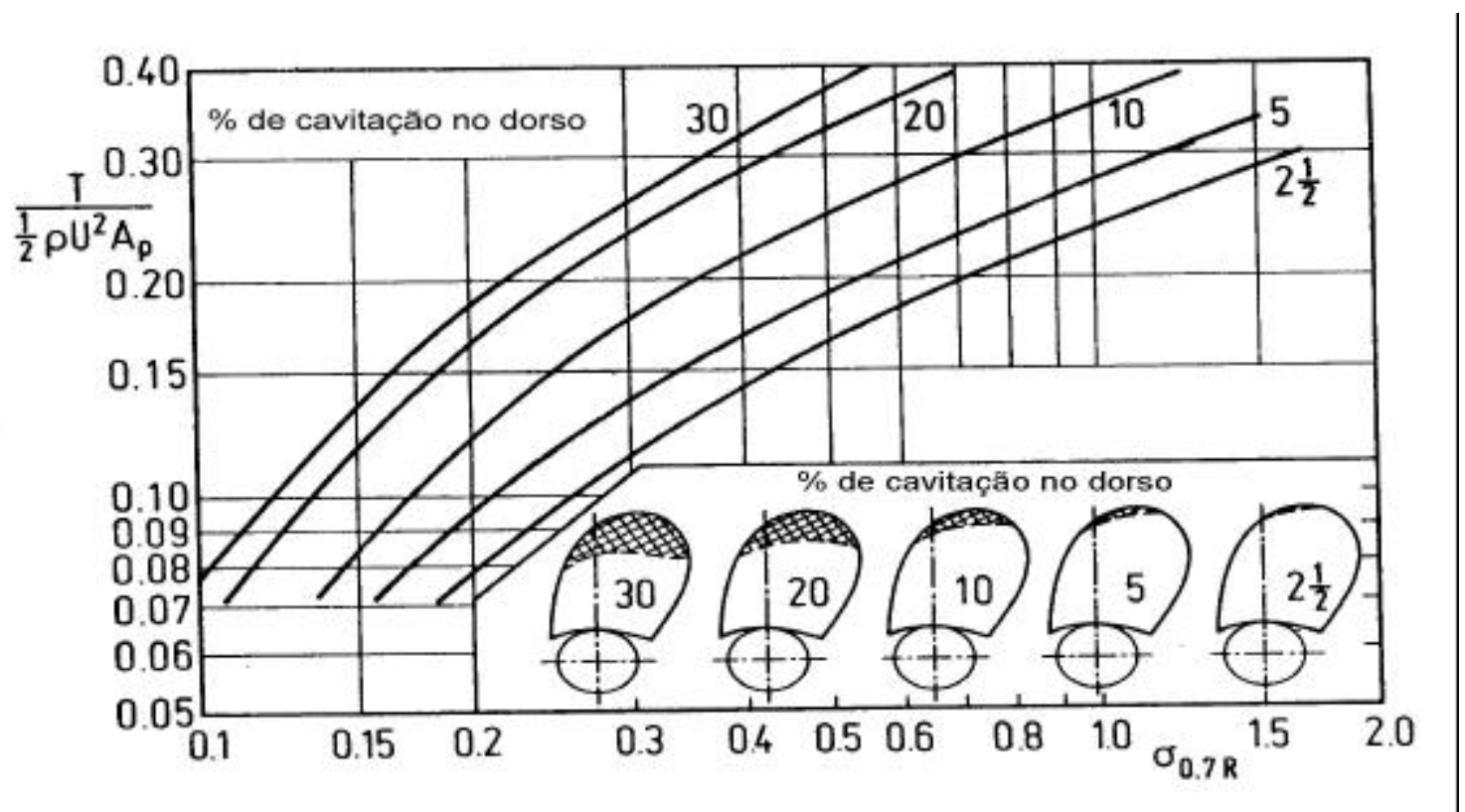

Figura 27 - Diagrama de Burril para Previsão de Quantidades de Cavitação em Pás de Hélices.

(Fonte: Burril \& Emerson, "Propeller Cavitation: Further Tests on 16 in Propeller Models in the King's College Cavitation Tunnel”. Transactions of NECIES, 1962, vol.79, pp. 295-320, [6]).

A Tabela 7 apresenta equações das curvas para estimar porcentagens de cavitação do dorso (lado de sucção) das pás cobertas por cavitação, obtidas a partir do diagrama de Burril.

Tabela 7 - Equações Aproximadas para Estimativas de Áreas Cobertas de Cavitação no Dorso das Pás Obtidas do Diagrama de Burril.

\begin{tabular}{|c|c|c|}
\cline { 2 - 3 } \multicolumn{1}{c|}{} & \multicolumn{2}{c|}{$\tau_{C}=A \cdot\left(\sigma_{0,7 R}\right)^{B}$} \\
\hline Cavitação no Dorso & $\mathbf{A}$ & $\mathbf{B}$ \\
\hline $2,5 \%$ & 0,302 & 0,763 \\
\hline $10 \%$ & 0,494 & 0,880 \\
\hline $20 \%$ & 0,661 & 0,880 \\
\hline Queda de Empuxo & 0,700 & 1,000 \\
\hline
\end{tabular}

$$
\begin{array}{lc}
\tau_{C}=\frac{T}{\frac{1}{2} \cdot \rho \cdot V_{R}^{2} \cdot A_{P}} & \sigma_{0,7 R}=\frac{P_{o}-P_{V}}{\frac{1}{2} \cdot \rho \cdot V_{R}^{2}} \\
V_{R}=\sqrt{V_{A}^{2}+(0,7 \cdot \pi \cdot n \cdot D)^{2}} & A_{P}=\left(1,067-0,229 \cdot \frac{P}{D}\right) \cdot A_{E}
\end{array}
$$


A utilização do diagrama de Burril apenas possibilita estimar a quantidade de cavitação nas pás e verificar se há risco de ocorrer queda de empuxo (e de torque) no hélice, resultante da presença de cavitação excessiva. O diagrama não indica o tipo de cavitação presente nem se há possibilidade de ocorrer erosão por cavitação nas pás. A referência [34] mostrou que a escolha das áreas das pás utilizando as estimativas de cavitação por meio do diagrama de Burril, apresentam margens de segurança adequadas para hélices de todos os tipos, inclusive para os projetados por teoria da circulação.

A ocorrência de erosão por cavitação está ligada principalmente a um dos três casos:

a) hélices de grandes embarcações marítimas, com altos $C_{B}$ e grandes diâmetros de hélices, resultando em distribuições de esteiras que fazem variar de modo significativo a velocidade resultante em cada pá à medida que ela faz uma rotação de $360^{\circ}$. Nestes casos, mesmo com pequena área das pás cobertas por cavitação (5\%, por exemplo), pode ocorrer erosão devido à natureza da cavitação, predominantemente de bolhas. As bolhas se formam e desaparecem através de implosões junto à superfície das pás, por força da variação periódica e abrupta das velocidades na região do hélice;

b) ocorrência de velocidades altíssimas de escoamento que levam a pressões locais muito baixas, fazendo com que quaisquer descontinuidades das superfícies das pás se constituam em pontos preferenciais de implosões de bolhas de cavitação;

c) presença de cavitação excessiva nas pás, induzindo turbulência local de caráter periódico que pode levar à erosão.

As causas de vibrações induzidas por cavitação são muito próximas daquelas que levam à erosão, basicamente ligadas à não uniformidade do escoamento com cavitação, com variações abruptas de velocidades e pressões.

No caso dos hélices de embarcações fluviais, que apresentam diâmetros reduzidos de hélices, baixas velocidades e esteiras relativamente uniformes, a probabilidade de ocorrência de erosão e de vibrações por cavitação é reduzida, quando se toma os cuidados para que a quantidade de cavitação não seja demasiada. Adota-se, geralmente, $10 \%$ como a porcentagem máxima aceitável de cavitação no dorso das pás, para que não ocorram problemas de queda de empuxo, de erosão e de vibrações or cavitação [11]. 


\subsection{O PROJETO DE HÉLICES POR SÉRIE SISTEMÁTICA}

O projeto do hélice é a determinação da geometria mais adequada para operar junto ao casco, em certo número de rotações, consumindo uma potência que deve ser fornecida por um conjunto motor-redutor, e impulsionando a embarcação (em sua condição de deslocamento de projeto) em uma determinada velocidade.

No caso de hélices de séries sistemáticas, onde vários parâmetros geométricos já estão fixos, a definição do hélice é feita através da escolha do diâmetro, do número de pás, do passo e da área das pás. Da interação com o conjunto motor-redutor-eixo deve resultar o número de rotações de operação e a potência consumida. A condição de deslocamento do casco escolhida para o projeto e a definição da velocidade desejada completam o quadro,

Quando os dados iniciais são baseados nas características do casco, ou seja, está disponível o valor do empuxo requerido do hélice para uma velocidade escolhida como de projeto, utiliza-se o coeficiente de empuxo $\mathrm{K}_{\mathrm{T}}$. Quando o projeto vai ser baseado em um sistema motor-redutor já existente, utiliza-se o coeficiente de torque $\mathrm{K}_{\mathrm{Q}}$.

No caso de ser conhecido o diâmetro, uma das formas mais utilizadas para obter-se o número de rotações ótimo é utilizar uma combinação de equações que permite buscar a máxima eficiência $\eta_{\mathrm{o}}$ sem a necessidade da definição "a priori” o número de rotações. Assim, para os casos onde estão disponíveis os dados do casco, tem-se:

$$
\frac{K_{T}}{J^{2}}=\frac{R_{T}}{\rho \cdot D^{2} \cdot(1-t) \cdot(1-\omega)^{2} \cdot V^{2}} .
$$

Com os dados existentes do casco e com o diâmetro, fixando-se a velocidade de projeto, calcula-se o segundo membro da equação anterior, que será constante para a condição de projeto escolhida, obtendo-se:

$$
\mathrm{K}_{\mathrm{T} \text { navio }}=\text { cte. } \mathrm{J}^{2}
$$

Escolhidos a série sistemática do hélice, o número de pás e a razão de área expandida, são utilizadas as curvas de água aberta correspondentes. Para cada razão P/D (passo/diâmetro) deverá haver uma solução, onde o $\mathrm{K}_{\mathrm{T}}$ navio será igualado ao $\mathrm{K}_{\mathrm{T}}$ das curvas da série. Determinado o $\mathrm{K}_{\mathrm{T}}$ solução para cada P/D, e, consequentemente, os coeficientes de avanço $\mathrm{J}$ e de torque KQ e a eficiência em água aberta, conforme mostra a Figura 28. Comparando-se todos os casos calculados, escolhe-se o P/D que corresponde à maior eficiência. Com o coeficiente de avanço $\mathrm{J}$ da solução 
desta razão $\mathrm{P} / \mathrm{D}$, obtém-se o número de rotações ótimo do hélice, determinando a relação de redução de rotações motor/hélice a ser adotada.

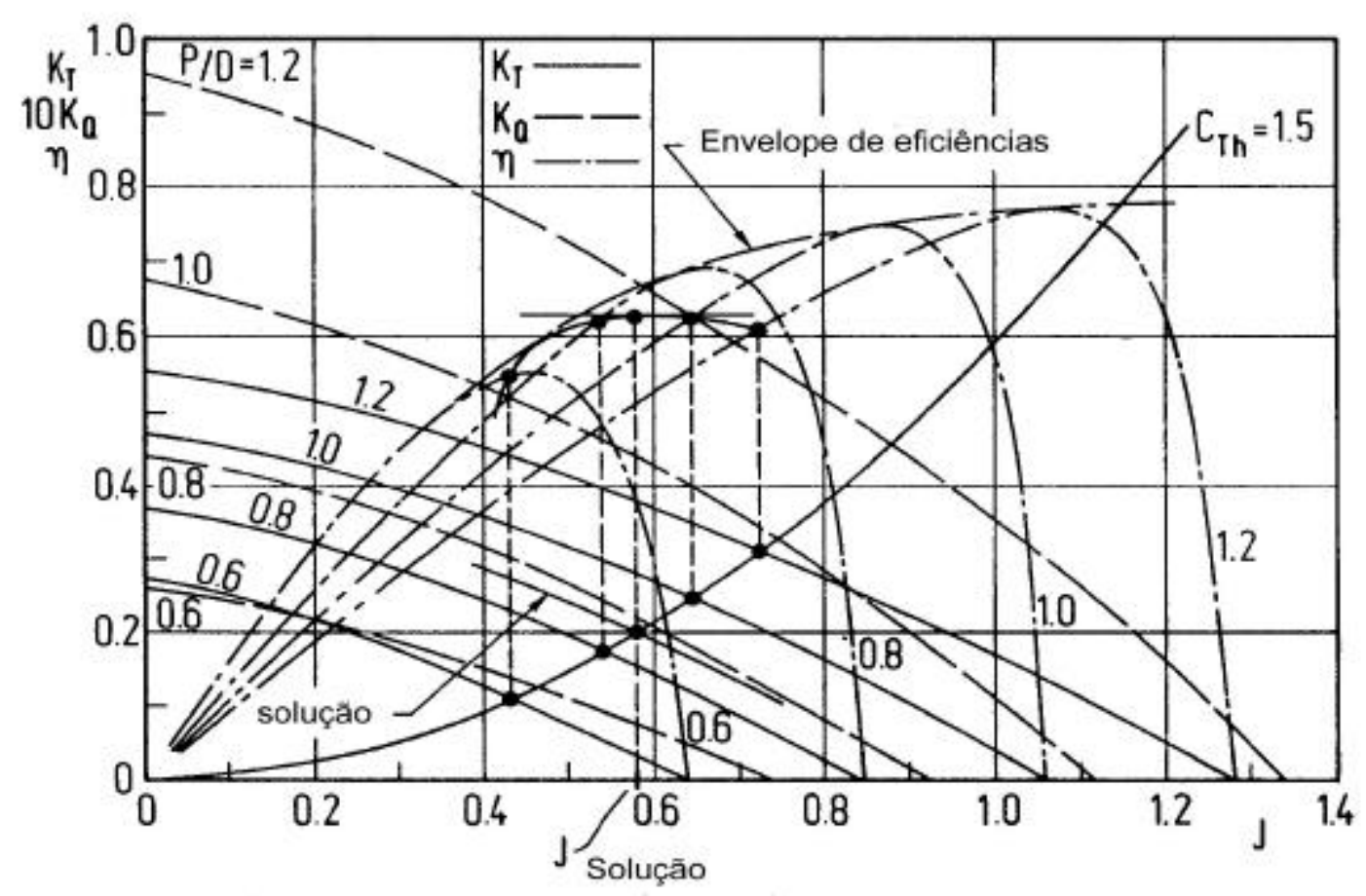

Figura 28 - Representação do Projeto a Partir das Curvas de Água Aberta. Caso a partir da Relação $\mathrm{K}_{\mathrm{T} \text { navio }}=$ cte. $\mathrm{J}^{2}[6]$.

Para os casos em que são conhecidos os diâmetros e quando existem os dados de potência do motor, utiliza-se a seguinte relação:

$$
\frac{K_{Q}}{J^{3}}=\frac{102 \cdot P_{D}}{2 \cdot \pi \cdot \rho \cdot D^{2} \cdot V_{A}^{3}} \text {. }
$$

A seqüência de projeto é, então, análoga à exposta anteriormente: ao final, com a obtenção do $\mathrm{J}$ correspondente à razão $\mathrm{P} / \mathrm{D}$ de maior eficiência, é obtido $\mathrm{n}$.

De forma semelhante, quando é conhecido o número de rotações e deve ser buscado o diâmetro que corresponda à maior eficiência, utiliza-se uma das duas funções seguintes, dependendo se os dados de entrada são do casco $\left(\mathrm{R}_{\mathrm{T}}\right)$ ou do motor $\left(\mathrm{P}_{\mathrm{D}}\right)$, respectivamente:

$$
\frac{K_{T}}{J^{4}}=\frac{R_{T} \cdot n^{2}}{\rho \cdot(1-t) \cdot(1-\omega)^{4} \cdot V^{4}} \quad \text { ou } \quad \frac{K_{Q}}{J^{5}}=\frac{102 \cdot P_{D} \cdot n^{2}}{2 \cdot \pi \cdot \rho \cdot V_{A}^{5}} .
$$

A Figura 29 apresenta uma representação gráfica das quatro formas básicas de projeto de hélices utilizando séries sistemáticas de hélices. 


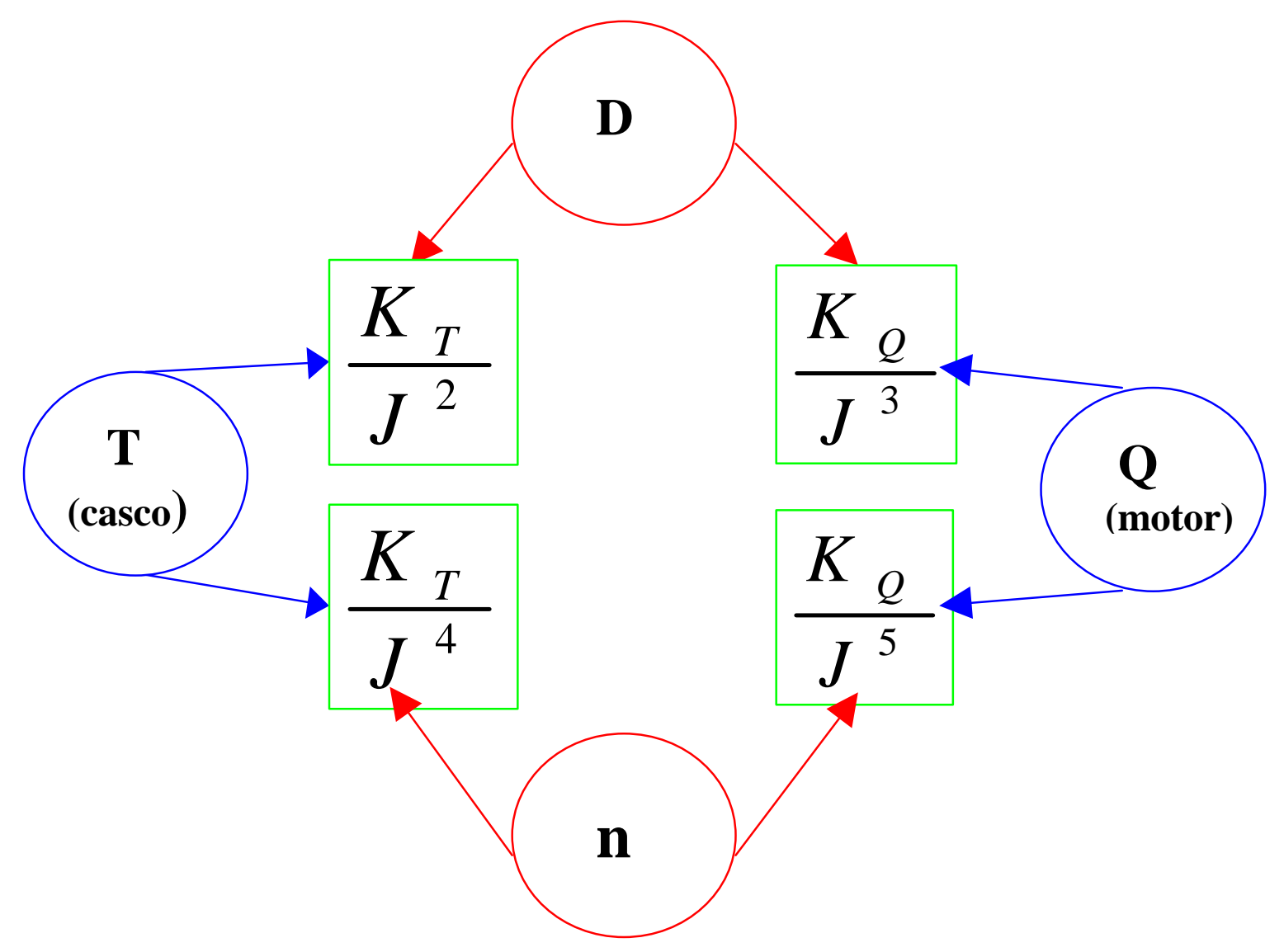

Figura 29 - Representação das Formas Básicas de Projeto de Hélices

\subsection{DEFINIÇÃO DA GEOMETRIA DOS HÉLICES}

Dada a extrema complexidade da operação de embarcações fluviais, a tendência atual é que a geometria dos seus hélices tenha algumas características como simetria do contorno das pás, espessuras maiores que aquelas de séries sistemáticas de propulsores, grande área de pás e diâmetros reduzidos. Para compensar a restrição de diâmetros, são utilizadas pequenas razões de redução de rotações dos motores, a fim de resultar em altas rotações nos eixos dos hélices. 


\subsubsection{Número de Hélices}

Evidentemente, a escolha do número de hélices de uma embarcação tem reflexo direto sobre a geometria que deverá resultar de um projeto. Basta atentar ao fato que quanto maior o número de hélices, menor o carregamento das suas pás, pois haverá uma maior divisão da produção de empuxo.

O diâmetro necessário dos hélices pode ser diminuído se aumentada a quantidade de hélices da embarcação, o que leva a uma subdivisão maior da potência disponível em cada eixo. Em embarcações para navegar em águas muito rasas, pode ser conveniente adotar três ou quatro hélices. Neste caso, a maior quantidade de motores, redutores, eixos e mancais necessários resultará em custos proporcionalmente maiores.

A prática tem mostrado que a adoção de uma embarcação fluvial monohélice não contribui para a segurança da navegação já que o desempenho em manobras é pior que os de bihélices e não há confiabilidade - qualquer componente avariado do sistema propulsivo (motor, eixo, caixa de redução, mancal, hélice) põe em risco a embarcação, sem alternativas de operação emergencial. Desta forma, a maioria expressiva das embarcações fluviais possui dois hélices.

\subsubsection{Diâmetro}

A eficiência dos hélices tende a crescer com o aumento do diâmetro, porque o carregamento específico das pás (representado por $C_{T H}=\frac{T}{\frac{1}{8} \cdot \rho \cdot V_{A}^{2} \cdot \pi \cdot D^{2}}$ ) decresce. Como já visto, a eficiência ideal $\eta_{\mathrm{I}}$ aumenta com a diminuição de $\mathrm{C}_{\mathrm{TH}}$.

O diâmetro de um hélice é limitado pela geometria da região onde vai ser instalado. Tal região deve ficar totalmente imersa para que não ocorra aeração (recolhimento de ar pelas pás do hélice). Em embarcações com restrições extremas de calado, pode haver a necessidade de aplicação de túneis de popas, que, com geometria apropriada de uma "escavação" nas linhas da popa da embarcação, de modo a permitir hélices com diâmetros superiores ao calado (até cerca de 10\% a mais) [10].

A experiência tem mostrado que os túneis de popa, que encarecem a construção e aumentam riscos de vibrações e de perdas de eficiência, devem ser adotados como alternativa radical, quando 
não há possibilidade de absorção das potências necessárias dos motores por diâmetros menores que os calados das embarcações.

A distância das pontas das pás ao casco deve ter um valor mínimo que garanta que os esforços variáveis induzidos pelo propulsor não sejam elevados, a ponto de introduzir intensidades de vibrações indesejadas. Quanto maiores as distâncias das pás ao casco, menores as possibilidades do hélice induzir vibrações. Estas distâncias (claras) são recomendadas por projetistas e sociedades classificadoras em valores que variam de $8 \%$ a $25 \%$ do diâmetro do hélice, dependendo do tipo de embarcação [8].

No caso de embarcações fluviais de cargas, onde as restrições de calados são determinantes, há uma tendência de utilizar os maiores diâmetros possíveis, diminuindo as claras em valores próximos dos limites onde as vibrações induzidas pelo propulsor podem tornar-se inconvenientes e danosas. Não raro, há a necessidade de diminuição do diâmetro de hélices de determinada embarcação em operação, devida à constatação de altas intensidades de vibrações na popa, ocasionadas por uma distância do hélice ao casco insuficiente.

A Figura 30 apresenta curvas obtidas da série sistemática B-Troost, que relacionam as eficiências em água aberta $\eta_{\mathrm{o}}$ com a razão $1 / \mathrm{J}$, para vários valores de $C T J=\sqrt[4]{\frac{K_{T}}{J^{4}}}$ e de razões passo/diâmetro P/D. Percebe-se que, para valores maiores de $\frac{K_{T}}{J^{4}}$, há uma tendência muito bem definida de aumentar a eficiência com o aumento do diâmetro $\left(\frac{1}{J}=\frac{n \cdot D}{V_{A}}\right)$. Em menores valores de $\frac{K_{T}}{J^{4}}$, o diâmetro ótimo não é o maior possível.

De forma análoga, se o diâmetro é definido e o número de rotações n é a incógnita, a Figura 31 pode ser útil para verificar as tendências dos valores de eficiências em água aberta, para valores de $R T J 2=\sqrt{\frac{K_{T}}{J^{2}}}$ e de P/D. Como pode ser verificado, com o aumento de $\frac{K_{T}}{J^{2}}$, ou seja, do carregamento $\mathrm{C}_{\mathrm{TH}}$, não há variações significativas de eficiência com o aumento de $1 / \mathrm{J}$ ou do número de rotações, diferentemente do que ocorre em valores menores de $\frac{K_{T}}{J^{2}}$, quando pode ocorrer queda sensível de eficiência com o aumento de $n$. 


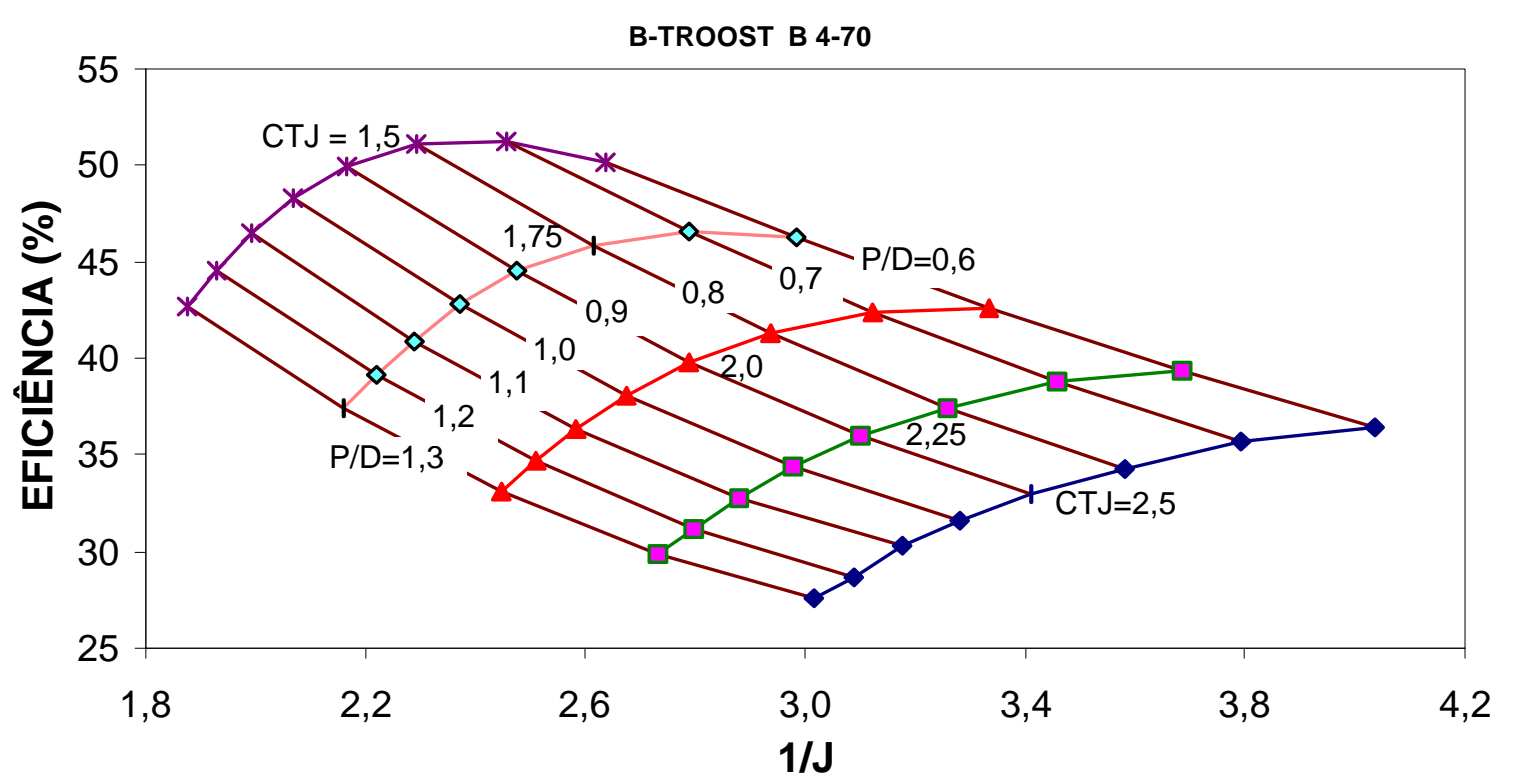

Figura 30 - Representação da Eficiência em Água Aberta de Hélice da Série B-Troost (B 4-70) em Função de $1 / \mathrm{J}$, Parametrizados em P/D e $C T J=\sqrt[4]{\frac{K_{T}}{J^{4}}}$. Faixa de Operação Típica de Embarcações Fluviais.

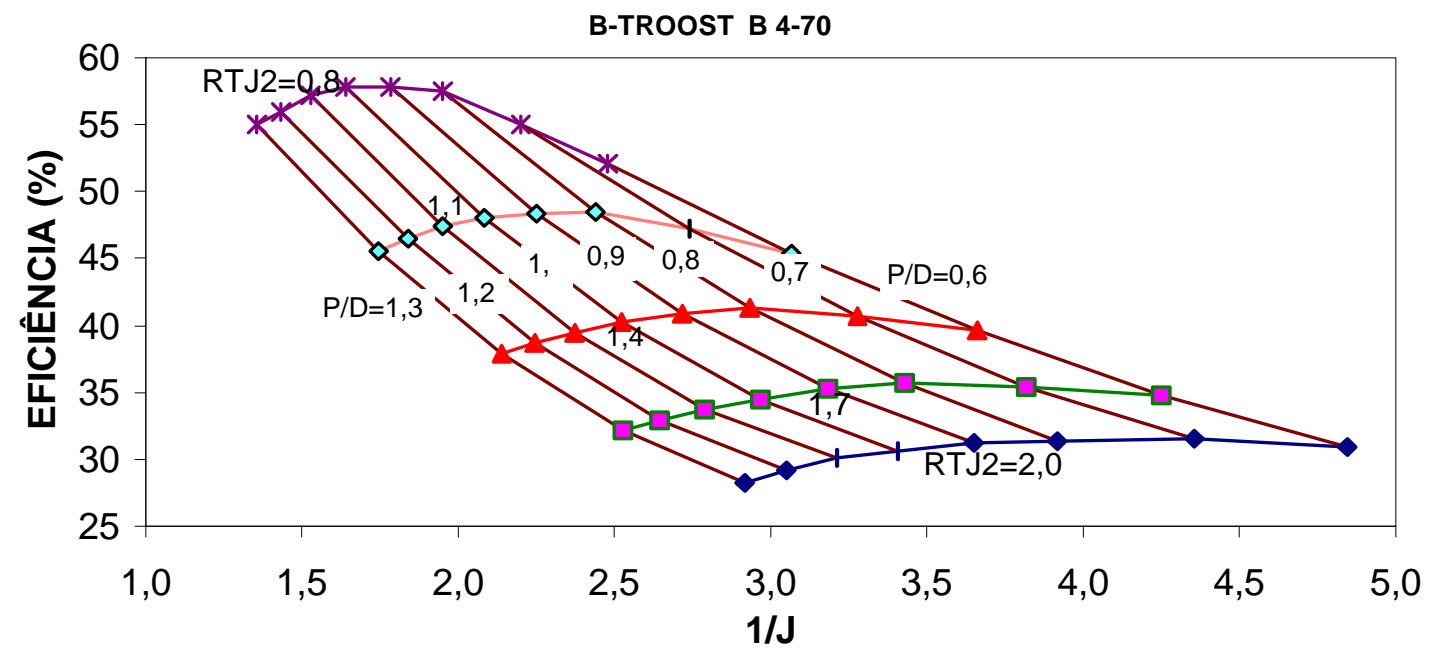

Figura 31 - Representação da Eficiência em Água Aberta de Hélice da Série B-Troost (B 4-70) em Função de $1 / J$, Parametrizados em P/D e $R T J 2=\sqrt{\frac{K_{T}}{J^{2}}}$. Faixa de Operação Típica de Embarcações Fluviais. 
As Figuras 32 e 33 apresentam as variações de eficiência de água aberta dos hélices da série Kaplan com dutos, em função de 1/J e parametrizados da mesma forma que as Figuras 30 e 31.

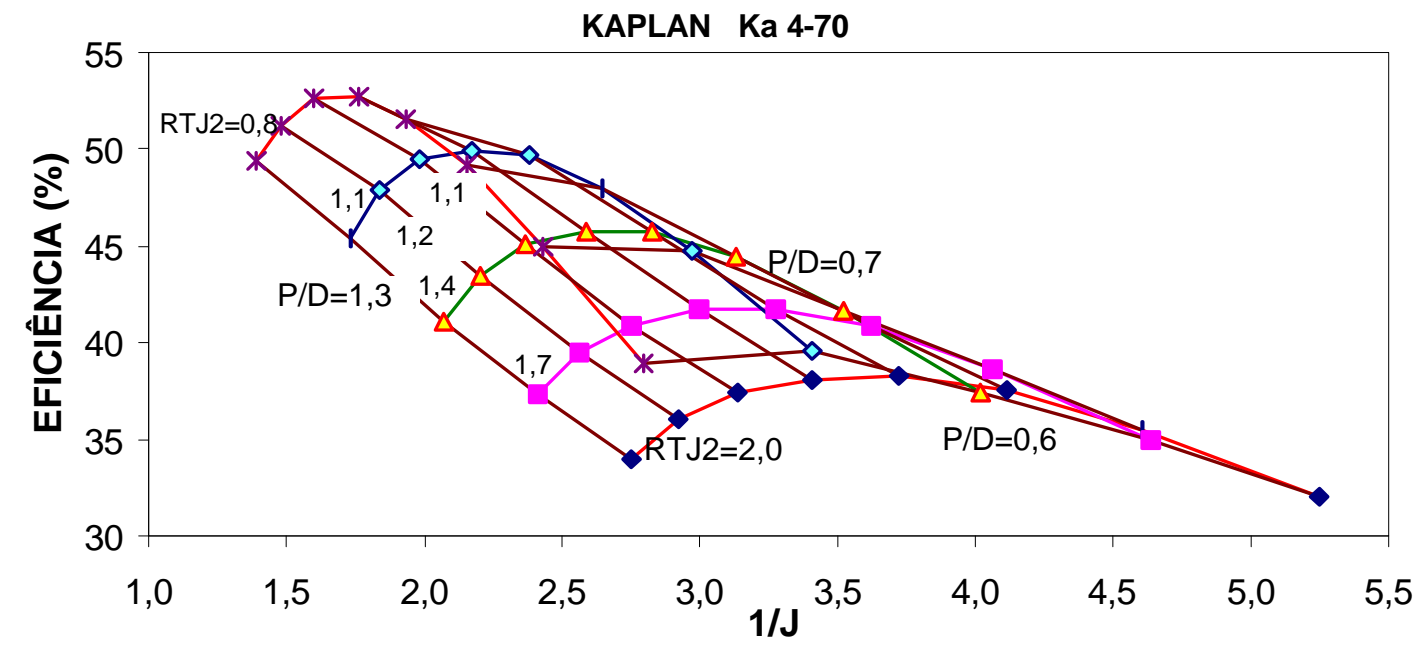

Figura 32 - Representação da Eficiência em Água Aberta de Hélice da Série B-Troost (B 4-70) em Função de $1 / \mathrm{J}$, Parametrizados em P/D e $C T J=\sqrt[4]{\frac{K_{T}}{J^{4}}}$. Faixa de Operação Típica de Embarcações Fluviais.

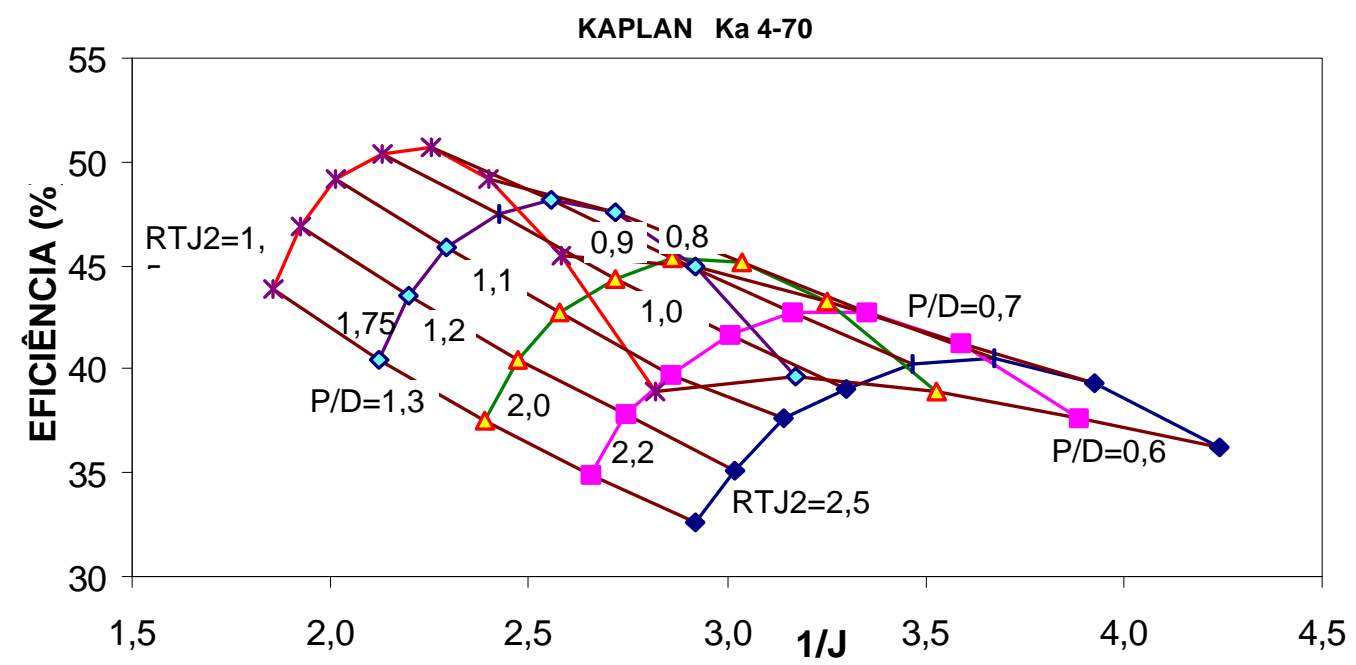

Figura 33 - Representação da Eficiência em Água Aberta de Hélice da Série Kaplan em Dutos em Função de $1 / \mathrm{J}$, Parametrizados em P/D e $R T J 2=\sqrt{\frac{K_{T}}{J^{2}}}$. Faixa de Operação Típica de Embarcações Fluviais. 
No caso dos hélices da série Kaplan em dutos, nota-se que há uma tendência das curvas de eficiência, na faixa de 1/J considerada, apresentarem variações maiores, com quedas abruptas de eficiência em valores de parâmetros $R T J 2=\sqrt{\frac{K_{T}}{J^{2}}}$ e $C T J=\sqrt[4]{\frac{K_{T}}{J^{4}}}$ menores, em $1 / \mathrm{J}$ menores.

Para explicar esta tendência, basta lembrar que a eficiência dos hélices em dutos é dependente do valor de $\mathbf{J}$ de uma forma mais crítica do que os hélices convencionais, devido ao fato do duto contribuir cada vez menos com empuxo à medida que a velocidade (e $\mathrm{J}$ ) aumenta, até um ponto em que o empuxo torna-se negativo (a resistência de arrasto do duto passa ser maior que suas contribuições em sustentação em sentido contrário).

\subsection{3. Área das Pás}

A área das pás de um hélice tem influência sobre dois aspectos importantes: em princípio, quanto menor a área das pás, menores as perdas por atrito (arrasto) e maior a eficiência do hélice; por outro lado, quanto menor a área da pá maior a sua suscetibilidade ao fenômeno de cavitação. Este último ponto, a cavitação e sua relação com a área das pás, já foi devidamente tratado no item 3.5. Trataremos a seguir a correlação entre a área das pás e a eficiência do hélice.

Os projetistas tendem a buscar sempre a utilização da menor área possível das pás pois a eficiência tende a decrescer com o aumento da área devido ao fato das perdas por atrito aumentarem. No caso de hélices de alto carregamento (altos valores de $\mathrm{C}_{\mathrm{TH}}$ ), as perdas axiais são tão grandes que as pequenas perdas por atrito passam a ser irrelevantes, quando se considera a vantagem de haver uma maior margem de segurança em relação à cavitação proporcionada por uma área maior de pá.

A Tabela 8 mostra alguns valores de eficiências em água aberta de três hélices da série BTroost de 4 pás e razão $\mathrm{P} / \mathrm{D}=1,0$ mas com razões de áreas expandidas Ae/Ao diferentes $(0,40$, 0,70 e 1,00), variando com o coeficiente de carregamento das pás $\mathrm{C}_{\mathrm{TH}}$.

Como se pode notar na Tabela 8, as diferenças de eficiências só são importantes em valores menores de $\mathrm{C}_{\mathrm{TH}}$. A razão principal pode ser explicada pela Figura 34, baseada em dados da referência [6], que mostra as várias componentes das perdas de eficiências em hélices. Segundo indicado na figura, a eficiência de um hélice em água aberta pode ser definida da seguinte forma: 
$\eta_{\mathrm{O}}=1$ - (perdas axiais) - (perdas rotacionais) - (perdas por arrasto nas pás).

Tabela 8 - Comparações de Eficiências em Água Aberta de Hélices B-Troost com Três Razões de Áreas Expandidas, em Função do Coeficiente de Carregamento $\mathrm{C}_{\mathrm{TH}}$. 4 Pás, $\mathrm{P} / \mathrm{D}=1,00$.

\begin{tabular}{|c|c|c|c|}
\hline \multirow{2}{*}{$\mathrm{C}_{\mathrm{TH}}$} & \multicolumn{3}{|c|}{ EFICIÊNCIAS EM ÁGUA ABERTA $\eta_{\mathrm{O}}(\%)$} \\
\cline { 2 - 4 } & Ae/Ao=0,40 & Ae/Ao=0,70 & Ae/Ao=1,00 \\
\hline 0,5 & 69,9 & 69,0 & 63,8 \\
\hline 1,0 & 64,8 & 63,7 & 61,0 \\
\hline 3,0 & 49,6 & 48,3 & 47,6 \\
\hline 5,0 & 41,7 & 40,7 & 40,3 \\
\hline 6,0 & 39,0 & 38,0 & 37,8 \\
\hline 7,0 & 36,7 & 35,8 & 35,7 \\
\hline 8,0 & 34,8 & 34,0 & 33,9 \\
\hline 9,0 & 33,2 & 32,4 & 32,4 \\
\hline 10,0 & 31,8 & 31,0 & 31,0 \\
\hline
\end{tabular}

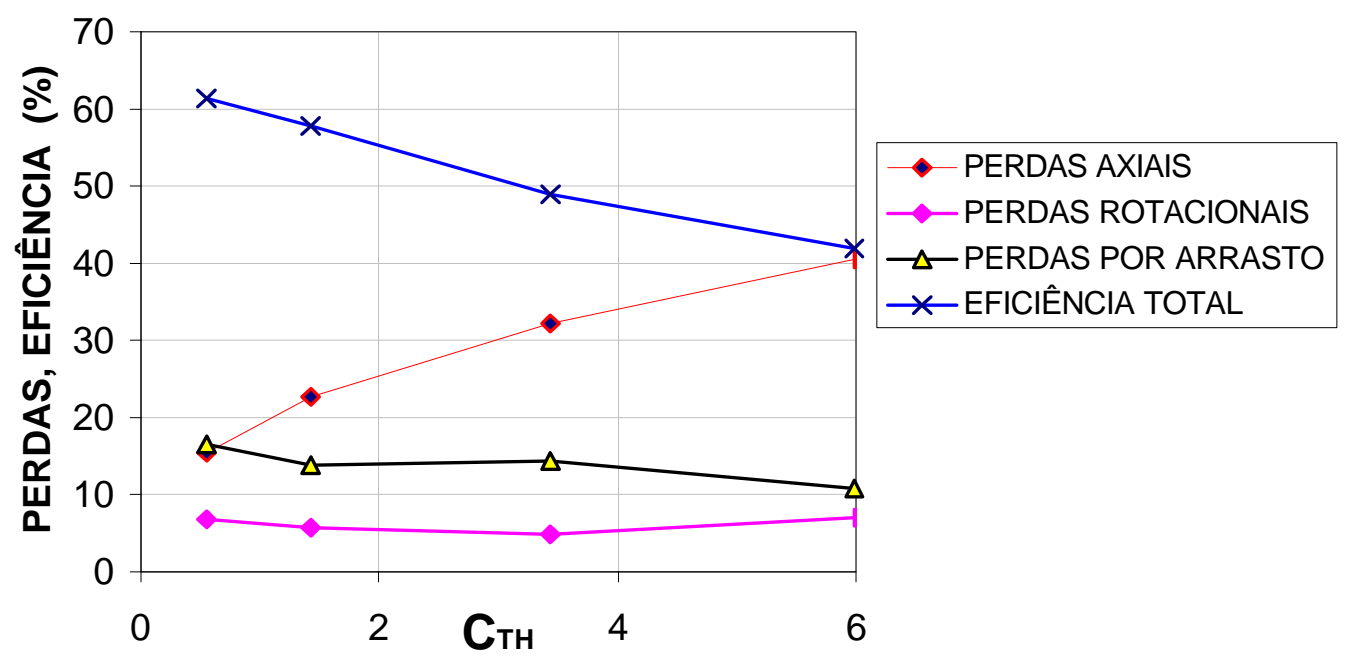

Figura 34 - Perdas de Eficiência de Um Hélice em Função do Carregamento das Pás [6].

As perdas relacionadas com a área das pás são aquelas devidas ao arrasto nas pás, que apresentam tendência de diminuir com o aumento de $\mathrm{C}_{\mathrm{TH}}$.

Proporcionalmente, a importância das perdas por arrasto diminui mais ainda com o acréscimo de $\mathrm{C}_{\mathrm{TH}}$, devido ao fato das perdas axiais crescerem de uma maneira significativa, fazendo cair drasticamente a eficiência total. 


\subsubsection{Número de Pás}

O número de pás de hélices de embarcações fluviais varia geralmente de 3 a 5 , sendo mais comum hélices de 4 pás. Hélices com menores números de pás tendem a ter eficiências levemente maiores que aqueles com mais pás. Por outro lado, os hélices com números de pás menores apresentam níveis de vibrações induzidas significativamente maiores que os hélices de maior número de pás.

Contudo, o aspecto mais importante ligado à escolha do número de pás de um hélice está relacionado com a freqüência de excitação de vibrações no casco e no sistema eixo-propulsor. A frequiência de excitação (Z.n) deve ser diferente das frequiências de ressonâncias do casco e do sistema de eixos propulsores [43]. Evidentemente, trata-se de uma tarefa difícil prever as frequiências naturais de partes do casco e do sistema propulsivo - é comum utilizar-se dados de embarcações semelhantes ou aplicar fórmulas empíricas [37].

A Figura 35 apresenta um resultado de análise espectral de uma medição de torque em um eixo do empurrador. Como pode ser notado, a freqüência mais importante presente no eixo, que capta o resultado da interação hélice-eixo-redutor-motor, é a freqüência da passagem das pás, de 35,9 Hz, que corresponde exatamente ao produto Z.n. A outra frequiência mais importante mostrada na figura, com energia um pouco menor que a máxima, corresponde à freqüência da passagem de uma pá, no caso, 8,9 Hz.

Quando não há problemas de proximidades de freqüências de ressonâncias, há uma tendência de utilizar 4 pás, por duas razões principais:

- há uma maior facilidade de construção e balanceamento estático e dinâmico das pás,

- está entre $\mathrm{Z}=3$ (eficiência um pouco maior) e $\mathrm{Z}=5$ (vibrações induzidas menores).

\subsubsection{Espessuras Máximas}

Basicamente, a determinação das espessuras máximas das seções das pás de um hélice depende do cálculo de resistência estrutural necessária. As sociedades classificadoras indicam formulações para calcular as espessuras mínimas requeridas que, inclusive, levam em consideração a probabilidade de fadiga do material. 


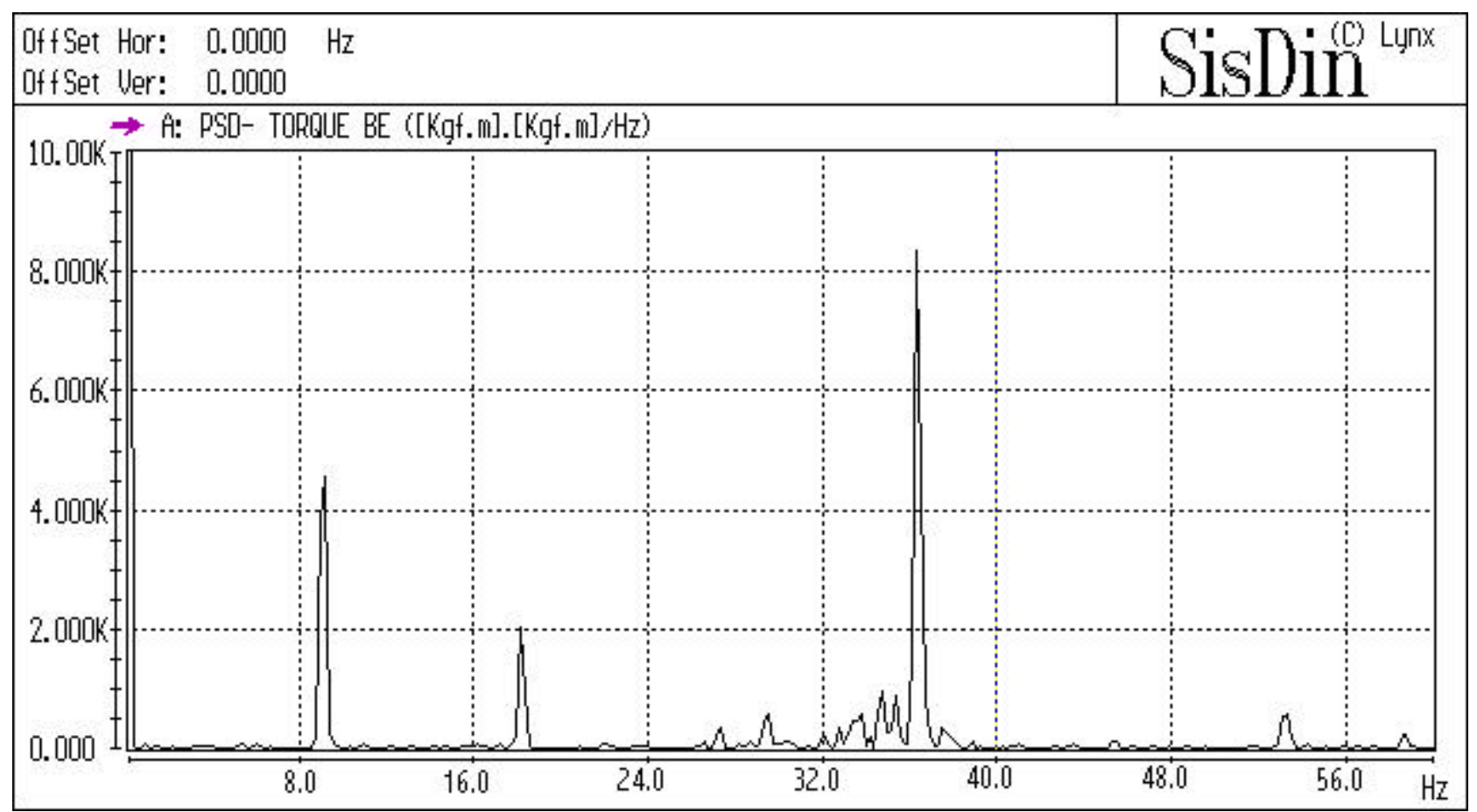

Figura 35 - Análise Espectral de Uma Série Temporal de Medidas de Torques no Eixo do Empurrador, $\mathrm{n}=1690 \mathrm{rpm}=8,99 \mathrm{rps}$.

$\mathrm{Na}$ grande maioria dos casos, quando se utiliza materiais apropriados para confecção de hélices (ligas manganês-bronze, ligas de níquel-alumínio, etc.) as espessuras definidas pelas séries sistemáticas são maiores que as espessuras mínimas requeridas pelas sociedades classificadoras. Quando o material é menos resistente, como é o caso de ferro nodular fundido (às vezes utilizado por ser mais barato), as espessuras necessárias serão maiores que aquelas indicadas pela série sistemática, obrigando o projetista a uma adaptação das formas das seções.

No caso de embarcações que operam em águas onde há grande probabilidade de ocorrência de choques nas pás de seus hélices, como acontece com navios quebra-gelo e algumas embarcações fluviais, pode haver necessidade de aumento das espessuras para que haja uma resistência adicional que evite fraturas e deformações das pás durante sua operação. A Tabela 9 mostra os valores de razões de espessuras máximas por diâmetro de hélices da série B-Troost e Kaplan e de um navio quebra-gelo [46]. No caso do navio quebra-gelo, o diâmetro do bosso é cerca de $30 \%$ do diâmetro do hélice e nota-se que o aumento de espessuras é maior proporcionalmente nas proximidades das pontas das pás, onde há maiores riscos de choques. 
A referência [38] apresenta alguns dados de correções de passos e de eficiências medidos em hélices com aumentos de espessuras de 100\% com relação às espessuras previstas pela série BTroost. Os resultados obtidos para hélices operando em coeficientes de avanço J baixos e com alto carregamento, para que o hélice com o dobro de espessuras mantenha a mesma condição de operação que outro com espessuras de série (mesmo empuxo resultante, em mesmo número de rotações) foram os seguintes:

- na condição de tração estática (“bollard-pull”), a correção em passo deve ser de cerca de $3 \%$,

- para velocidades entre 3 e 4 nós (1,5 a 3,0 m/s), as correções de passos devem ser de cerca de $6 \%$;

- em velocidades maiores, a correção necessária de passo chega a 10\%;

- a diminuição de eficiências nas várias condições é da ordem de $2 \%$, para o caso de embarcações onde o projeto do hélice é feito a partir de restrição de diâmetro.

O aumento de espessuras máximas implica em aumento da razão t/c (espessura/corda) das seções, alterando a forma dos perfis das seções das pás (distribuições das espessuras ao longo das cordas). As distribuições de pressões sofrem alterações que podem fazer com que piorem as condições de cavitação dos perfis mais próximos das pontas das pás. Para compensar o aumento de espessura, uma solução satisfatória é aumentar as cordas das pás (a área expandida).

Tabela 9 - Valores de Espessuras Máximas das Seções das Pás ao Longo do Raio para Séries BTroost, Kaplan e Navio Quebra-Gelo. Hélices de 4 pás.

\begin{tabular}{|c|c|c|c|}
\hline \multirow{2}{*}{$r / R$} & \multicolumn{3}{|c|}{ tr/D } \\
\cline { 2 - 4 } & B-TROOST & KAPLAN & QUEBRA-GELO \\
\hline 0,200 & 0,0366 & 0,0400 & - \\
\hline 0,300 & 0,0324 & 0,0352 & 0,0530 \\
\hline 0,400 & 0,0282 & 0,0300 & 0,0476 \\
\hline 0,500 & 0,0240 & 0,0245 & 0,0421 \\
\hline 0,600 & 0,0198 & 0,0190 & 0,0367 \\
\hline 0,700 & 0,0156 & 0,0138 & 0,0313 \\
\hline 0,800 & 0,0114 & 0,0092 & 0,0259 \\
\hline 0,900 & 0,0072 & 0,0061 & 0,0204 \\
\hline 1,000 & 0,0030 & 0,0050 & 0,0150 \\
\hline
\end{tabular}




\subsubsection{Passos}

A distribuição de ângulos de passos ao longo do raio está diretamente ligada à distribuição de circulação e de carregamento das pás. Neste sentido, às vezes, modifica-se a distribuição de passos para resolver problemas específicos, como, por exemplo, aliviar o carregamento das pontas das pás de embarcações de guerra, a fim de diminuir intensidades de cavitação e, consequentemente, de ruído.

No caso de embarcações fluviais, não há muito espaço para modificações nas distribuições de passos. Recomenda-se seguir formas simplificadas das séries sistemáticas, com passos constantes ao longo do raio, o que, no mínimo, facilita a construção dos hélices.

\subsubsection{Caimento ("rake") e Assimetria do Contorno das Pás ("skew")}

O caimento é uma inclinação do eixo das pás no sentido longitudinal da embarcação, geralmente para ré. Trata-se de um expediente para aumentar as distâncias das pontas das pás ao casco ou para aumentar o diâmetro do hélice possível de ser instalado em determinada popa. Como inconveniente, introduz momentos que obrigam a adoção de maiores espessuras nas raízes das pás.

O "skew", assimetria do contorno em relação à linha geratriz da pá, apresenta uma grande contribuição para a redução dos níveis de cavitação intermitente (que pode provocar erosão) e de vibrações induzidas pelo propulsor em operação em campo não-uniforme de velocidades. O "skew" torna mais amena a passagem das pás pelas várias regiões de intensidades diferentes do campo de esteiras, diminuindo as intensidades das flutuações de pressões junto às pás.

Tanto o caimento como o "skew" não introduzem diferenças nas eficiências dos propulsores em condições de operações normais, a vante. Contudo, quando em operação à ré, os hélices com estas assimetrias apresentam certa redução de eficiência quando comparados com hélice sem caimento e sem "skew". Nas embarcações fluviais, onde a operação à ré dos hélices é freqüente, tem havido uma tendência de evitar-se tanto o caimento como o "skew" no projeto dos hélices. 


\section{ANÁLISES DOS ENSAIOS EM ESCALA REAL}

\subsection{COEFICIENTES PROPULSIVOS OBTIDOS EM ESCALA REAL}

A análise dos dados da sexta viagem, por meio da igualdade do coeficiente de empuxo, adotando-se um valor de eficiência relativa rotativa $\eta_{R}$ medido no modelo em escala 1:13 no tanque de provas do IPT [23], levou a valores estimados de coeficientes de esteira efetiva e de redução da força propulsora mostrados nas Figura 36 e 37.

Os valores de $\mathrm{t}$ foram obtidos a partir da resistência ao avanço para cada condição de carregamento estimada pela expressão de Howe [10] para comboios fluviais, conforme item 3.3.1 .

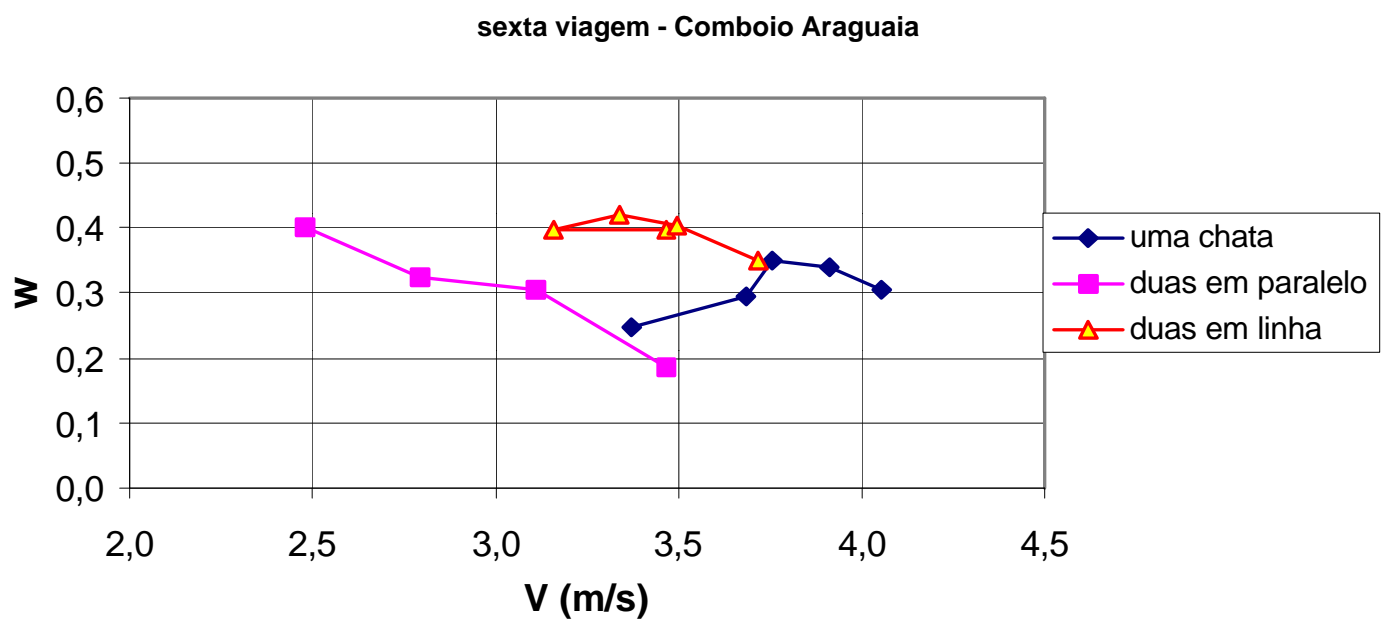

Figura 36 - Estimativa de Coeficientes de Esteira Efetiva a Partir dos Ensaios em Escala Real - Sexta Viagem - Hélices Convencionais. $\mathrm{H}=1,6 \mathrm{~m}$.

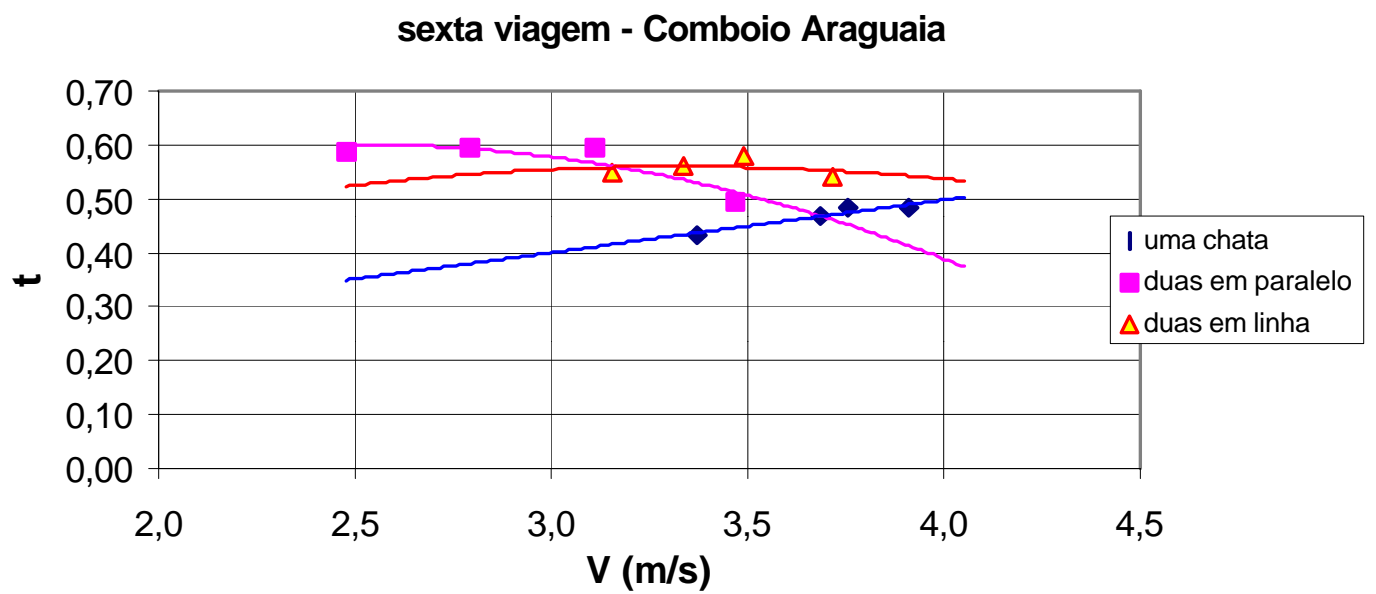

Figura 37 - Estimativa de Coeficientes de Redução da Força Propulsora a Partir dos Ensaios em Escala Real - Sexta Viagem - Hélices Convencionais. H=1,6 m. 
Nas Figura 38, 39 e 40 há comparações dos coeficientes propulsivos obtidos em escala real na sexta viagem (hélices B-Troost) com os coeficientes propulsivos dos ensaios de autopropulsão no Tanque de Provas, para as três formações de comboio ensaiadas. É importante lembrar as diferenças entre as condições comparadas: em escala real o calado das chatas era de 1,6 m e no modelo o calado era o correspondente a $2,0 \mathrm{~m}$; em escala real a profundidade era de $5 \mathrm{~m}$ e no modelo era praticamente infinita.

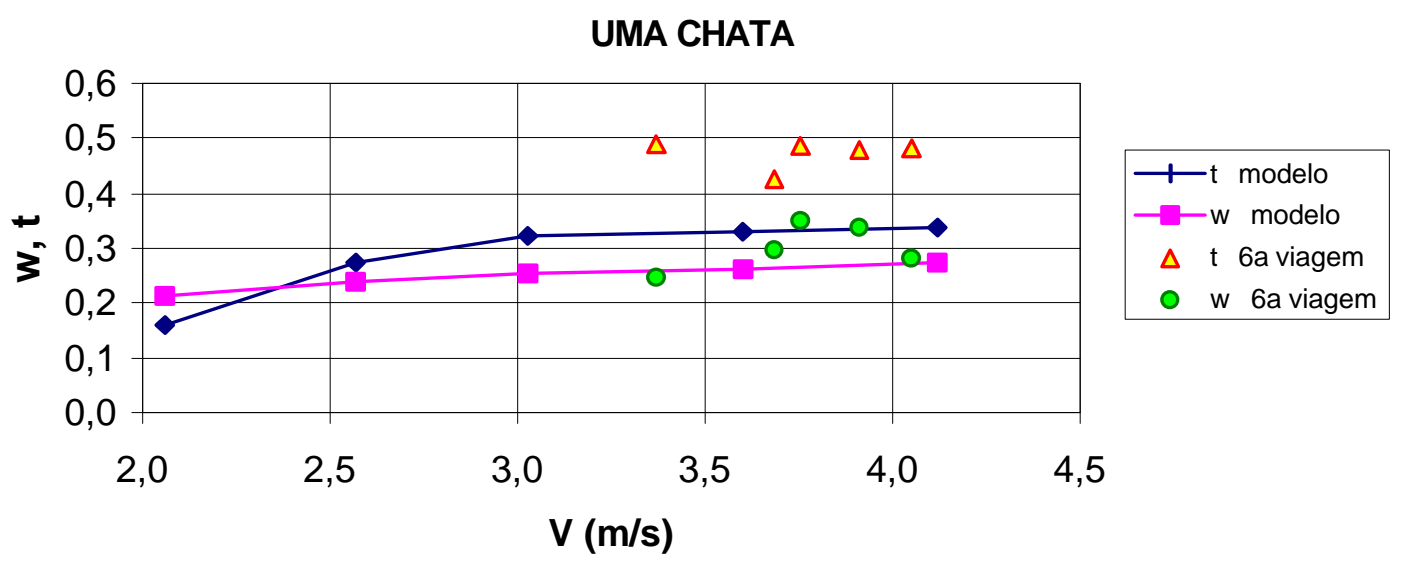

Figura 38 - Estimativa de Coeficientes Propulsivos a Partir dos Ensaios em Escala Real - Sexta Viagem - Hélices Convencionais. Comparações com Curvas Obtidas em Ensaios na Escala 1:13. Uma chata $\mathrm{H}=1,6 \mathrm{~m}$.

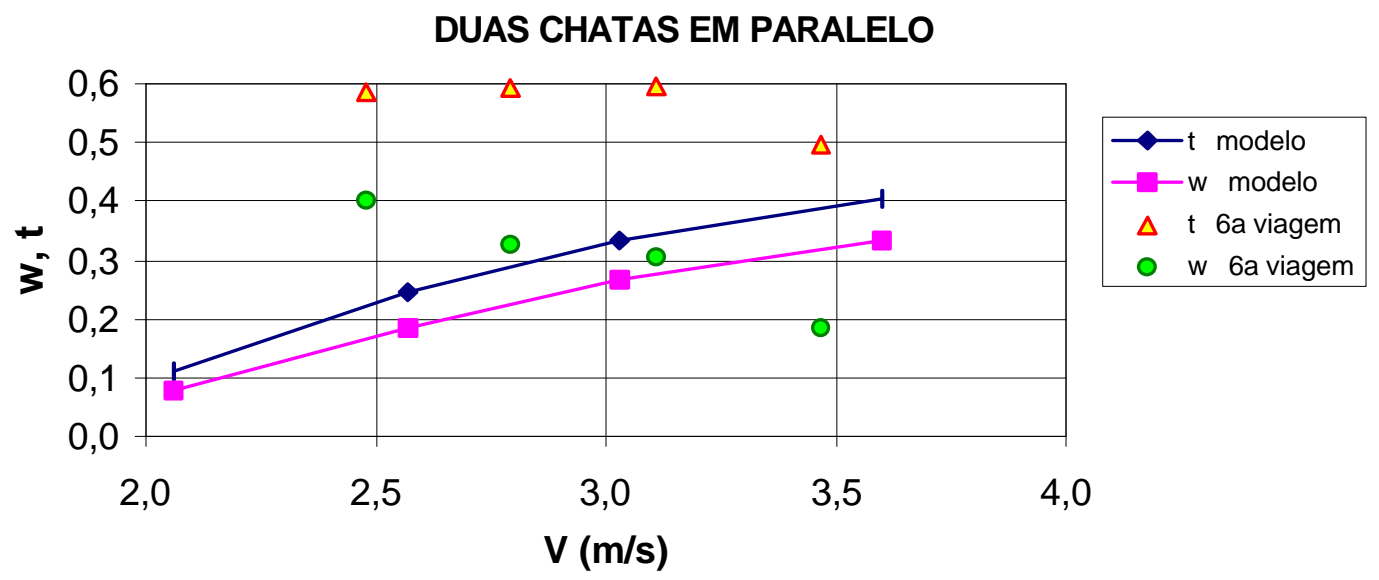

Figura 39 - Estimativa de Coeficientes Propulsivos a Partir dos Ensaios em Escala Real - Sexta Viagem - Hélices Convencionais. Comparações com Curvas Obtidas em Ensaios na Escala 1:13. Duas Chatas em Paralelo, $\mathrm{H}=1,6 \mathrm{~m}$. 


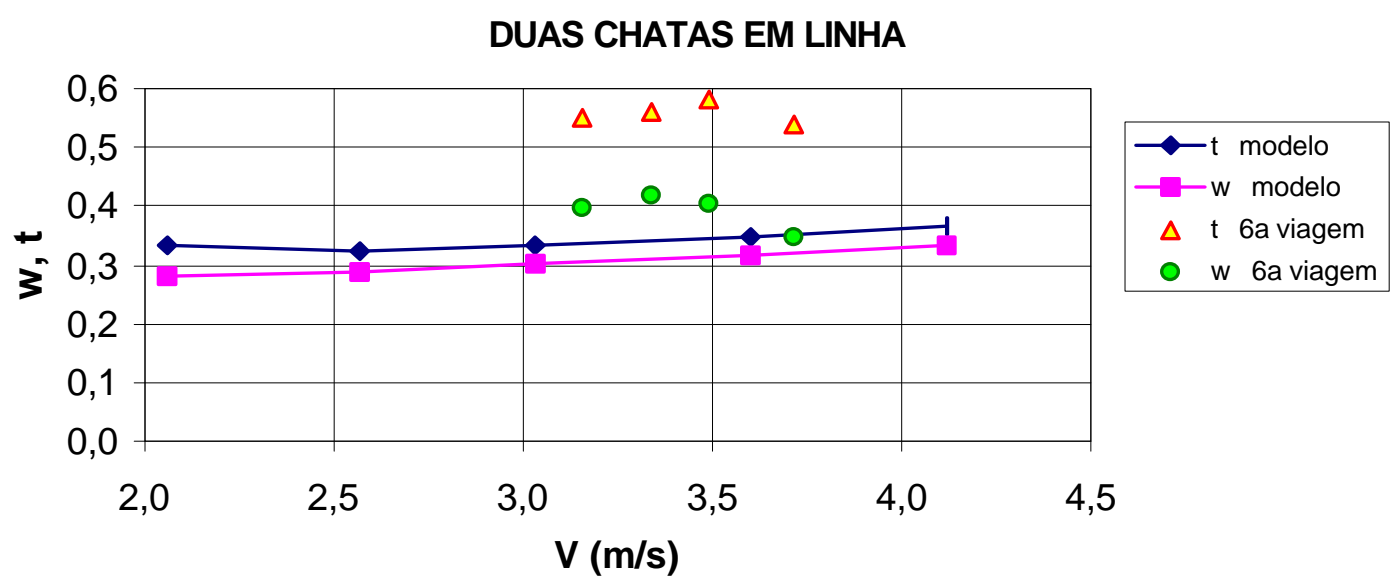

Figura 40 - Estimativa de Coeficientes Propulsivos a Partir dos Ensaios em Escala Real - Sexta Viagem - Hélices Convencionais. Comparações com Curvas Obtidas em Ensaios na Escala 1:13. Duas Chatas em Linha, $\mathrm{H}=1,6 \mathrm{~m}$.

Do mesmo modo, as Figura 41 e 42 mostram, respectivamente, os resultados de coeficientes de esteira e de redução da força propulsora, obtidos com os dados medidos na oitava viagem, assumindo-se $\eta_{\mathrm{R}}$ igual a 0,95 ; neste caso, com hélices em dutos, não foram realizados ensaios com modelos.

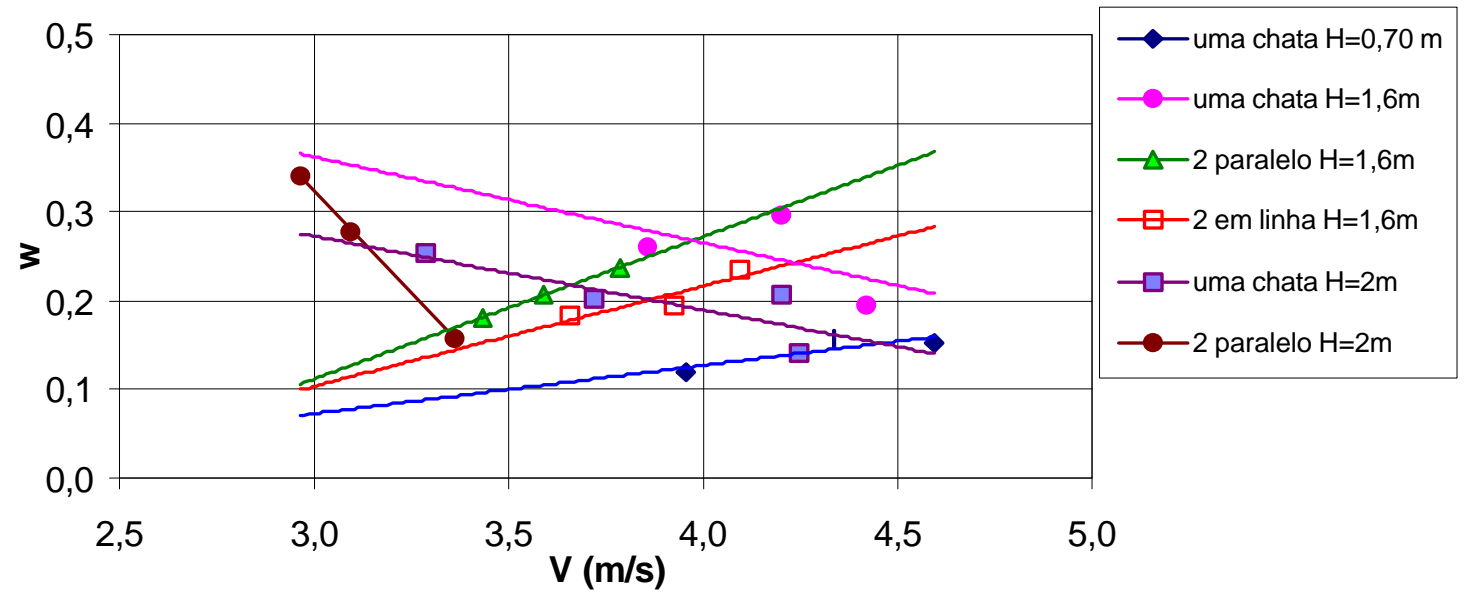

Figura 41 - Estimativa do Coeficiente de Esteira a Partir dos Ensaios em Escala Real - Oitava Viagem. Hélices em Dutos. 


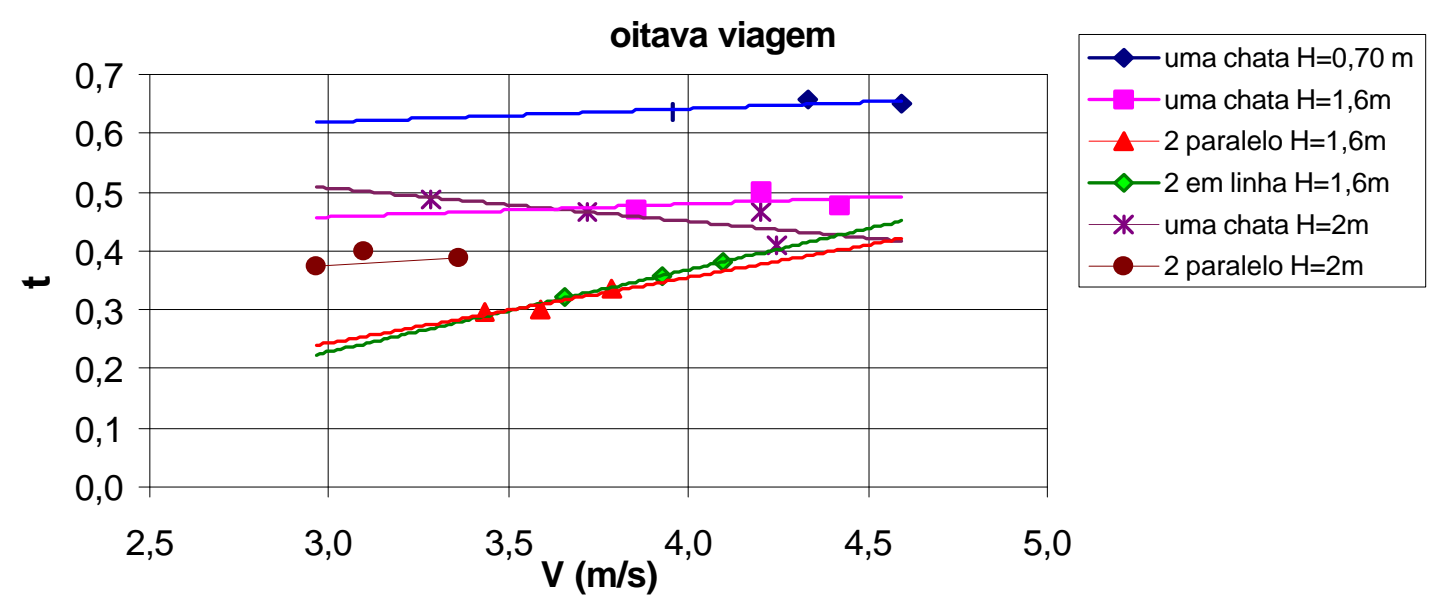

Figura 42 - Estimativa do Coeficiente de Redução da Força Propulsora a Partir dos Ensaios em Escala Real - Oitava Viagem. Hélices em Dutos.

As Tabelas 10 e 11 mostram, respectivamente, valores médios de coeficiente de esteiras e de redução da força propulsora, comparando estimativa por formulação empírica [2], por ensaios em modelo (neste caso, com calado um pouco maior, equivalente a 2,0 m), e aqueles obtidos na sexta e na oitava viagem do Comboio Araguaia.

Tabela 10 - Valores de Coeficientes Médios de Esteiras $\omega$ para as Condições da Sexta e Oitava Viagens $(\mathrm{H}=1,6 \mathrm{~m})$ e Estimados de Acordo com Item 3.3.2.

\begin{tabular}{|c|c|c|c|}
\hline FORMAÇÃO & UMA CHATA & $\begin{array}{l}\text { DUAS EM } \\
\text { LINHA }\end{array}$ & $\begin{array}{c}\text { DUAS EM } \\
\text { PARALELO }\end{array}$ \\
\hline$\omega$ Estimados & 0,280 & 0,298 & 0,298 \\
\hline$\omega$ ensaios modelo IPT & 0,248 & 0,304 & 0,215 \\
\hline$\omega$ médios sexta viagem & 0,207 & 0,344 & 0,393 \\
\hline$\omega$ médios oitava viagem & 0,250 & 0,204 & 0,260 \\
\hline
\end{tabular}


Tabela 11 - Valores de Coeficientes Médios de Redução da Força Propulsora t para as Condições da Sexta e Oitava Viagens ( $\mathrm{H}=1,6 \mathrm{~m})$ e Estimados de Acordo com Item 3.3.2.

\begin{tabular}{|l|c|c|c|}
\hline FORMAÇÃO & UMA CHATA & $\begin{array}{c}\text { DUAS EM } \\
\text { LINHA }\end{array}$ & $\begin{array}{c}\text { DUAS EM } \\
\text { PARALELO }\end{array}$ \\
\hline t Estimados & 0,280 & 0,298 & 0,298 \\
\hline t ensaios modelo IPT & 0,310 & 0,346 & 0,296 \\
\hline t médios sexta viagem & 0,470 & 0,568 & 0,558 \\
\hline t médios oitava viagem & 0,483 & 0,353 & 0,332 \\
\hline
\end{tabular}

A Tabela 12 apresenta os valores de eficiência propulsiva $\eta_{D}=\frac{P_{E}}{P_{D}}=\eta_{O} \cdot \eta_{H} \cdot \eta_{R}$ em função da velocidade, obtidos a partir dos resultados da sexta viagem. As eficiências propulsivas esperadas, com os dados de projeto, se encontravam na faixa entre 0,30 e 0,35 .

Tabela 12 - Valores de Eficiência Propulsiva $\eta_{D}$ em Função da Velocidade. Sexta Viagem (H=1,6m).

\begin{tabular}{|l|c|c|}
\hline condição & $\mathbf{V}(\mathbf{m} / \mathbf{s})$ & $\boldsymbol{\eta}_{\mathbf{D}}$ \\
\hline \multirow{4}{*}{ uma chata } & 3,370 & 0,190 \\
\cline { 2 - 3 } & 3,685 & 0,222 \\
\cline { 2 - 3 } & 3,756 & 0,204 \\
\cline { 2 - 3 } & 3,912 & 0,205 \\
\cline { 2 - 3 } em paralelo & 4,052 & 0,190 \\
\cline { 2 - 3 } & 2,478 & 0,142 \\
\cline { 2 - 3 } & 2,793 & 0,134 \\
\cline { 2 - 3 } & 3,468 & 0,164 \\
\hline \multirow{3}{*}{ em linha } & 3,110 & 0,132 \\
\cline { 2 - 3 } & 3,156 & 0,183 \\
\cline { 2 - 3 } & 3,338 & 0,177 \\
\cline { 2 - 3 } & 3,493 & 0,163 \\
\hline
\end{tabular}

As Figuras 43 e 44 apresentam os resultados de eficiência propulsiva $\eta_{D}$ em função das velocidades obtidas a partir das medições na sexta e na oitava viagens, respectivamente. 


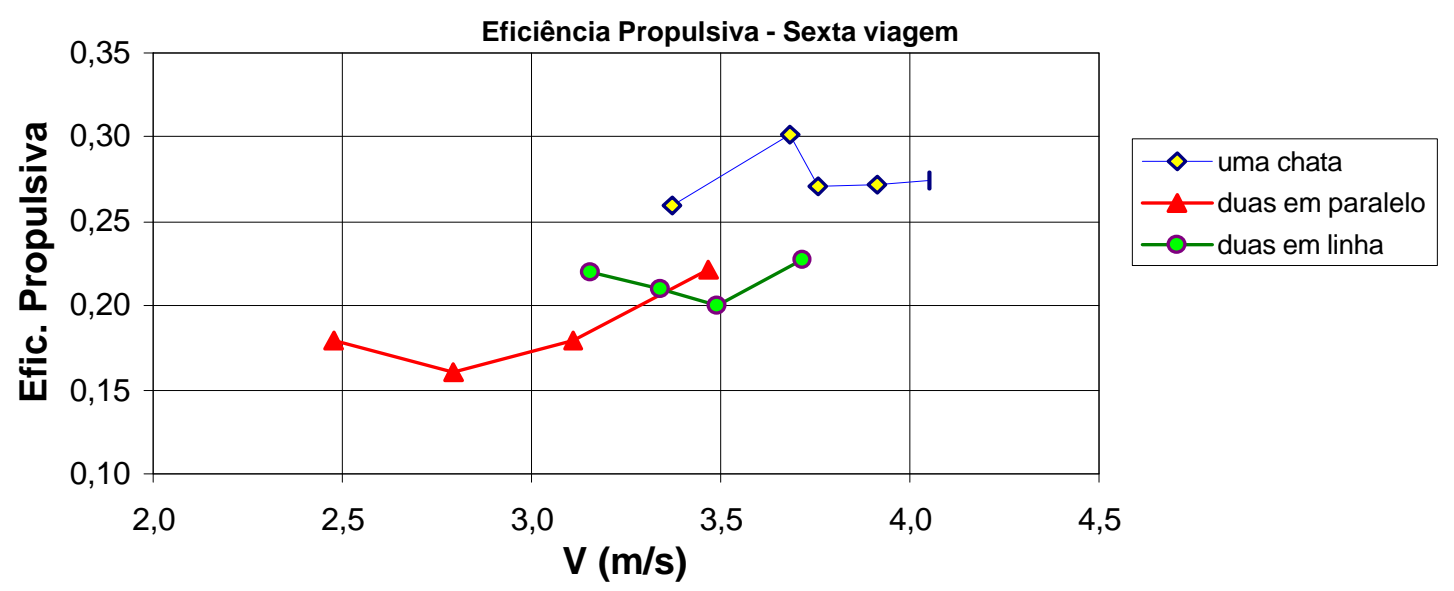

Figura 43 - Valores de Eficiências Propulsivas. Sexta Viagem. H=1,60 m. h=5,0 m.

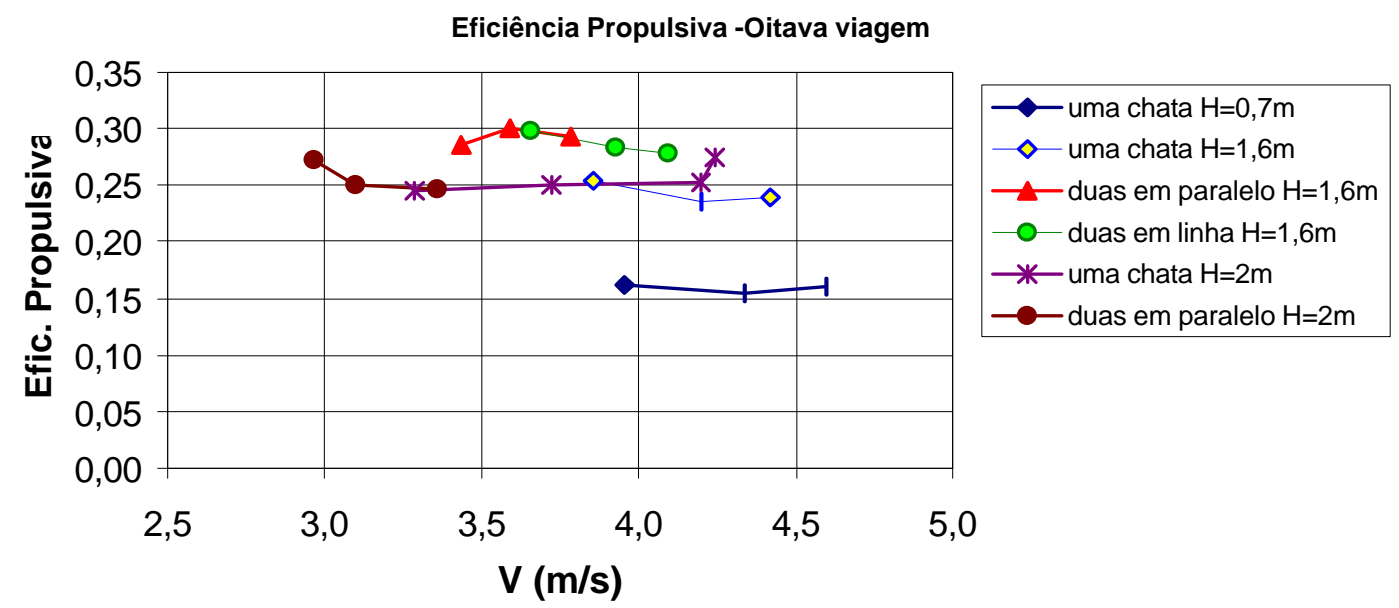

Figura 44 - Valores de Eficiências Propulsivas. Oitava Viagem. h=5,0 m.

As comparações dos resultados obtidos dos coeficientes propulsivos $\omega$ e $\mathrm{t}$ a partir dos ensaios em escala real, mesmo levando-se em conta o erro previsto de medições e análise, mostram que:

- os valores de coeficientes de esteiras $\omega$ obtidos são da ordem daqueles esperados através de formulação empírica e de ensaios em tanque de provas;

- os valores de coeficiente de redução da força propulsora t estão muito acima dos valores esperados (deveriam estar próximos dos valores de $\omega$ ). Este fato fez com que a eficiência do casco baixasse drasticamente e diminuísse a eficiência propulsiva para valores abaixo do esperado para este tipo de embarcação. 
A explicação para a ocorrência de coeficientes de redução da força propulsora muito altos, com conseqüente queda da eficiência do casco, deve estar relacionada com o grave problema detectado de afundamento acentuado da proa do empurrador quando operando sozinho. Formando comboio, o trim dinâmico do empurrador é contido pela(s) chata(s), mas, com certeza, há perdas de energia relativamente grandes no escoamento nos túneis na parte à ré dos hélices, e tais perdas devem estar se refletindo na eficiência propulsiva.

Interessante notar que este problema não foi constatado nos ensaios com modelo no tanque de provas, inclusive, não se refletiu nos próprios resultados dos ensaios de autopropulsão, que tiveram valores próximos dos esperados. O fenômeno deve estar ligado ao escoamento em regime turbulento em escala real, com possível influência das restrições de profundidades.

Outro fato digno de nota é que o túnel do empurrador Araguaia seguiu indicações de formas e proporções de referências bibliográficas sobre empurradores com túneis de popa, como, por exemplo [5] e [10].

Nas referências bibliográficas consultadas, o problema considerado grave e freqüente relacionado com os túneis de popa é o de vibrações, não havendo citações sobre a questão de indução de trim dinâmico de proa. Relatos orais de projetistas brasileiros mostram a ocorrência de alguns casos semelhantes. Como o projeto de túneis de popa pode reservar dissabores difíceis de prever, como o ocorrido no presente caso, a solução que tem sido adotada é evitar utilizá-los; no máximo, adota-se o que tem sido chamado de "semi-túnel", mantendo a entrada da forma que se utiliza normalmente, mas fazendo com que o ângulo de saída da linha do casco seja quase próximo de $0^{\circ}$, ou seja, com a linha mais horizontal possível. Neste caso, logicamente o diâmetro não poderá ser da ordem do calado, deverá ser, no máximo, cerca de $85 \%$ de $\mathrm{H}$. 


\subsection{PONTOS DE PROJETOS DOS HÉLICES}

\subsubsection{Verificação de Cavitação}

A Figura 45 mostra os valores de $\mathrm{K}_{\mathrm{Q}}$, no eixo de bombordo, obtidos nas medições em escala real e a curva de eficiência em água aberta dos hélices da série sistemática B-Troost utilizado na sexta viagem. A principal constatação é que não há quaisquer tendências de queda de torque (diminuição brusca de valores de $\mathrm{K}_{\mathrm{Q}} \mathrm{em} \mathrm{J}$ menores), o que significa que, certamente, não ocorrem problemas sérios de cavitação nos hélices. Aliás, este comportamento, com folgas em relação à cavitação era esperado desde a etapa de projeto, já que a razão de áreas Ae/Ao=0,50 é relativamente reduzida.

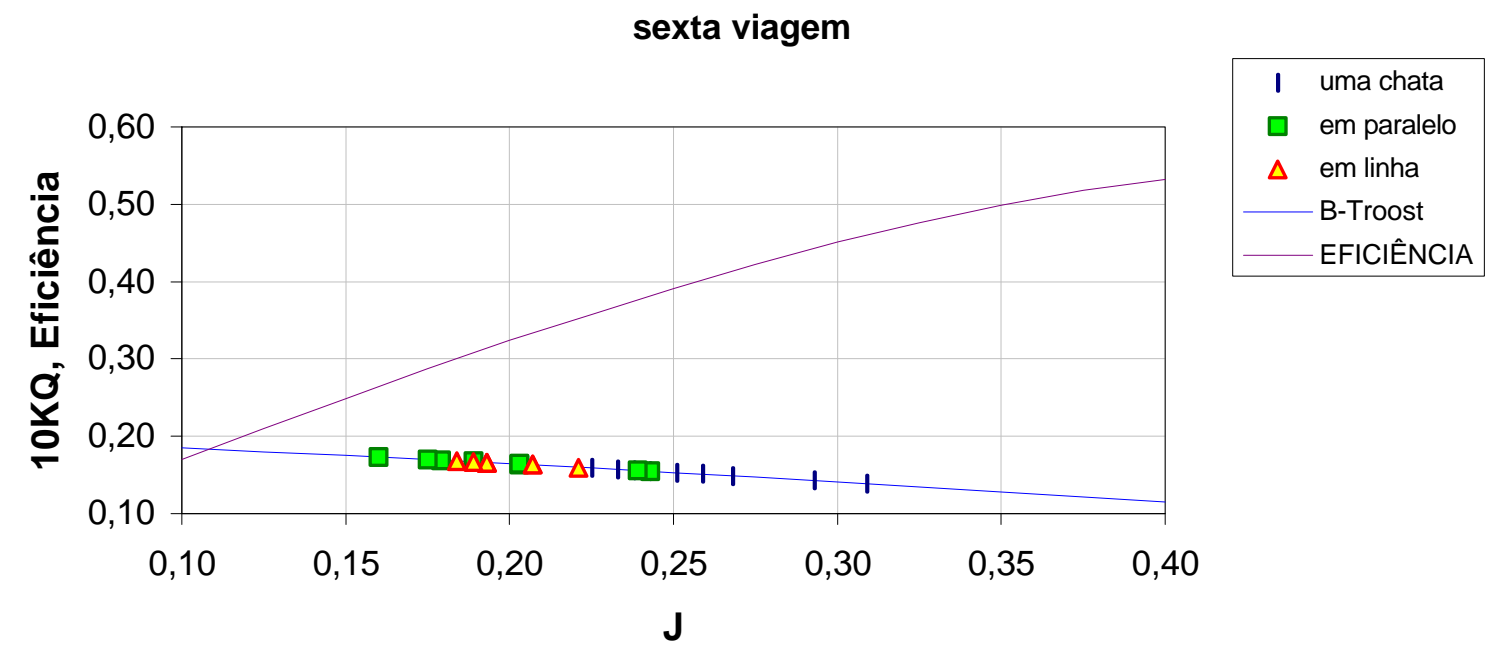

Figura 45 - Valores de $\mathrm{K}_{\mathrm{Q}}$ em Função de J, Utilizados na Estimativa de $\omega$ em Escala Real - Sexta Viagem. Indicação das Eficiências em Água Aberta. Eixo de Bombordo.

\subsubsection{Pontos de Operação dos Hélices}

As Tabelas 13 e 14 mostram os valores relacionados com os pontos de operações dos hélices nas duas viagens, sexta e oitava, respectivamente. A forma apresentada dos coeficientes obtidos em escala real permite que sejam comparados com as Figuras 30, 31, 32 e 33 do item 3.7.2. Aquelas figuras indicam as tendências de variações das eficiências dos hélices em função de $1 / J$, 
parametrizados em $\sqrt{\frac{K_{T}}{J^{2}}}$ e $\sqrt[4]{\frac{K_{T}}{J^{4}}}$. Quando se compara estes valores, percebe-se que os hélices do empurrador Araguaia estão operando em condições correspondentes aos extremos das suas curvas de água aberta.

Os valores dos coeficientes de carregamento das pás $\mathrm{C}_{\mathrm{TH}}$ são altíssimos, principalmente no caso dos hélices da sexta viagem (B-Troost), implicando em eficiências muito baixas.

Tabela 13 - Valores dos Coeficientes $\mathrm{C}_{\mathrm{TH}}, \sqrt{\frac{K_{T}}{J^{2}}}$ e $\sqrt[4]{\frac{K_{T}}{J^{4}}}$ dos Pontos Experimentais. Sexta Viagem.

\begin{tabular}{|c|c|c|c|c|c|}
\hline CONDIÇÃO & $V(\mathrm{~m} / \mathrm{s})$ & $\frac{1}{J}$ & $\mathrm{C}_{\mathrm{TH}}$ & $\sqrt{\frac{K_{T}}{J^{2}}}$ & $\sqrt[4]{\frac{K_{T}}{J^{4}}}$ \\
\hline \multirow{5}{*}{$\begin{array}{l}\text { UMA CHATA } \\
\mathrm{H}=1,60 \mathrm{~m}\end{array}$} & 3,370 & 3,41 & 4,034 & 1,259 & 3,486 \\
\hline & 3,685 & 3,62 & 4,730 & 1,363 & 2,222 \\
\hline & 3,756 & 4,06 & 6,370 & 1,582 & 2,533 \\
\hline & 3,912 & 4,13 & 6,696 & 1,622 & 2,589 \\
\hline & 4,052 & 4,02 & 6,247 & 1,566 & 2,649 \\
\hline \multirow{4}{*}{$\begin{array}{l}\text { DUAS CHATAS } \\
\text { EM PARALELO } \\
\mathrm{H}=1,60 \mathrm{~m}\end{array}$} & 2,478 & 5,90 & 15,688 & 2,482 & 3,827 \\
\hline & 2,793 & 5,29 & 12,190 & 2,188 & 3,402 \\
\hline & 3,468 & 4,15 & 6,752 & 1,628 & 2,599 \\
\hline & 3,110 & 5,10 & 11,202 & 2,097 & 3,271 \\
\hline \multirow{4}{*}{ DUAS CHATAS } & 3,156 & 4,94 & 10,309 & 2,012 & 3,152 \\
\hline & 3,338 & 5,18 & 11,553 & 2,130 & 3,322 \\
\hline & 3,493 & 5,24 & 11,866 & 2,159 & 3,362 \\
\hline & 3,717 & 4,83 & 9,806 & 1,962 & 3,079 \\
\hline
\end{tabular}


Tabela 14 - Valores dos Coeficientes $\mathrm{C}_{\mathrm{TH}}, \sqrt{\frac{K_{T}}{J^{2}}}$ e $\sqrt[4]{\frac{K_{T}}{J^{4}}}$ dos Pontos Experimentais. Oitava Viagem.

\begin{tabular}{|c|c|c|c|c|c|}
\hline CONDIÇÃO & $\mathrm{V}(\mathrm{m} / \mathrm{s})$ & $\frac{1}{J}$ & $\mathrm{C}_{\mathrm{TH}}$ & $\sqrt{\frac{K_{T}}{J^{2}}}$ & $\sqrt[4]{\frac{K_{T}}{J^{4}}}$ \\
\hline \multirow{3}{*}{$\begin{array}{l}\text { UMA CHATA } \\
\mathrm{H}=0,70 \mathrm{~m}\end{array}$} & 3,955 & 2,674 & 2,585 & 1,008 & 1,641 \\
\hline & 4,335 & 2,801 & 2,977 & 1,081 & 1,740 \\
\hline & 4,595 & 2,755 & 2,841 & 1,056 & 1,706 \\
\hline \multirow{3}{*}{$\begin{array}{l}\text { UMA CHATA } \\
\mathrm{H}=1,6 \mathrm{~m}\end{array}$} & 3,855 & 3,190 & 4,327 & 1,304 & 2,039 \\
\hline & 4,200 & 3,384 & 5,074 & 1,412 & 2,186 \\
\hline & 4,420 & 3,008 & 3,674 & 1,201 & 1,901 \\
\hline \multirow{3}{*}{$\begin{array}{l}\text { DUAS CHATAS } \\
\text { EM PARALELO } \\
\mathrm{H}=1,60 \mathrm{~m}\end{array}$} & 3,435 & 4,141 & 8,492 & 1,826 & 2,750 \\
\hline & 3,590 & 3,472 & 5,434 & 1,461 & 2,252 \\
\hline & 3,785 & 3,643 & 6,168 & 1,556 & 2,381 \\
\hline \multirow{3}{*}{$\begin{array}{l}\text { DUAS CHATAS } \\
\text { EM LINHA } \\
\mathrm{H}=1,60 \mathrm{~m}\end{array}$} & 3,655 & 3,115 & 4,053 & 1,262 & 1,982 \\
\hline & 4,095 & 3,378 & 5,072 & 1,411 & 2,184 \\
\hline & 3,925 & 3,215 & 4,423 & 1,318 & 2,059 \\
\hline \multirow{4}{*}{$\begin{array}{l}\text { UMA CHATA } \\
\mathrm{H}=1,98 \mathrm{~m}\end{array}$} & 4,245 & 2,907 & 3,335 & 1,144 & 1,824 \\
\hline & 3,285 & 3,378 & 5,072 & 1,411 & 2,184 \\
\hline & 4,200 & 3,190 & 4,327 & 1,304 & 2,039 \\
\hline & 3,720 & 3,185 & 4,313 & 1,301 & 2,036 \\
\hline \multirow{3}{*}{$\begin{array}{l}\text { DUAS CHATAS } \\
\text { EM PARALELO } \\
\mathrm{H}=1,98 \mathrm{~m}\end{array}$} & 3,095 & 4,193 & 8,797 & 1,859 & 2,792 \\
\hline & 3,360 & 3,683 & 6,357 & 1,580 & 2,412 \\
\hline & 2,965 & 4,854 & 12,512 & 2,217 & 3,280 \\
\hline
\end{tabular}


A questão que se coloca, neste momento, é se é possível evitar operar em situações, ou condições operacionais tão desfavoráveis quanto as medidas no Comboio Araguaia.

A primeira resposta é que os valores de $\mathrm{C}_{\mathrm{TH}}$ em escala real estão exagerados devido ao problema verificado dos coeficientes de redução da força propulsora estarem muito altos.

Como pode ser visto pelas definições (veja item 3.6) abaixo, um acréscimo de $80 \%$ em t (um dos casos mais críticos), aumenta o $\mathrm{C}_{\mathrm{TH}}$ em mais de $50 \%$, o que explica as condições extremamente negativas de operação dos hélices.

$$
\begin{aligned}
& \frac{K_{T}}{J^{2}}=\frac{R_{T}}{\rho \cdot D^{2} \cdot(1-t) \cdot(1-\omega)^{2} \cdot V^{2}} \\
& C_{T H}=\frac{T}{\frac{1}{2} \cdot \rho \cdot A_{0} \cdot V_{A}^{2}}=\frac{8}{\pi} \cdot \frac{K_{T}}{J^{2}}
\end{aligned}
$$

A segunda resposta está ligada à escolha do ponto de projeto do hélice. Se o hélice é projetado, ou seja, tem a sua geometria definida para responder de maneira otimizada em uma condição muito diferente daquelas em que a embarcação vai operar a maior parte do tempo, as suas eficiências em operação podem não ser as mais apropriadas.

Outro ponto digno de nota é que as rotações com os hélices B-Troost (veja Figura 14) ultrapassaram freqüentemente o valor de rotação nominal (em operação contínua) dos motores, que é de 1.800 rpm, o que confirma que a razão P/D está subdimensionada para operação normal do comboio.

\subsubsection{Novos Projetos}

A seguir, serão apresentados, para aprofundamento da análise do desempenho propulsivo do comboio, alguns exemplos de hélices que poderiam ser projetados para o empurrador. O objetivo é possibilitar comparações com os desempenhos medidos com os hélices B-Troost e Kaplan com dutos na sexta e na oitava viagens, respectivamente. Foram elaborados três novos projetos, sempre para um mesmo ponto de projeto (duas chatas em paralelo, $\mathrm{H}=1,6 \mathrm{~m} \mathrm{e} \mathrm{h=5} \mathrm{m}$ ) e identificados da seguinte forma: 
"Ajuste"- hélice projetado para as condições atuais, com os coeficientes propulsivos obtidos na análise dos dados das medições,

"Novo B" - hélice da série B-Troost, mantidos os motores e redutores, mas diminuindo o diâmetro a fim de melhorar os coeficientes propulsivos (estes foram estimados através de formulação do item 3.3.2.).

"Novo K" - semelhante ao hélice "Novo B", porém, da série Kaplan, com duto NSMB 37.

A Tabela 15 mostra os principais resultados obtidos nos três projetos, com comparações com o hélice atual.

Tabela 15 - Comparações Entre Valores Medidos e os Esperados por Três Novos Projetos. Condição: Duas Chatas em Paralelo. $\mathrm{H}=1,6 \mathrm{~m} . \mathrm{h}=5 \mathrm{~m}, \mathrm{P}_{\mathrm{B}}=224 \mathrm{~kW}, \mathrm{n}=1800 \mathrm{rpm}$, Relação de Redução 3,13 : 1.

\begin{tabular}{|l|c|c|c|c|c|c|c|c|c|c|}
\cline { 2 - 9 } \multicolumn{1}{c|}{} & $\begin{array}{c}\mathrm{V} \\
(\mathrm{m} / \mathrm{s})\end{array}$ & $\omega$ & $\mathrm{t}$ & $\mathrm{J}$ & $\begin{array}{c}\eta_{\mathrm{O}} \\
(\%)\end{array}$ & $\begin{array}{c}\eta_{\mathrm{D}} \\
(\%)\end{array}$ & $\begin{array}{c}\mathrm{N} \\
\text { motor } \\
(\mathrm{rpm})\end{array}$ & $\mathrm{D} \quad(\mathrm{m})$ & Ae/Ao & $\mathrm{P} / \mathrm{D}$ \\
\hline $\begin{array}{l}\text { MEDIDO } \\
6^{\mathrm{a}} \text { viagem }\end{array}$ & 3,5 & 0,210 & 0,500 & 0,241 & 37,6 & 23,8 & 1.912 & 1,15 & 0,50 & 0,55 \\
\hline “AJUSTE” & 3,5 & 0,210 & 0,500 & 0,248 & 37,9 & 24,0 & 1.800 & 1,15 & 0,50 & 0,59 \\
\hline “NOVO B" & 3,75 & 0,298 & 0,298 & 0,288 & 31,4 & 31,4 & 1.800 & 0,95 & 0,95 & 0,91 \\
\hline “NOVO K" & 4,0 & 0,298 & 0,298 & 0,255 & 33,3 & 31,9 & 1.800 & 0,95 & 0.95 & 1,07 \\
\hline
\end{tabular}

A Figura 46 mostra os resultados de (V x n) esperados com os três hélices projetados e os resultados das medições na sexta e na oitava viagens para a condição escolhida como de projeto.

A Tabela 16 mostra os resultados dos três novos projetos na condição de tração estática ("bollard-pull"). 


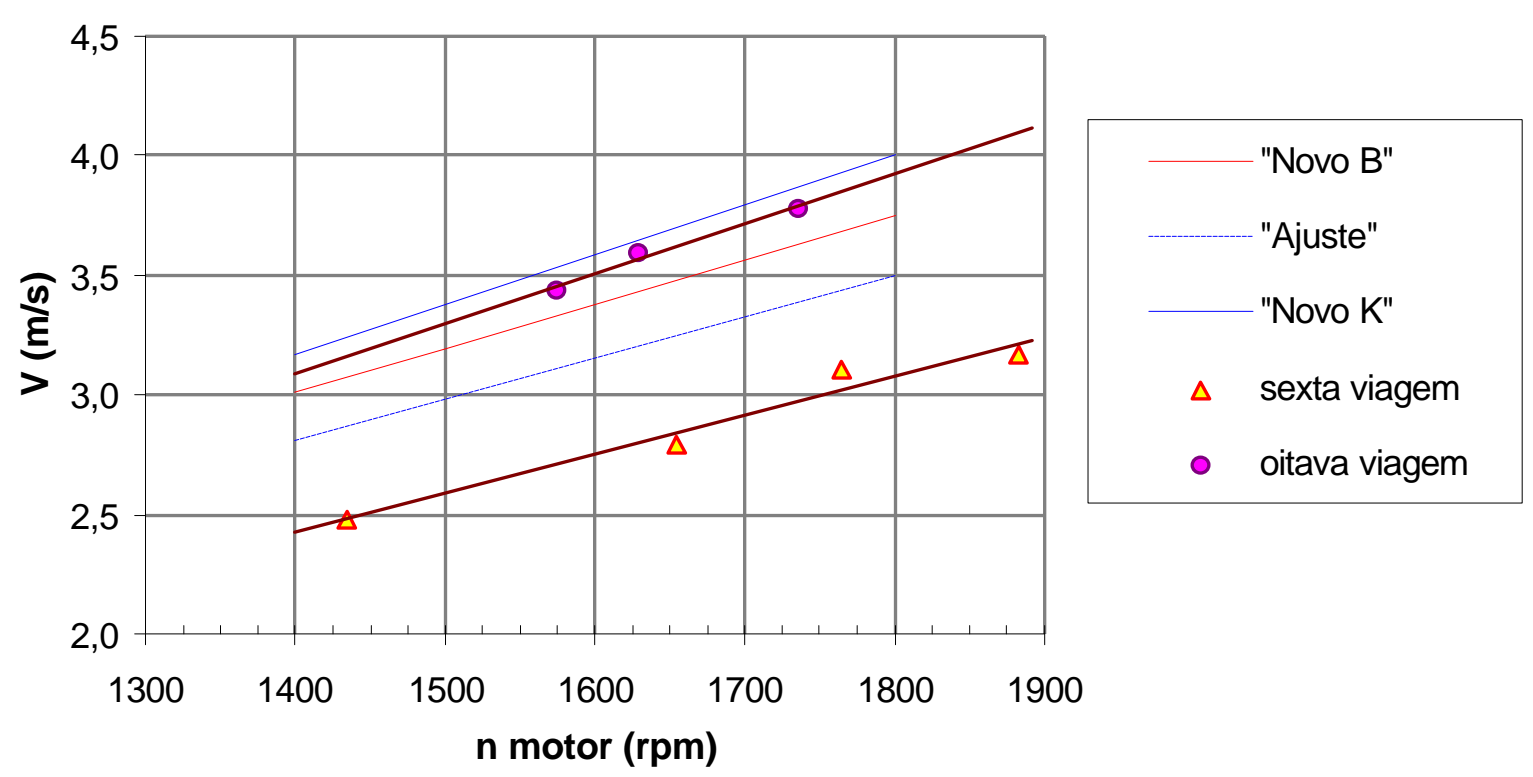

Figura 46 - Valores de Velocidades em Função do Número de Rotações dos Motores $n$. Comparações dos Resultados Medidos para a Condição de Duas Chatas em Paralelo $\mathrm{H}=1,6$ m, com Aqueles Esperados nos Três Projetos.

Tabela 16 - Comparações Entre Valores Medidos e Esperados na Condição de Tração Estática ("Bollard-Pull").

\begin{tabular}{|c|c|c|c|c|c|c|}
\hline & $\begin{array}{c}\mathrm{K}_{\mathrm{Q}} \\
\text { em } \mathrm{J}=0\end{array}$ & $\begin{array}{c}\mathrm{K}_{\mathrm{T}} \\
\text { em } \mathrm{J}=0\end{array}$ & t $\mathrm{J}=0^{\mathrm{em}}$ & $\begin{array}{c}N \text { motor } \\
\text { (rpm) }\end{array}$ & $\begin{array}{c}\mathrm{T} \\
(\mathrm{MN})\end{array}$ & $\begin{array}{c}\text { Força de } \\
\text { Tração (MN) }\end{array}$ \\
\hline MEDIDO & 0,0203 & 0,224 & 0,05 & 1.736 & 33,4 & 63,5 \\
\hline “AJUSTE” & 0,0219 & 0,241 & 0,05 & 1.672 & 33,3 & 63,3 \\
\hline ““NOVO B”" & 0,0614 & 0,442 & 0,05 & 1.610 & 26,4 & 50,1 \\
\hline “NOVO K” & 0,0509 & 0,506 & 0,05 & 1.768 & 36,4 & 69,2 \\
\hline
\end{tabular}

Os resultados das comparações dos três projetos de hélices com aqueles obtidos nas medições em escala real (Tabelas 15 e 16 e Figura 46) serão explicitados a seguir.

a) Pequenas mudanças de passos implicam em alterações significativas de desempenho. Como pode ser visto pelas comparações entre os resultados "medidos" e do hélice "Ajuste". O acréscimo de razão de passo P/D de 0,55 para 0,59, correspondendo a 7,3 \%, resulta em cerca de $14 \%$ de aumento de potência e de $10 \%$ de aumento de empuxo, em uma mesmo coeficiente de avanço J. O passo do hélice "Ajuste" permitiria que a velocidade de $3,5 \mathrm{~m} / \mathrm{s}$ fosse alcançada na condição de potência máxima contínua dos motores (224 kW a $1800 \mathrm{rpm})$. 
b) A diminuição dos diâmetros dos hélices nos projetos "Novo B" e "Novo K" tem a finalidade de diminuir a influência da proximidade da popa sobre os hélices. Considerou-se que aumentando a distância entre hélices e casco, os coeficientes propulsivos seriam melhorados. No caso, adotou-se os coeficientes calculados com as formulações do item 3.3.2.

c) A diminuição dos diâmetros dos hélices leva ao aumento do carregamento $\mathrm{C}_{\mathrm{TH}}$, o que obriga um aumento da área das pás, como forma de evitar cavitação excessiva. Para se chegar a esta área mínima necessária foi utilizado o diagrama de Burril (item 3.5).

d) Comparando-se os hélices "Ajuste" e "Novo B", ambos da série B-Troost, nota-se que a diminuição do diâmetro tende a levar a uma menor eficiência em água aberta $\eta_{\mathrm{o}}$. Contudo, a diferença em $\eta_{\mathrm{O}}$ é compensada, com vantagens, pela melhoria da eficiência propulsiva $\eta_{\mathrm{D}}$, resultante do aumento de eficiência do casco $\eta_{H}=(1-t) /(1-\omega)$.

e) Como esperado após a elaboração das Figuras 31 e 33 do Capítulo 3, para as condições de alto carregamento das pás, a variação do número de rotações de projeto dos hélices B-Troost não leva a grandes diferenças de eficiência $\eta_{\mathrm{O}}$, enquanto que para a série Kaplan podem ocorrer diferenças significativas. A fim de facilitar as comparações, optou-se por manter a mesma relação de redução de rotações nos novos projetos.

f) A comparação dos hélices "Novo B”, da série B-Troost, com o hélice "Novo K”, da série Kaplan, evidencia uma vantagem sensível da utilização dos hélices em dutos em embarcações fluviais. A vantagem dos hélices em dutos é mais clara ainda quando são comparados os desempenhos em tração estática ("bollard-pull”), na Tabela 16. Deve ser observado que, no ponto do hélice "Novo K”, foi levada em conta a porcentagem do perímetro do duto junto ao casco (considerada como $20 \%$ devida à diminuição do diâmetro).

g) Os três projetos foram feitos para a potência máxima contínua de $224 \mathrm{~kW}$ fosse exigida do motor a $1800 \mathrm{rpm}$, na formação de duas chatas em paralelo, com calados de 1,60 m, e canal com profundidade de $5 \mathrm{~m}$ e largura de $300 \mathrm{~m}$. Adotou-se uma margem sobre a potência efetiva do casco, estimada por Howe (item 3.3.1) de $20 \%$, a fim de levar em consideração os acréscimos de $\mathrm{P}_{\mathrm{E}}$ devidos às estruturas de proteções contra choques, à rugosidade dos cascos e aos efeitos dos parâmetros ambientais como variações de profundidades e larguras de canais, ventos e pequenas ondas. 


\subsection{ENSAIOS EM ÁGUAS PROFUNDAS EM TANQUE DE PROVAS}

As Figuras 47, 48 e 49 mostram os valores medidos de $P_{D}$ em várias viagens do Comboio com hélices convencionais B-Troost, comparados com os resultados medidos com modelo em escala 1:13 no Tanque de Provas do IPT, em águas profundas $(\mathrm{h} / \mathrm{H}=30)$, nas três formações de comboios. Estes resultados indicam que a realização de ensaios de embarcações fluviais em águas profundas, por si só, trazem poucas informações sobre as potências $\mathrm{P}_{\mathrm{E}}$ e $\mathrm{P}_{\mathrm{D}}$ reais em águas rasas.

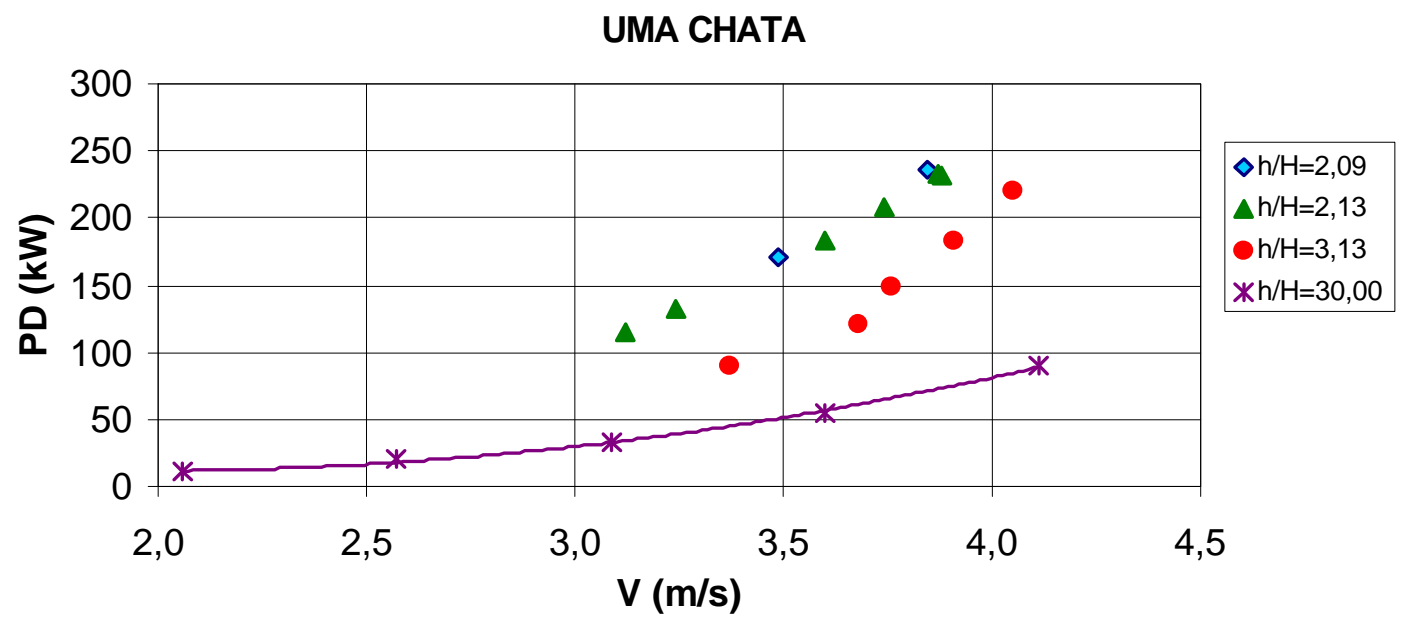

Figura 47 - Comparações de Potências Medidas em Escala Real e em Tanque de Provas. Uma Chata. Hélices B-Troost.

\section{DUAS CHATAS EM LINHA}

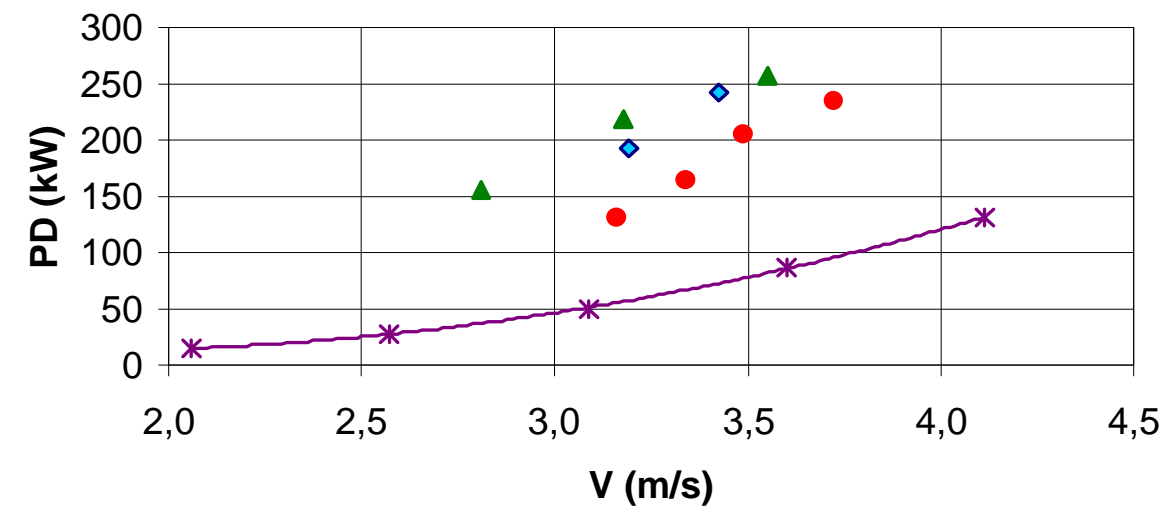

Figura 48 - Comparações de Potências Medidas em Escala Real e em Tanque de Provas. Duas Chatas em Linha. Hélices B-Troost. 
DUAS CHATAS EM PARALELO

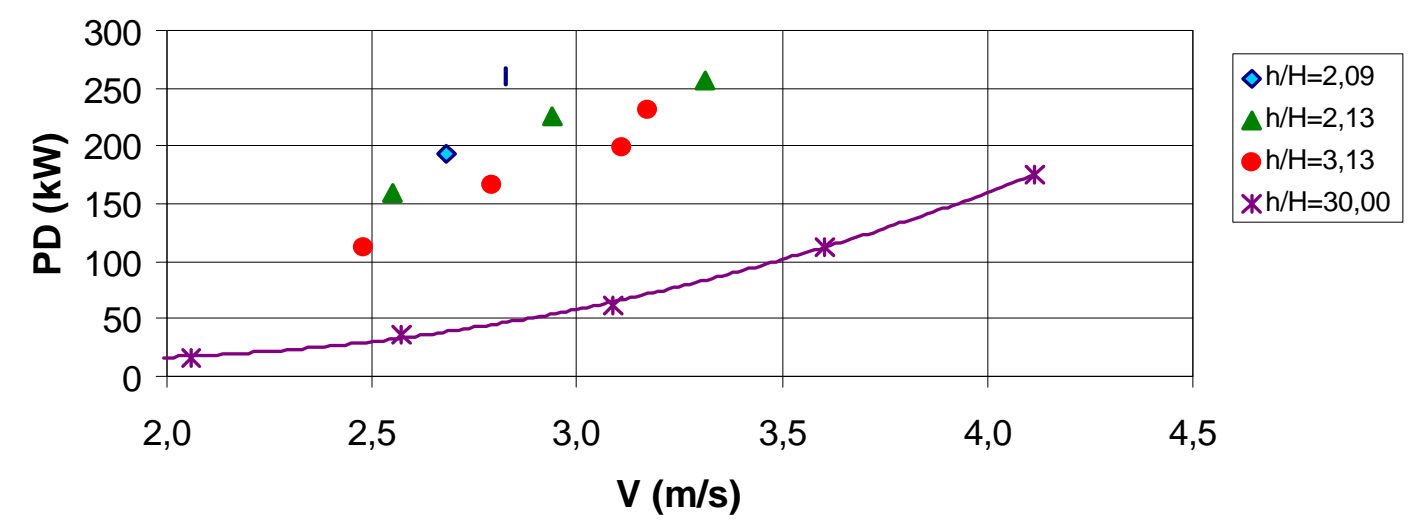

Figura 49 - Comparações de Potências Medidas em Escala Real e em Tanque de Provas. Duas Chatas em Paralelo. Hélices B-Troost.

O ideal seria realizar ensaios com modelos de embarcações fluviais em escala reduzida em águas rasas. Os ensaios em água rasa poderiam, então, possibilitar estimativas de resistências ao avanço com boa precisão.

No entanto, como verificado em comparações com ensaios com modelos em alguns tanques de provas internacionais, as previsões dos valores de coeficientes propulsivos de embarcações fluviais em escala real ainda apresentariam sérios problemas de extrapolações. Vem reforçar este aspecto, as grandes diferenças obtidas de coeficientes propulsivos, principalmente de coeficiente de redução da força propulsora t, para modelo (em águas profundas) e em escala real do Comboio de Pesquisas do Araguaia. Os resultados dos estudos existentes ([1], [2], [3], [5], [21], [33]) não indicam que as grandes diferenças obtidas de t possam ser creditadas ao fato de o modelo ter sido ensaiado em águas profundas. Outra questão digna de nota é que nos ensaios com modelos não foram verificados os problemas de afundamentos da proa apresentados pelo empurrador em escala real.

Ao final da análise dos dados dos ensaios com o comboio Araguaia, fica a certeza que os estudos futuros, tantos os experimentais com modelos e em escala real como os teóricos, devem se aprofundar no entendimento dos coeficientes propulsivos de embarcações fluviais, principalmente levando em conta a operação em águas rasas. 


\section{CONTRIBUIÇÕES PARA O PROJETO DE HÉLICES DE EMBARCAÇÕES FLUVIAIS}

O projeto de um hélice é, basicamente, a definição de uma geometria adequada para ser instalada junto à popa de uma embarcação, para operar o mais eficientemente possível em determinadas condições. A geometria do hélice deve ser tal que consiga absorver a potência disponível proveniente do motor e transformá-la em força de empuxo para impulsionar a embarcação. A partir desta visão, o projeto do hélice pode ser resumido em quatro etapas principais, que se inserem dentro de um processo iterativo:
A. definição das condições de projeto,
B. estudo das características do casco e sua interação com o hélice,
C. definição das características geométricas do hélice,
D. verificação da integração entre casco, hélice e motor.

A avaliação atualmente existente é que há lacunas que devem ser preenchidas para que os projetos de hélices de embarcações fluviais sejam realizados com melhor embasamento e eficiência. Desta forma, à luz dos resultados de ensaios em escala real apresentados e analisados neste estudo, serão descritos alguns pontos considerados importantes.

\subsection{ESCOLHA DO PONTO DE PROJETO DO PROPULSOR}

A forma com que o projeto de hélices de passos fixos de embarcações fluviais tem sido realizado é ainda muito pouco eficiente e precária. Ou simplesmente projeta-se os hélices para a condição de carregamento extremo que é a tração estática ("bollard-pull”), onde a velocidade da embarcação é zero e o empuxo o máximo possível, ou projeta-se para otimização em um deslocamento e uma velocidade de cruzeiro escolhidos, sem conhecimento pleno de todas as variáveis envolvidas na operação do hélice junto ao casco da embarcação.

A condição de projeto em tração estática é tentadora quando não se tem conhecimento dos características hidrodinâmicas da embarcação, pois é praticamente independente delas, e quando se deseja preservar o motor de problemas gerados por sobrecargas de potência, já que representa o ponto extremo de seu funcionamento, ficando as demais condições operacionais da embarcação 
aquém dos limites de potências. Com hélices projetados em tração estática, a eficiência do sistema propulsivo é adequada para operação da embarcação em velocidades baixas; contudo, esta condição de projeto é prejudicial ao desempenho da embarcação em velocidades de cruzeiro, geralmente resultando em ângulos de passos das pás dos hélices menores que os necessários, e, conseqüentemente, em menores potências absorvidas, apesar de disponíveis nos motores. Por outro lado, se os hélices são projetados para a condição de deslocamento mais leve da embarcação, o hélice poderá ficar com razão passo/diâmetro alta, tornando-se inconveniente para operação em baixas velocidades.

O ideal é projetar o hélice para determinada velocidade e deslocamento que representem a média ponderada das condições operacionais da embarcação. Por exemplo, se um empurrador opera metade do tempo com quatro chatas e metade com duas chatas, deve ser estudada uma condição de projeto intermediária entre estas duas situações, levando-se em consideração as profundidades médias de cada trecho dos percursos.

\subsection{ESTIMATIVAS DE RESISTÊNCIA AO AVANÇO E DE COEFICIENTES PROPULSIVOS}

A compreensão da resistência ao avanço de embarcações fluviais, que têm formas peculiares e simplificadas - geralmente fundos chatos, baixos calados e seções transversais quase retangulares e o seu equacionamento, de forma a haver segurança em fazer estimativas de valores de potências efetivas dos cascos em várias profundidades e larguras de canais de navegação, é um primeiro desafio. Logicamente, o caminho mais indicado é a utilização de ensaios em tanques de provas, de preferência em águas rasas, e a aplicação de métodos corretos de extrapolações para escala real; contudo, a realização de ensaios nem sempre é possível, dado o seu custo relativamente alto. Outra alternativa é a adoção de métodos de estimativas baseados em resultados experimentais e teóricos, que apresentem, comprovadamente, resultados consistentes.

A formulação de Howe [10], cuja forma foi adaptada aos comboios fluviais de uma e de duas chatas no presente trabalho, mostrou uma consistência que a credencia como ferramenta auxiliar do projeto e da análise de desempenho de sistemas propulsivos de embarcações fluviais.

Por outro lado, como já visto no Capítulo 4, as estimativas de coeficientes propulsivos carecem ainda de estudos mais apurados, principalmente com confirmações com ensaios em escala 
real, que levem em conta as formas das popas, os diâmetros dos hélices e as restrições dos canais de navegação.

\subsection{DEFINIÇÃO DA GEOMETRIA MAIS APROPRIADA DOS HÉLICES}

A geometria do hélice é definida pelas características: diâmetro, área das pás, número de pás, ângulos de passos, perfis das seções ou distribuição de espessuras ao longo das cordas, distribuições de espessuras máximas das pás e diâmetro do bosso. Cada uma delas tem sua importância dentro do projeto, a qual deve ser verificada à luz das particularidades apresentadas por hélices com altos carregamentos de pás aplicados a embarcações fluviais.

A premissa que se tem que partir na escolha da geometria dos hélices de embarcações fluviais é que a sua operação é, quase sempre, com alto carregamento das pás. E este fato deve alterar a maior parte das concepções referentes a hélices moderadamente carregados, ou seja, de embarcações convencionais.

No caso do projeto de hélices não carregados, por exemplo, há uma tendência de buscar o maior diâmetro e a menor área das pás, para que a eficiência em água aberta seja a maior possível.

Em hélices carregados, grandes alterações das áreas das pás não implicam em diferenças significativas de eficiências, como visto na Tabela 8 do item 3.7.3, e, portanto, a escolha da razão de área das pás passa ser apenas em função da garantia de não cavitação excessiva. A cavitação em hélices carregados, que operam sempre em velocidades relativamente baixas, não tem apresentado problemas sérios relacionados com erosão e com vibrações, o que pode levar à conclusão que a utilização do diagrama de Burril (item 3.5.) para indicação da área de pá mínima para determinado hélice não apresentar cavitação excessiva é suficiente para o seu projeto. A área coberta por cavitação no dorso das pás dos hélices deve ser, por garantia, no máximo de $10 \%$ da área total.

Em embarcações fluviais, os diâmetros sempre são limitados pelas restrições de calados. A visão, contudo, relacionada com a forma de projeto de hélices não carregados, faz com que até sejam adotados túneis de popa, para permitir o alojamento de diâmetros maiores. Este procedimento, contudo, se pode garantir uma eficiência em água aberta levemente maior por resultar em um diâmetro maior, cria problemas de várias ordens, inclusive com perda de eficiência do casco. Tal perda pode vir a ser maior que o ganho em eficiência em água aberta. No Capítulo 4 foi mostrado 
que a diminuição de diâmetro dos hélices pode ser vantajosa, apesar de resultar em eficiência em água aberta (só o hélice, sem o casco) menor.

As embarcações fluviais operam em certos períodos à ré, devido à realização de manobras de acostagens, de formações de comboios e para ultrapassagens de pontos críticos das vias. Para que as eficiências à ré dos hélices não sejam muito menores que as eficiências a vante, os hélices de embarcações fluviais devem ter uma certa simetria. Pelo menos, deve ser evitada a utilização de caimento ("rake") e de assimetria do contorno das pás ("skew"). No caso de embarcações convencionais, o "skew" é praticamente indispensável, dada a sua contribuição na diminuição dos níveis de vibrações induzidas pelos propulsores em operação em regiões de esteiras não-uniformes. Em embarcações fluviais, contudo, a desvantagem de utilização do "skew" nos hélices, pela diminuição de eficiência à ré, é maior que o possível ganho em diminuição de vibrações.

Em algumas hidrovias, como a do rio Araguaia, há sempre grande probabilidade de choques de pedras e pedaços de troncos com as pás dos hélices. O parâmetro geométrico que pode fazer frente a esta questão é a espessura máxima de cada seção, que, se aumentada, garante maior resistência estrutural, diminuindo a probabilidade de ocorrências de danos nas pás. Desta forma, para os hélices de embarcações que operam em hidrovias com altas chances de choques em hélices, recomenda-se aumentar as espessuras das pás, de forma mais acentuada nas pontas, que sempre estão mais expostas e apresentam maiores velocidades angulares. A avaliação dos efeitos dos acréscimos de espessuras sobre o desempenho hidrodinâmico dos hélices deve ser feita a partir de experimentos e resultados obtidos em referências bibliográficas, como, por exemplo, em [38] e [42].

A experiência no rio Araguaia demostrou que as pás relativamente finas, com espessuras obtidas das séries sistemáticas, sem acréscimos, mostraram-se muito suscetíveis a deformações após choques com pequenos objetos em suspensão na água.

Com relação ao número de pás dos hélices, a operação do empurrador do comboio Araguaia não apresentou problemas sérios de vibrações induzidas pelos propulsores. As vibrações aconteciam quando havia desbalanceamentos (principalmente hidrodinâmicos) decorrentes de deformações da geometria das pás dos hélices após choques com pedras ou pedaços de troncos. Neste sentido, considera-se que a escolha de quatro pás para os hélices é plenamente justificada pelas razões já citadas anteriormente (maiores facilidades de construção e balanceamentos, bom desempenho). A escolha de outro número de pás (cinco, por exemplo) pode ser necessária se, com quatro pás, houver coincidências da freqüência de excitação Z.n com as freqüências de ressonâncias do casco ou do sistema de propulsão. Por exemplo, se a relação de redução de rotações for 4 : 1, tem sido 
recomendado que seja evitado $\mathrm{Z}=4$ pois a frequiência de passagem das pás junto ao casco Z.n estará coincidindo com a freqüência ligada à rotação do próprio motor.

\subsection{RESUMO DOS PROBLEMAS DE PROPULSORES DE EMBARCAÇÕES FLUVIAIS}

A Tabela 17 apresenta um resumo dos problemas típicos de propulsores de embarcações fluviais, já referidos neste documento.

As soluções de tais problemas devem sempre levar em conta a especificidade dos hélices de embarcações fluviais, como, por exemplo:

- O problema da baixa eficiência do sistema propulsivo destas embarcações, praticamente inevitável por conta do alto carregamento das pás, pode piorar muito se as linhas da popa e os sistemas auxiliares de manobras e de proteção contra choques levarem a um comprometimento dos coeficientes propulsivos, refletidos em baixos valores de eficiência do casco $\eta_{H}$. No presente caso, o comboio Araguaia apresentou baixos valores de $\eta_{H}$ provavelmente devido à utilização de túneis na popa. Uma popa com linhas mais convencionais aliada à adoção de menores diâmetros dos hélices poderia resultar em eficiência propulsiva maior que as obtidas com túneis e diâmetros praticamente iguais ao calado do empurrador.

- A questão da utilização de hélices em dutos, se é praticamente resolvida no caso de rebocadores portuários e embarcações marítimas de apoio, devido às maiores eficiências apresentadas em velocidades relativamente baixas, pode sofrer algum questionamento em se tratando de certos empurradores fluviais. Por exemplo, se os calados são muito reduzidos, a instalação de dutos nos cascos (com parte, inclusive, "dentro" do casco) pode não ser tão vantajosa em termos de eficiências resultantes. 
Tabela 17 - Resumo dos Problemas Típicos de Hélices de Embarcações Fluviais e Soluções Possíveis

\begin{tabular}{|l|l|}
\hline PROBLEMA & SOLUÇÕES POSSÍVEIS \\
\hline
\end{tabular}

\begin{tabular}{|l|l|}
\hline \multirow{4}{*}{ CHOQUES COM HÉLICES } & ESTRUTURAS DE PROTEÇÃO \\
\cline { 2 - 3 } & FORMAS DE POPAS \\
\cline { 2 - 3 } & $\begin{array}{c}\text { GEOMETRIA DOS HÉLICES } \\
\bullet \quad \text { diâmetro } \\
\bullet \quad \text { espessuras das pás }\end{array}$ \\
\cline { 2 - 2 } & MATERIAL DAS PÁS \\
\hline
\end{tabular}

\begin{tabular}{|l|l|}
\hline VARIAÇÕES DAS & PROJETO DOS HÉLICES EM \\
CONDIÇÕES DE OPERAÇÃO & CONDIÇÃO MÉDIA PONDERADA \\
\hline
\end{tabular}

\begin{tabular}{|l|l|}
\hline BAIXAS EFICIÊNCIAS & PROJETO INTEGRADO POPA x HÉLICES \\
\hline
\end{tabular}

\begin{tabular}{|l|l|}
\hline UTILIZAR DUTO OU NÃO ? & CONHECER PARTICULARIDADES \\
& (VANTAGENS / DESVANTAGENS) \\
& TENDÊNCIA GERAL: UTILIZAR DUTOS \\
\hline
\end{tabular}

\begin{tabular}{|l|l|}
\hline CAVITAÇÃOO & ÁREA ADEQUADA DAS PÁS \\
\cline { 2 - 2 } & $\begin{array}{l}\text { EVITAR DESCONTINUIDADES } \\
\text { GEOMÉTRICAS }\end{array}$ \\
\hline
\end{tabular}

\begin{tabular}{|l|l|}
\hline \multirow{2}{*}{ VIBRAÇÃO } & NÚMERO DE PÁS / ROTAÇÕES \\
\cline { 2 - 2 } & CLARAS DOS HÉLICES \\
\cline { 2 - 2 } & BALANCEAMENTOS \\
\hline
\end{tabular}




\section{CONCLUSÕES}

As principais conclusões da análise das medições de desempenho propulsivo do Comboio de Pesquisas do Araguaia, são relatadas a seguir.

- A formulação de Howe apresentada neste estudo, com adaptações às dimensões e formações do comboio Araguaia, mostrou-se apropriada para utilização na previsão de resistências ao avanço de comboios fluviais com pequeno número de chatas.

- Os coeficientes propulsivos variam significativamente com as alterações da formação do comboio e com as mudanças de calados médios. Há necessidade, ainda, de estudos mais apurados relacionados com a obtenção de valores de coeficientes propulsivos para embarcações fluviais nas suas várias condições operacionais, incluindo os efeitos de águas rasas. A relação dos coeficientes propulsivos com as diferentes formas de popas também deve ser investigada profundamente.

- Tão importante quanto o projeto adequado dos hélices, é a definição das formas da popa do empurrador. No caso do empurrador do comboio Araguaia, por exemplo, as formas da saída dos túneis de popa chegaram a comprometer o desempenho propulsivo, resultando em forças verticais que tendiam emergir a popa e imergir a proa do empurrador.

- A condição de projeto do hélice deve ser escolhida, de preferência, fazendo-se uma média ponderada (em função do tempo) de todas as condições de operação do comboio;

- É, na maior parte dos casos, vantajosa a adoção de hélices em dutos (tubos Kort) em embarcações fluviais de cargas, pois possibilita maiores empuxos a baixos coeficientes de avanço, garantindo bom desempenho em tração estática ("bollard-pull”) e em velocidades de cruzeiro. As maiores desvantagens (certa porcentagem do duto pode não contribuir com empuxo devido a proximidade do casco e exigência de cuidados redobrados em não permitir choques das pás com pedaços de troncos) são de importância relativamente menor.

- O projeto de hélices para a condição de tração estática não é recomendável para as embarcações fluviais, pois tem como conseqüência a limitação da razão passo/diâmetro, implicando em sub-utilização das potências disponíveis dos motores quando em condições normais de operação a vante. A obtenção de grandes forças de tração estática, para 
aumentar a segurança e a manobrabilidade com a embarcação em velocidade zero, pode ser garantida pela adoção de hélices em dutos.

- A freqüência de choques dos hélices com troncos e pedras é relativamente alta, introduzindo alterações geométricas nas pás, provocando perdas de eficiências, vibrações e aumento de cavitação. Desta forma, passa a ser inevitável a utilização de estruturas de proteção contra choques nos empurradores que operam em locais como o rio Araguaia.

- A geometria adequada das pás dos hélices de embarcações fluviais de cargas deve possuir: $\Rightarrow$ contorno simétrico das pás (ou seja, sem "skew") e não utilização de caimento ("rake"), a fim de possibilitar maior eficiência em operação à ré;

$\Rightarrow$ diâmetros que permitam a instalação dos hélices nas popas sem problemas - é preferível operar com hélices de menores diâmetros (eficiências $\eta_{0}$ um pouco menores) do que correr riscos de comprometer a eficiência do casco $\eta_{\mathrm{H}}$, cujos efeitos sobre a eficiência propulsiva $\eta_{D}$ tendem a ser mais determinantes;

$\Rightarrow$ áreas de pás suficientes para haver garantia de não ocorrência de cavitação excessiva, a partir da constatação que, com altos carregamentos $\mathrm{C}_{\mathrm{TH}}$, as diferenças de eficiências de hélices de diferentes razões de áreas expandidas não são muito significativas - o diagrama de Burril, exaustivamente testado e utilizado no mundo inteiro, apresenta confiabilidade suficiente para obtenção das áreas necessárias aos hélices de embarcações fluviais de cargas;

$\Rightarrow$ possível aumento das espessuras máximas das seções das pás, de uma forma mais localizada nas pontas, tomando como base a experiência acumulada em embarcações quebra-gelo, para que as pás possam resistir a choques com uma certa intensidade, evitando distorções nas formas das pás.

O presente estudo cumpriu uma tarefa importante de apresentar as informações obtidas em medições em escala real em um comboio fluvial com características próximas daquelas da maioria dos comboios das hidrovias brasileiras. Foi elaborada uma análise dos dados a partir de procedimentos colhidos em referências bibliográficas, que possibilitou indicar ou sugerir formas de melhorar o projeto de hélices de embarcações fluviais. 
Foram indicadas formulações para estimativas de resistências ao avanço, de coeficientes propulsivos, de quantidade de cavitação nas pás, assim como houve uma série de reflexões sobre os parâmetros geométricos mais adequados para os hélices de alto carregamento.

A busca de um melhor procedimento de projeto de propulsores de embarcações fluviais também mostrou, neste estudo, a necessidade de realçar a importância da melhoria das formas das popas dos empurradores, evitando soluções que introduzam riscos de comprometimento do rendimento global do sistema propulsivo. Neste sentido, conclui-se que os túneis de popa só devem ser adotados em último caso, quando não houver solução possível para o projeto dos hélices. $\mathrm{Na}$ maior parte das vezes, há soluções satisfatórias aumentando o número de hélices e diminuindo os diâmetros (com aumentos do número de rotações e das áreas das pás, para compensar). No caso do empurrador do comboio Araguaia ficou comprovado que poderia ser evitada a utilização dos túneis.

Finalmente, cabe ressaltar que a realização de um estudo de propulsores, a partir dos dados acumulados de ensaios com o comboio Araguaia, mostrou-se útil, pela quantidade de informações e pelas recomendações de procedimentos, para o desenvolvimento do projeto de hélices e da análise do desempenho propulsivo de embarcações fluviais. 


\section{REFERÊNCIAS BIBLIOGRÁFICAS}

1. BASIN, A. M. "Influence of Shallow Water on the Hull-Propeller Interaction of Passenger Vessels". In: Basin, A.M. et alli,, Ship Hydrodynamics in Shallow Waters, Sudostroeniye, Leningrad. 1976, pp. 150-163. English translation: LATORRE \& DÜNOW [29].

2. BASIN, A. M. \& MINIOVICH, I. Y. "Empirical Formulas for Estimating the Wake Fraction and Thrust Deduction Factors for Ocean and Inland Waterway Vessels". In: Basin, A.M. et alli,, Theory of Design of Screw Propellers, Sudostroeniye, Leningrad. 1963, pp. 143-148. English translation: LATORRE et alli. [31].

3. BINEK, H. \& MÜLLER, E. "Propulsionsversuche mit Schubverbänden auf Begrenzter Wassertiefe". Schiff \& Hafen, vol. 30, no. 11, Jan. 1978. "Ensaios de Propulsão com Comboios de Chatas em Profundidade Restrita". Tradução de Letícia P. Rocco, IPT/DITT (inédita), Agosto 1993.

4. BLOUNT, D.L. \& FOX, D.L. "Design Considerations for Propellers in a Cavitating Environment". Marine Technology, vol. 15 , no. 2, April 1978, pp. 144-178.

5. BOGDANOV, B. V. "Towing Vessel Hull Form Coefficients". In: Bogdanov et alli., Towing Vessels, Design and Construction. Sudostroeniye, Leningrad. 1974, pp. 118-132. English translation: LATORRE \& DÜNOW [29].

6. BRESLIN, J. P. \& ANDERSEN, P. "Hydrodynamics of Ship Propellers". Cambridge Ocean Technology Series 3, Cambridge University Press, 1994, 559 pages, Cambridge, USA.

7. BRESLIN, J. P. et alli. "Theoretical and Experimental Propeller-Induced Hull Pressures Arising from Intermittent Blade Cavitation, Loading and Thickness". Transactions of Society of Naval and Marine Engineering - SNAME. vol. 90, 1982, pp. 111-151.

8. BROCKETT et alli. "Design Theory for Marine Propellers" Cambridge MIT Course on Design Theory for Propellers - Lecture Notes, June 1981.

9. BURRIL, L.C. "The Optimum Diameter of Marine Propellers: a New Approach". Transactions of North East Coast Institution of Engineers and Shipbuilders - NECIES, vol. 72, 1955-1956, pp. 57-82.

10. CHRISTOPOUlOS, B \& LATORRE, R. "River Towboat Hull and Propulsion". Marine Technology, SNAME, vol. 20, no. 3, July 1983, pp. 209-226.

11. CHRISTOPOULOS, B \& LATORRE, R. "Design and Trials of a New River Towboat Propeller”. Marine Technology, vol. 28, no. 4, July 1991, pp. 236-246.

12. COX, G.G. \& MORGAN, Wm. B. "The Use of Theory in Propeller Design". Marine Technology, SNAME, vol. 8, no. 4, October, 1972, pp. 419-429.

13. DYNE, G. "On The Efficiency of a Propeller in Uniform Flow". Transactions of the Royal Institution of Naval Architects - RINA. vol. 136, 1994, pp. 105-129.

14. DYNE, G. "The Principles of Propulsion Optimization". Transactions of the Royal Institution of Naval Architects - RINA. vol. 137, 1995, pp. 189-208.

15. ENGLISH, J. W. "One-Dimensional Ducted Propeller Theory. Influence of Tip Clearance on Performance”. National Physical Laboratory - Ship Division, Ship Report 94, May 1967. 
16. GENT, W. Van "Derivation of Propeller Section Properties from Lifting Surface Theory". International Shipbuilding Progress, vol. 27, no. 314, July 1980, pp. 257-267.

17. GENT, W. Van \& OOSTERVELD, W. C. “ Ducted Propeller Systems and Energy Saving”. International Symposium on Ship Hydrodynamics and Energy Saving. El Pardo, September 6-9, 1983. Paper No. VI-3, 19 pages.

18. GENT, W.Van "On the Use of Lifting Surface Theory for Moderately and Heavily Loaded Ship-Propellers". Netherlands Ship Model Basin, Publication 536, 1979, 89 pages.

19. GÓMES, G. P. et alli. "Some Improvements of Traditional Lifting Line Theory for Ship Propellers". International Shipbuilding Progress, vol. 27, no. 311, July 1980, pp. 154-175.

20. GRIGSON, C. "Screws Working in Behind and Prediction of the Performance of Full Ships". Journal of Ship Research, vol. 34, no. 4, December 1990, pp. 262-282.

21. HARVALD, S. A. "Wake and Thrust Deduction at Extreme Propeller Loadings for a Ship Running in Shallow Water". Transactions of the Royal Institution of Naval Architects. vol. 118, 1976, pp. 213-233.

22. INSTITUTO DE PESQUISAS TECNOLÓGICAS DO ESTADO DE SÃO PAULO “Comboio de Pesquisas do Rio Araguaia: Análise do Desempenho Propulsivo e de Manobras. Sexta Viagem”. IPT/ Divisão de Tecnologia de Transportes. Relatório Técnico no. 29.925. Abril, 1992.

23. INSTITUTO DE PESQUISAS TECNOLÓGICAS DO ESTADO DE SÃO PAULO “Análise dos Resultados dos Ensaios de Desempenho Propulsivo com Modelos do Comboio de Pesquisas do Rio Araguaia - Correlação com os Resultados em Escala Real”. IPT/ Divisão de Tecnologia de Transportes. Relatório Técnico no. 31.237. Abril, 1993.

24. INSTITUTO DE PESQUISAS TECNOLÓGICAS DO ESTADO DE SÃO PAULO “Comboio de Pesquisas do Rio Araguaia: Análise do Desempenho Propulsivo e de Manobras. Oitava Viagem”. IPT/ Divisão de Tecnologia de Transportes. Relatório Técnico no. 31.468. Junho, 1993.

25. INTERNATIONAL TOWING TANK CONFERENCE, 14 $4^{\text {st }}$. Proceedings of Performance Committee - Appendix 6 - "Scale Effects on Propulsion Factors", by K. J. MINSAAS et alli. Ottawa, Canada, September 1975.

26. INTERNATIONAL TOWING TANK CONFERENCE, $15^{\text {st }}$. Proceedings of Performance Committee. Hague, Netherlands, September 3-10, 1978.

27. INTERNATIONAL TOWING TANK CONFERENCE, $21^{\text {st }}$. Proceedings of the Resistance and Flow Committee, Trondheim, Norway, September 15-21, 1996.

28. KINNAS, S.A. "A General Theory for the Coupling Between Thickness and Loading for Wings and Propellers". Journal of Ship Research, vol. 36, no. 1, March 1992, pp. 59-68.

29. LATORRE, R. \& DÜNOW, H-H "Improvement of River Towboat Propulsion: Translations of Selected German and Russian Technical Articles". Department of Naval Architecture and Marine Engineering, Report No. 243, University of Michigan, Ann Arbor, November 1981.

30. LATORRE, R. "Flow Around Full Ship Stern: Translation of Selected Japanese and German Technical Articles". Department of Naval Architecture and Marine Engineering, Report No. 198, University of Michigan, Ann Arbor, 1976.

31. LATORRE, R. et alli. "Improvement of Inland Waterway Vessel and Barge Tow Performance". Department of Naval Architecture and Marine Engineering, Report No. 249, University of Michigan, Ann Arbor, September 1981. 
32. LEWIS, E.V. "Principles of Naval Architecture". Vol. II - Resistance, Propulsion and Vibration. The Society Of Naval Architects and Marine Engineers - SNAME, Jersey City, NJ, 1988.

33. LUTHRA, G. "Investigation of the Wake Distribution of a Towboat Pushing a Barge Train". Hansa, vol. 111, no. 18, September 1974, pp. 1515-1521. English translation: LATORRE \& DÜNOW [29].

34. MANEN, Van, J.D. "Recent Data on Cavitation Criteria". International Shipbuilding Progress, vol. 1 , no. 1,1954 , pp. 39-47.

35. MINSAAS, K. J. et alli. "Scale Effects on Propulsion Factors". 14th. International Towing Tank Conference. Proceedings of Performance Committee. Appendix 6. Ottawa, September, 1975.

36. NARITA, H. et alli. "Application and Development of a Large Ducted Propeller for the 280,000dwt Tanker MS Thorsaga". Transactions of Society of Naval and Marine Engineering SNAME. vol. 83, 1975, pp. 244-273.

37. NIPPON KAIJI KYOKAI “Guide to Ship Vibration”. NKK, Tokio, Japan, 1984.

38. O’BRIEN, T.P. “The Design of Marine Screw Propellers”. Hutchinson \& Co. LTD. London, England, 1962, $397 \mathrm{pg}$.

39. OOSTERVELD, M.W.C. \& OOSSANEN, P. Van "Further Computer Analyzed Data of the Wageningen B-Screw Series”. International Shipbuilding Progress, vol. 22, no. 251 , July 1975, pp. 251-262.

40. PADOVEZI, C.D. \& HIRATA, K. "Escolha e Projeto de Propulsores". 9. Congresso Nacional de Transportes Marítimos e Construção Naval - SOBENA. Proceedings. Rio de Janeiro, Setembro, 1982.

41. SCHWANECKE, H. “On the Propulsion Quality of Ships Operating at Restricted Water Depth". Ocean Engineering, vol. 6, pp. 571-580, 1979.

42. TACHIBANA, T. , PADOVEZI, C.D. \& TAKEI, Y. "Avaliação Experimental dos Efeitos de Imperfeição nas Pás de Hélices". 15. Congresso Nacional de Transportes Marítimos e Construção Naval - SOBENA. Proceedings. Rio de Janeiro, Agosto/Setembro, 1994.

43. TRIANTAFYLLOU, M.S. “Computer-Aided Propeller Preliminary Design Using the B-Series". Marine Technology, SNAME, vol. 16, no. 4, October 1979, pp. 381-391.

44. VELEDNITSKY, I. O. "Determination of Resistance of Displacement Ships in Shallow Waters”. In: Basin, A.M. et alli,, Ship Hydrodynamics in Shallow Waters, Sudostroeniye, Leningrad. 1976, pp. 266-275. English translation: LATORRE et alli. [31].

45. VOLKER, H. written discussion to POHL, K.H., "Über die Weehsel Wirkung Zwisschen Schiff und Propeller". English translation: LATORRE, R. [30].

46. WALKER, D. et alli. "Hydrodynamic Load on Ice-Class Propellers During Propeller-Ice Interaction". Journal of Marine Science and Technology, SNAJ. 2:12-20. 1997.

47. WU, T. Y. "Flow Through a Heavily Loaded Actuator Disc". Schiffstechnik, Band 9, 1962, Heft 47, pp. 134-138. 


\section{APÊNDICE A \\ DADOS MEDIDOS NOS ENSAIOS COM O COMBOIO DE PESQUISAS DO RIO ARAGUAIA}

$\Rightarrow$ ENSAIOS COM MODELOS EM ESCALA 1:13 NO TANQUE DE PROVAS DO IPT
\[ \text { Ensaio de Resistência ao Avanço } \]
$\bullet$ Ensaios de Autopropulsão

$\Rightarrow$ ENSAIOS DE DESEMPENHO PROPULSIVO EM ESCALA REAL

- Sexta Viagem, com Hélices B-Troost

- Oitava Viagem, com Hélices Kaplan em Dutos 
Tabela A.1 - Resultados dos Ensaios de Resistência ao Avanço no Tanque de Provas do IPT com Modelo em Escala (1:13) do Comboio de Pesquisas do Rio Araguaia. Extrapolação para Escala Real. $h=\infty$.

\begin{tabular}{|c|c|c|c|c|c|c|c|c|c|c|}
\hline \multicolumn{11}{|c|}{ UMA CHATA $\mathrm{H}=2,0 \mathrm{~m}$} \\
\hline $\begin{array}{l}\mathrm{Vm} \\
(\mathrm{m} / \mathrm{s})\end{array}$ & $\begin{array}{l}\text { RTm } \\
\text { (gf) }\end{array}$ & $\begin{array}{c}\text { CTm. } 10 \\
\wedge 3\end{array}$ & Rnm & $\begin{array}{c}\text { CFm.10 } \\
\wedge 3\end{array}$ & $\begin{array}{c}\mathrm{CRm} .10^{\wedge} \\
3\end{array}$ & $\begin{array}{c}\text { Vs } \\
(\mathrm{m} / \mathrm{s})\end{array}$ & Rns & \begin{tabular}{|l|} 
CFs.10 \\
3 (ITTC)
\end{tabular} & $\begin{array}{c}\text { CTs. } 10^{\wedge} \\
3\end{array}$ & RTs(kgf) \\
\hline 0,571 & 340 & 6,19 & $2,23 E+06$ & 3,97 & 2,22 & 2,06 & $1,05 E+08$ & 2,058 & 4,278 & 516,2 \\
\hline 0,713 & 515 & 6,00 & $2,79 E+06$ & 3,80 & 2,22 & 2,57 & $1,31 \mathrm{E}+08$ & 1,996 & 4,216 & 794,9 \\
\hline 0,856 & 710 & 5,74 & $3,35 \mathrm{E}+06$ & 3,66 & 2,08 & 3,09 & $1,57 \mathrm{E}+08$ & 1,946 & 4,026 & 1094,2 \\
\hline 0,999 & 970 & 5,76 & $3,91 \mathrm{E}+06$ & 3,56 & 2,21 & 3,60 & $1,83 E+08$ & 1,906 & 4,116 & 1522,9 \\
\hline 1,141 & 1370 & 6,23 & $4,46 \mathrm{E}+06$ & 3,47 & 2,76 & 4,11 & $2,09 E+08$ & 1,872 & 4,632 & 2238,1 \\
\hline
\end{tabular}

\begin{tabular}{|c|c|c|c|c|c|c|c|c|c|c|}
\hline \multicolumn{11}{|c|}{ DUAS CHATAS EM PARALELO H=2,0 m } \\
\hline $\begin{array}{l}\mathrm{Vm} \\
(\mathrm{m} / \mathrm{s})\end{array}$ & $\begin{array}{c}\text { RTm } \\
\text { (gf) }\end{array}$ & \begin{tabular}{|c|} 
CTm.10 \\
$\wedge 3$
\end{tabular} & Rnm & $\begin{array}{c}\text { CFm.10 } \\
\wedge 3\end{array}$ & $\begin{array}{c}\mathrm{CRm}_{.10^{\wedge}} \\
3\end{array}$ & $\begin{array}{c}\text { Vs } \\
(\mathrm{m} / \mathrm{s})\end{array}$ & Rns & $\begin{array}{l}\text { CFs. } 10^{\wedge} \\
3 \text { (ITTC) }\end{array}$ & \begin{tabular}{|c|} 
CTs.10^ \\
3
\end{tabular} & RTs(kgf) \\
\hline 0,571 & 535 & 6,20 & $2,23 \mathrm{E}+06$ & 3,90 & 2,23 & 2,06 & $1,05 \mathrm{E}+08$ & 2,058 & 4,288 & 812,9 \\
\hline 0,713 & 910 & 6,75 & $2,79 \mathrm{E}+06$ & 3,80 & 2,95 & 2,57 & $1,31 \mathrm{E}+08$ & 1,996 & 4,946 & 1464,8 \\
\hline 0,856 & 1270 & 6,54 & $3,35 \mathrm{E}+06$ & 3,66 & 2,88 & 3,09 & $1,57 \mathrm{E}+08$ & 1,946 & 4,826 & 2059,1 \\
\hline 0,999 & 1880 & 7,11 & $3,91 \mathrm{E}+06$ & 3,56 & 3,55 & 3,60 & $1,83 \mathrm{E}+08$ & 1,906 & 5,456 & 3169,7 \\
\hline 1,141 & 2530 & 7,33 & $4,46 \mathrm{E}+06$ & 3,47 & 3,86 & 4,11 & $2,09 \mathrm{E}+08$ & 1,872 & 5,732 & 4346,9 \\
\hline
\end{tabular}

DUAS CHATAS EM LINHA H=2,0 m

\begin{tabular}{|c|c|c|c|c|c|c|c|c|c|c|}
\hline $\begin{array}{c}\mathrm{Vm} \\
(\mathrm{m} / \mathrm{s})\end{array}$ & $\begin{array}{c}\text { RTm } \\
\text { (gf) }\end{array}$ & \begin{tabular}{|c|} 
CTm.10 \\
$\wedge 3$ \\
\end{tabular} & Rnm & $\begin{array}{c}\text { CFm.10 } \\
\wedge 3\end{array}$ & \begin{tabular}{|c|}
$\mathrm{CRm} .10^{\wedge}$ \\
3 \\
\end{tabular} & $\begin{array}{c}\mathrm{Vs} \\
(\mathrm{m} / \mathrm{s})\end{array}$ & Rns & \begin{tabular}{|l} 
CFs.10^ \\
3 (ITTC) \\
\end{tabular} & \begin{tabular}{|c} 
CTs. $10^{\wedge}$ \\
3 \\
\end{tabular} & RTs(kgf) \\
\hline 0,571 & 475 & 4,95 & $2,23 \mathrm{E}+06$ & 3,58 & 1,37 & 2,06 & $1,05 \mathrm{E}+08$ & 2,058 & 3,428 & 722,7 \\
\hline 0,713 & 735 & 4,91 & $2,79 E+06$ & 3,43 & 1,47 & 2,57 & $1,31 \mathrm{E}+08$ & 1,996 & 3,466 & 1139,7 \\
\hline 0,856 & 1055 & 4,89 & $3,35 \mathrm{E}+06$ & 3,32 & 1,57 & 3,09 & $1,57 \mathrm{E}+08$ & 1,946 & 3,516 & 1666,8 \\
\hline 0,999 & 1500 & 5,11 & $3,91 \mathrm{E}+06$ & 3,23 & 1,88 & 3,60 & $1,83 \mathrm{E}+08$ & 1,906 & 3,786 & 2441,8 \\
\hline 1,141 & 1975 & 5,15 & $4,46 \mathrm{E}+06$ & 3,15 & 2,00 & 4,11 & $2,09 \mathrm{E}+08$ & 1,87 & 3,872 & 3262,7 \\
\hline
\end{tabular}

Tabela A.2 - Resultados dos Ensaios de AutoPropulsão no Tanque de Provas do IPT com Modelo em Escala (1:13) do Comboio de Pesquisas do Rio Araguaia. Extrapolação para Escala Real. $\mathrm{H}=2,0$ m. $h=\infty$.

\begin{tabular}{|l|c|c|c|c|c|}
\hline CONDIÇÃO & $\mathrm{V}(\mathrm{m} / \mathrm{s})$ & $\mathrm{t}$ & $\mathrm{w}$ & $\eta_{\mathrm{H}}$ & $\eta_{\mathrm{R}}$ \\
\hline \multirow{4}{*}{ Uma Chata } & 4,120 & 0,339 & 0,272 & 0,908 & 1,014 \\
\cline { 2 - 6 } & 3,600 & 0,330 & 0,261 & 0,906 & 1,039 \\
\cline { 2 - 6 } & 3,030 & 0,321 & 0,253 & 0,909 & 1,075 \\
\cline { 2 - 6 } & 2,570 & 0,274 & 0,241 & 0,956 & 1,139 \\
\cline { 2 - 6 } & 2,060 & 0,161 & 0,212 & 1,065 & 1,200 \\
\hline \multirow{4}{*}{ em Linha } & 4,120 & 0,364 & 0,334 & 0,956 & 1,005 \\
\cline { 2 - 6 } & 3,600 & 0,348 & 0,317 & 0,954 & 1,020 \\
\cline { 2 - 6 } & 3,030 & 0,332 & 0,301 & 0,956 & 1,043 \\
\cline { 2 - 6 } & 2,570 & 0,324 & 0,287 & 0,948 & 1,093 \\
\cline { 2 - 6 } & 2,060 & 0,335 & 0,282 & 0,927 & 1,200 \\
\cline { 2 - 6 } & 3,600 & 0,405 & 0,332 & 0,891 & 0,980 \\
\cline { 2 - 6 } & 3,030 & 0,333 & 0,265 & 0,908 & 1,016 \\
\cline { 2 - 6 } & 2,570 & 0,244 & 0,185 & 0,927 & 1,070 \\
\cline { 2 - 6 } & 2,060 & 0,110 & 0,079 & 0,966 & 1,159 \\
\hline
\end{tabular}


Tabela A.3 - Resultados dos Ensaios em Escala Real do Comboio de Pesquisas do Rio Araguaia. Medidas nos Eixos (n e Q) e de Velocidades. Sexta Viagem. Hélices B-Troost. h=5 m.

\begin{tabular}{|c|c|c|c|c|c|c|}
\hline \multirow{3}{*}{ ENSAIO } & \multicolumn{2}{|c|}{ UMA CHATA CARREGADA } & \multicolumn{2}{|c|}{$\mathrm{H}=1,6 \mathrm{~m}$} & \multirow{3}{*}{$\begin{array}{c}\text { Q BE } \\
\text { (kgf.m) }\end{array}$} & \multirow{3}{*}{$\begin{array}{l}\text { sentido } \\
\text { da corrida }\end{array}$} \\
\hline & \multicolumn{2}{|c|}{ ROTACOES n (rpm) } & \multirow{2}{*}{$\begin{array}{c}\mathrm{V} \\
(\mathrm{m} / \mathrm{s})\end{array}$} & \multirow{2}{*}{$\begin{array}{c}\text { Q BB } \\
\text { (kgf.m) }\end{array}$} & & \\
\hline & $\mathrm{BB}$ & $\mathrm{BE}$ & & & & \\
\hline Dez/01 & 450 & 470 & 2,380 & 130,0 & 220,4 & subida \\
\hline Dez/02 & 452 & 470 & 4,360 & 158,1 & 216,7 & descida \\
\hline Dez/03 & 490 & 509 & 2,616 & 182,2 & 258,0 & subida \\
\hline Dez/04 & 490 & 506 & 4,754 & 203,3 & 251,4 & descida \\
\hline Dez/05 & 518 & 536 & 2,692 & 221,4 & 293,3 & subida \\
\hline Dez/06 & 518 & 537 & 4,820 & 236,7 & 288,9 & descida \\
\hline Dez/07 & 555 & 575 & 2,812 & 262,1 & 333,3 & subida \\
\hline Dez/08 & 561 & 574 & 5,012 & 275,8 & 329,8 & descida \\
\hline Dez/09 & 614 & 595 & 2,939 & 320,9 & 356,4 & subida \\
\hline Dez/10 & 612 & 597 & 5,165 & 328,1 & 351,5 & descida \\
\hline
\end{tabular}

DUAS CHATAS EM PARALELO

\begin{tabular}{|c|c|c|c|c|c|c|}
\hline \multirow[t]{2}{*}{ ENSAIO } & \multicolumn{2}{|c|}{ ROTACOES n (rpm) } & \multirow{2}{*}{$\begin{array}{c}\mathrm{V} \\
(\mathrm{m} / \mathrm{s})\end{array}$} & \multirow{2}{*}{$\begin{array}{c}\text { Q BB } \\
\text { (kgf.m) }\end{array}$} & \multirow{2}{*}{$\begin{array}{c}\text { Q BE } \\
\text { (kgf.m) }\end{array}$} & \multirow{2}{*}{$\begin{array}{c}\text { sentido } \\
\text { da corrida }\end{array}$} \\
\hline & $\mathrm{BB}$ & $\mathrm{BE}$ & & & & \\
\hline ONZE01 & 456 & 450 & 1,652 & 185,3 & 239,7 & subida \\
\hline ONZE13 & 456 & 470 & 3,304 & 189,3 & 253,8 & descida \\
\hline ONZE03 & 520 & 537 & 2,086 & 243,5 & 329,0 & subida \\
\hline ONZE04 & 520 & 538 & 3,500 & 252,0 & 334,0 & descida \\
\hline ONZE06 & 610 & 594 & 2,836 & 328,0 & 380,1 & subida \\
\hline ONZE07 & 612 & 590 & 4,099 & 332,6 & 383,5 & descida \\
\hline ONZE09 & 575 & 553 & 2,260 & 307,1 & 343,6 & subida \\
\hline ONZE10 & 575 & 553 & 3,960 & 312,9 & 343,9 & descida \\
\hline
\end{tabular}

DUAS CHATAS EM LINHA $\quad \mathrm{H}=1,6 \mathrm{~m}$

\begin{tabular}{|c|c|c|c|c|c|c|}
\hline \multirow[t]{2}{*}{ ENSAIO } & \multicolumn{2}{|c|}{ ROTACOES n (rpm) } & \multirow{2}{*}{$\begin{array}{c}\mathrm{V} \\
(\mathrm{m} / \mathrm{s})\end{array}$} & \multirow{2}{*}{$\begin{array}{c}\text { T BB } \\
\text { (kgf.m) }\end{array}$} & \multirow{2}{*}{$\begin{array}{c}\text { T BE } \\
\text { (kgf.m) }\end{array}$} & \multirow{2}{*}{$\begin{array}{c}\text { sentido } \\
\text { da corrida }\end{array}$} \\
\hline & BB & $\mathrm{BE}$ & & & & \\
\hline DOZE01 & 483 & 487 & 4,081 & 213,2 & 268,9 & descida \\
\hline DOZE03 & 495 & 504 & 2,231 & 212,9 & 287,8 & subida \\
\hline DOZE04 & 520 & 543 & 4,386 & 247,0 & 333,2 & descida \\
\hline DOZE06 & 527 & 530 & 2,290 & 254,1 & 317,0 & subida \\
\hline DOZE07 & 569 & 570 & 4,522 & 300,2 & 369,1 & descida \\
\hline DOZE09 & 568 & 575 & 2,464 & 301,7 & 360,3 & subida \\
\hline DOZE10 & 610 & 592 & 4,724 & 345,5 & 378,0 & descida \\
\hline \begin{tabular}{|l|} 
DOZE12 \\
\end{tabular} & 609 & 592 & 2,710 & 344,5 & 381,7 & subida \\
\hline
\end{tabular}

UMA CHATA LEVE $\quad \mathrm{H}=0,70 \mathrm{~m}$

\begin{tabular}{|c|c|c|c|c|c|c|}
\hline \multirow[t]{2}{*}{ ENSAIO } & \multicolumn{2}{|c|}{ ROTACOES n (rpm) } & \multirow{2}{*}{$\begin{array}{c}\mathrm{V} \\
(\mathrm{m} / \mathrm{s})\end{array}$} & \multirow{2}{*}{$\begin{array}{c}\text { T BB } \\
\text { (kgf.m) }\end{array}$} & \multirow{2}{*}{$\begin{array}{c}\text { T BE } \\
\text { (kgf.m) }\end{array}$} & \multirow{2}{*}{$\begin{array}{c}\text { sentido } \\
\text { da corrida }\end{array}$} \\
\hline & BB & $\mathrm{BE}$ & & & & \\
\hline TREZE01 & 459 & 474 & 4,895 & 180,6 & 210,5 & descida \\
\hline TREZE03 & 459 & 459 & 2,387 & 184,6 & 185,7 & subida \\
\hline TREZE04 & 482 & 508 & 4,940 & 209,5 & 233,5 & descida \\
\hline TREZE06 & 530 & 546 & 2,807 & 242,9 & 284,3 & subida \\
\hline TREZE07 & 575 & 581 & 5,330 & 284,8 & 319,1 & descida \\
\hline TREZE09 & 575 & 578 & 2,978 & 286,5 & 314,1 & subida \\
\hline TREZE10 & 610 & 598 & 5,324 & 331,4 & 329,2 & descida \\
\hline TREZE12 & 613 & 600 & 3,163 & 331,4 & 330,8 & subida \\
\hline
\end{tabular}


Tabela A.4 - Resultados dos Ensaios em Escala Real do Comboio de Pesquisas do Rio Araguaia. Medidas nos Eixos (n e Q) e de Velocidades. Oitava Viagem. Hélices Kaplan em Dutos. $\mathrm{h}=9 \mathrm{~m}$.

\begin{tabular}{|c|c|c|c|c|c|c|c|}
\hline \multirow[t]{3}{*}{ CONDIÇÃC } & \multirow[t]{2}{*}{ ENSAIO } & \multirow{2}{*}{$\begin{array}{c}\mathrm{V} \\
(\mathrm{m} / \mathrm{s})\end{array}$} & $\mathrm{nBB}$ & $\mathrm{n} \mathrm{BE}$ & \multirow{2}{*}{$\begin{array}{l}\text { Q BB } \\
\text { kgf.m }\end{array}$} & \multirow{2}{*}{$\begin{array}{l}\text { Q BE } \\
\text { kgf.m }\end{array}$} & \multirow{2}{*}{$\begin{array}{c}\text { sentido } \\
\text { da corrida }\end{array}$} \\
\hline & & & (rpm) & (rpm) & & & \\
\hline & D107 & 5,85 & 1546 & 1511 & 268 & 245,0 & descida \\
\hline \multirow{5}{*}{$\begin{array}{l}\text { UMA } \\
\text { CHATA } \\
\mathrm{H}=0,7 \mathrm{~m}\end{array}$} & \begin{tabular}{|l|}
$\mathrm{D} 207$ \\
\end{tabular} & 2,06 & 1521 & 1505 & 260 & 243,6 & subida \\
\hline & \begin{tabular}{|l|} 
D307 \\
\end{tabular} & 6,28 & 1690 & 1730 & 327 & 308,0 & descida \\
\hline & D507 & 2,39 & 1680 & 1690 & 323 & 298,2 & subida \\
\hline & D707 & 6,41 & 1770 & 1820 & 357 & 329,0 & descida \\
\hline & D807 & 2,78 & 1766 & 1776 & 354 & 323,4 & subida \\
\hline \multirow{6}{*}{$\begin{array}{l}\text { UMA } \\
\text { CHATA } \\
\mathrm{H}=1,6 \mathrm{~m}\end{array}$} & D109 & 5,54 & 1498 & 1528 & 269 & 251,3 & descida \\
\hline & D209 & 2,17 & 1501 & 1532 & 271 & 251,3 & subida \\
\hline & \begin{tabular}{|l|} 
D309 \\
\end{tabular} & 6,14 & 1635 & 1771 & 333 & 325,7 & descida \\
\hline & \begin{tabular}{|l|} 
D409 \\
\end{tabular} & 2,26 & 1660 & 1700 & 330 & 306,1 & subida \\
\hline & D609 & 6,18 & 1760 & 1770 & 360 & 322,9 & descida \\
\hline & D709 & 2,66 & 1770 & 1830 & 374 & 348,2 & subida \\
\hline \multirow{6}{*}{$\begin{array}{l}\text { DUAS EM } \\
\text { PARALELO } \\
\mathrm{H}=1,6 \mathrm{~m}\end{array}$} & D1009 & 5,15 & 1553 & 1654 & 319 & 315,0 & descida \\
\hline & D1109 & 1,72 & 1565 & 1528 & 299 & 273,0 & subida \\
\hline & D1209 & 5,27 & 1632 & 1641 & 333 & 309,4 & descida \\
\hline & D1309 & 1,91 & 1626 & 1618 & 320 & 296,8 & subida \\
\hline & D1809 & 5,41 & 1724 & 1730 & 367 & 334,6 & descida \\
\hline & D1609 & 2,16 & 1740 & 1744 & 380 & 341,6 & subida \\
\hline \multirow{6}{*}{$\begin{array}{l}\text { DUAS EM } \\
\text { LINHA } \\
\mathrm{H}=1,6 \mathrm{~m}\end{array}$} & D110 & 5,20 & 1562 & 1534 & 291 & 267,4 & descida \\
\hline & D410 & 2,11 & 1505 & 1528 & 270 & 266,0 & subida \\
\hline & D210 & 2,55 & 1758 & 1804 & 380 & 352,8 & descida \\
\hline & D310 & 5,64 & 1730 & 1763 & 364 & 334,6 & subida \\
\hline & D610 & 5,57 & 1685 & 1707 & 341 & 322,0 & descida \\
\hline & D710 & 2,28 & 1660 & 1665 & 332 & 308,0 & subida \\
\hline \multirow{8}{*}{$\begin{array}{l}\text { UMA } \\
\text { CHATA } \\
\mathrm{H}=1,98 \mathrm{~m}\end{array}$} & D111 & 2,64 & 1765 & 1720 & 363 & 315,9 & subida \\
\hline & \begin{tabular}{|l|} 
D311 \\
\end{tabular} & 5,85 & 1725 & 1691 & 346 & 285,0 & descida \\
\hline & \begin{tabular}{|l|} 
D511 \\
\end{tabular} & 1,65 & 1370 & 1349 & 228 & 203,6 & subida \\
\hline & \begin{tabular}{|l|}
$\mathrm{D} 611$ \\
\end{tabular} & 4,92 & 1362 & 1342 & 228 & 205,0 & descida \\
\hline & D711 & 5,77 & 1746 & 1722 & 365 & 315,9 & descida \\
\hline & \begin{tabular}{|l|}
$\mathrm{D} 911$ \\
\end{tabular} & 2,63 & 1755 & 1718 & 370 & 318,7 & subida \\
\hline & \begin{tabular}{|l|}
$\mathrm{D} 1011$ \\
\end{tabular} & 1,97 & 1524 & 1510 & 281 & 251,3 & subida \\
\hline & D1111 & 5,47 & 1587 & 1516 & 300 & 255,5 & descida \\
\hline \multirow{6}{*}{$\begin{array}{l}\text { DUAS EM } \\
\text { PARALELO } \\
\text { H=1,98 m }\end{array}$} & D112 & 4,53 & 1538 & 1579 & 305 & 282,2 & descida \\
\hline & D212 & 1,66 & 1557 & 1563 & 308 & 276,6 & subida \\
\hline & \begin{tabular}{|l|} 
D312 \\
\end{tabular} & 1,82 & 1728 & 1724 & 375 & 331,3 & subida \\
\hline & \begin{tabular}{|l|}
$\mathrm{D} 412$ \\
\end{tabular} & 4,90 & 1712 & 1701 & 363 & 317,3 & descida \\
\hline & D512 & 1,53 & 1433 & 1459 & 265 & 242,9 & subida \\
\hline & D712 & 4,40 & 1411 & 1494 & 263 & 251,3 & descida \\
\hline
\end{tabular}

